Aus der Abteilung Allgemein- und Viszeralchirurgie

(Prof. Dr. med. M. Ghadimi)

des Zentrums Chirurgie

der Universitätsmedizin Göttingen

\title{
Prädiktive und prognostische Relevanz von p53 und Ki67 beim lokal fortgeschrittenen Rektumkarzinom cUICC-II/III
}

Immunhistochemische Analysen im methodischen Vergleich

\author{
INAUGURAL - DISSERTATION \\ zur Erlangung des Doktorgrades \\ der Medizinischen Fakultät \\ der Georg-August-Universität zu Göttingen
}

vorgelegt von

Susanna Posern

aus

Grimma

Göttingen 2013 
De k a n:

I. Berichterstatter:

II. Berichterstatter:

III. Berichterstatter:

Promotor:

Tag der mündlichen Prüfung: 12. November 2013
PD Dr. med. Liersch

Prof. Dr. med. Radzun

Prof. Dr. med. Dobbelstein

Prof. Dr. med. Oppermann 


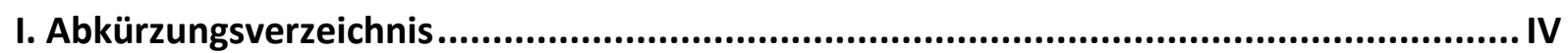

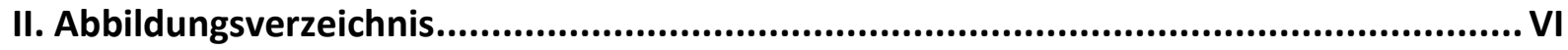

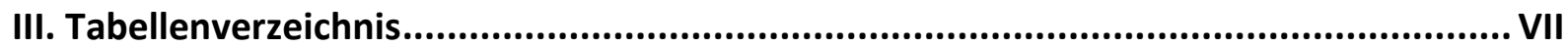

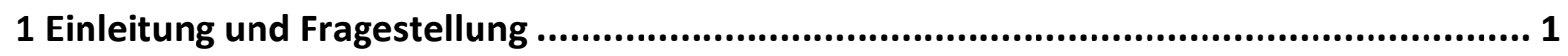

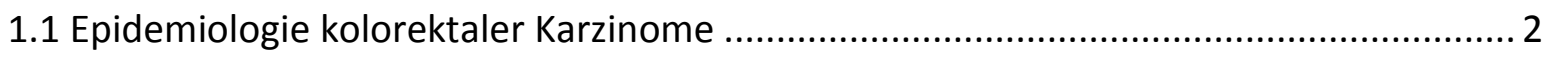

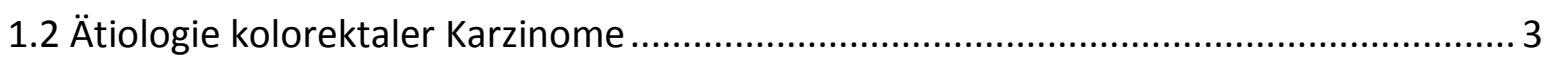

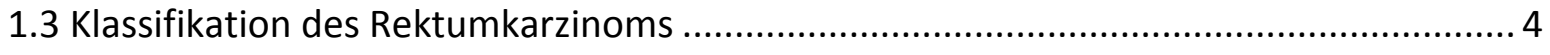

1.4 Diagnosesicherung und Staging des Rektumkarzinoms ............................................ 7

1.5 Stadien-adaptierte Therapie des Rektumkarzinoms .............................................. 9

1.5.1 Therapie lokal begrenzter Rektumkarzinome (cUICC-I-Stadien) ............................ 10

1.5.2 Therapie lokal fortgeschrittener Rektumkarzinome (cUICC-II/III-Stadien) .............. 10

1.5.3 Therapie des metastasierten Rektumkarzinoms (cUICC-IV-Stadium) .................... 11

1.6 Übersicht aktueller Studien zur Optimierung der multimodalen Therapie des lokal

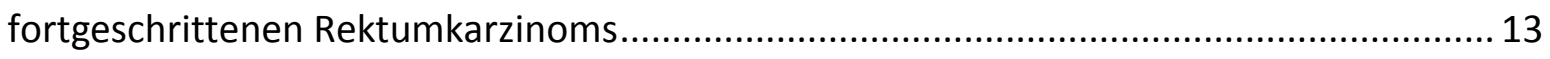

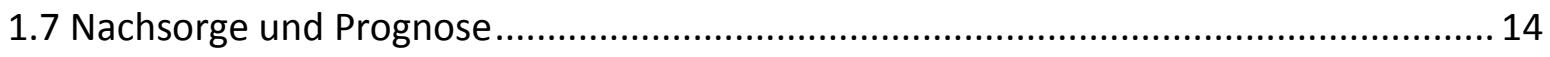

1.8 Prädiktive und prognostische Biomarker des Rektumkarzinoms................................. 15

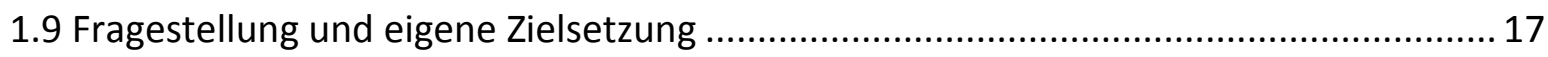

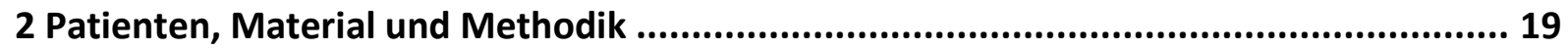

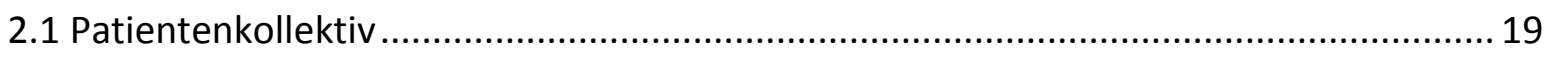

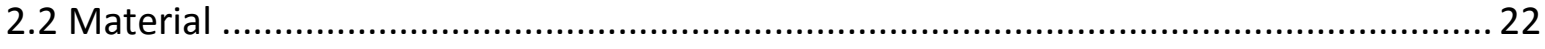

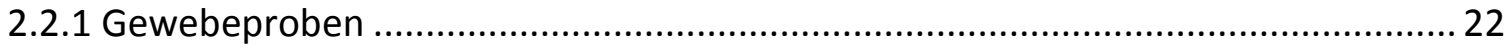

2.2.2 Perioperative Qualitätskontrolle des Rektumresektats ....................................... 22

2.2.3 Postoperative Aufarbeitung und histopathologische Beurteilung des Resektats... 26

2.3 Immunhistochemie und Anfertigung der Gewebeschnitte....................................... 28

2.3.1 Prinzip der immunhistochemischen Gewebeanfärbung ...................................... 28

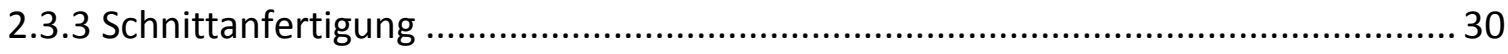

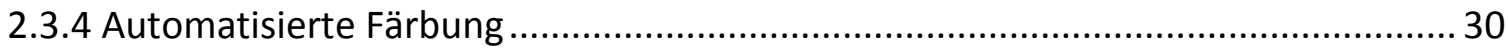

2.3.5 Probleme und Schwächen der quantitativen Immunhistochemie ........................ 31

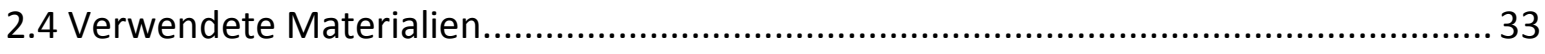

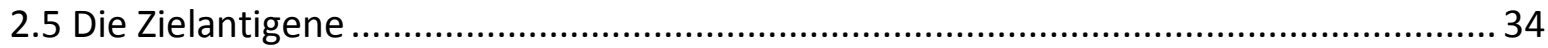


2.5.1 p53

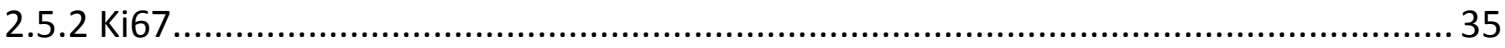

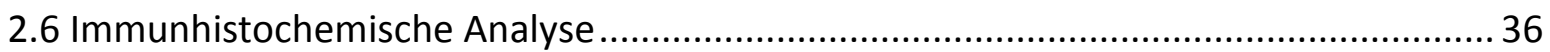

2.6.1 Analyse der immunhistochemischen Färbung .................................................. 36

2.6.2 Konventionell-manuelle Auswertung der immunhistochemischen Färbung .......... 38

2.6.3 Auswertung der immunhistochemischen Färbung mit Hilfe des digitalen

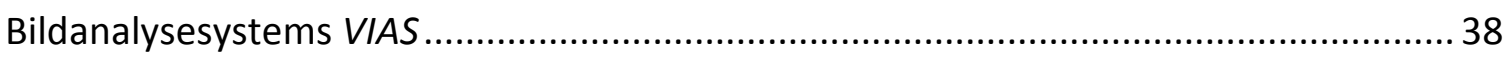

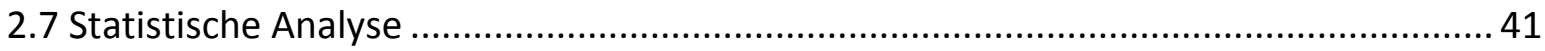

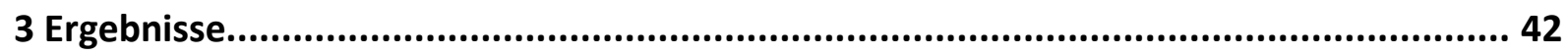

3.1 Ergebnisse der multimodalen Therapie ................................................................. 42

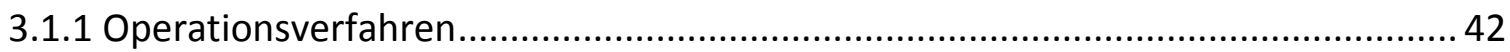

3.1.2 Histopathologische Tumorstadien und lokales Tumoransprechen ........................ 44

3.2 Fernmetastasen, Lokalrezidive und tumorbedingte Todesfälle im

Nachbeobachtungszeitraum.

3.3 Ergebnisse der Gegenüberstellung zweier immunhistochemischer Analyseverfahren 48

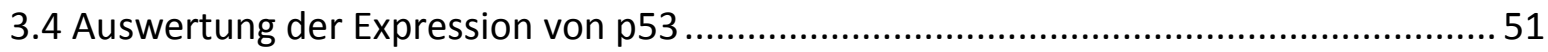

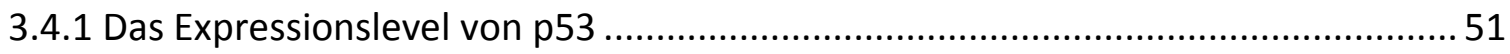

3.4.2 Korrelation des prätherapeutischen Expressionslevels von p53 mit dem TRG....... 53

3.4.3 Korrelation des Expressionslevels von p53 mit dem Nodalstatus und dem

Auftreten von Fernmetastasen.

3.4.4 Korrelation des Expressionslevels von p53 mit dem krankheitsfreien Überleben und dem Karzinom-spezifischen Überleben ............................................................. 55

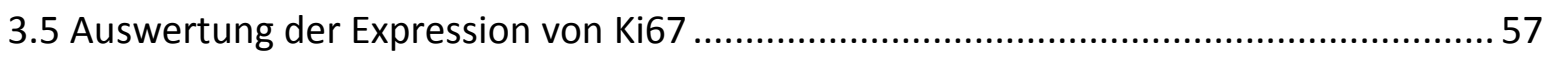

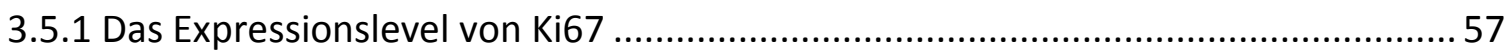

3.5.2 Korrelation des Expressionslevels von Ki67 mit dem TRG ................................... 59

3.5.3 Korrelation des Expressionslevels von Ki67 mit dem Nodalstatus und dem

Auftreten von Fernmetastasen..... 60

3.5.4 Korrelation des Expressionslevels von Ki67 mit dem krankheitsfreien Überleben und dem Karzinom-spezifischen Überleben 
4 Diskussion.

4.1 Klinikopathologische Parameter des Patientenkollektives 63

4.2 Quantitative Immunhistochemie mittels zweier Auswerteverfahren .65

4.3 Das prädiktive und prognostische Potential von p53 im lokal fortgeschrittenen

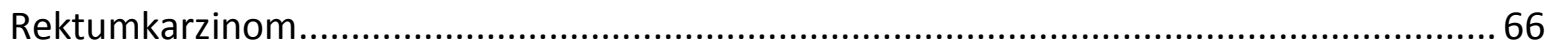

4.3.1 Prädiktion des Therapierespons gemessen am (y)pTNM-Status und dem TRG......66

4.3.2 Das prognostisches Potential von p53 gemessen an den Follow-up-Daten............ 68

4.4 Das prädiktive und prognostische Potential von Ki67 im lokal fortgeschrittenen Rektumkarzinom...

4.4.1 Prädiktion des Therapierespons gemessen am (y)pTNM-Status und dem TRG..... 74

4.4.2 Das prognostische Potential von Ki67 gemessen an den Follow-up-Daten ............ 76

4.5 Bedeutung der Ergebnisse für die klinische Praxis. 81

5 Zusammenfassung

6 Anhang 85

7 Literaturverzeichnis. 88 


\section{Abkürzungsverzeichnis}

AK

APE

CDK

CEA

$\mathrm{cm}$

CSS

CT

CTx

DAB

DFG

DFS

DIA

DNA

FAP

FOBT

5-FU

GRCSG

Gy

HNPCC

IHC

5-JÜR

$\mathrm{kDa}$

k-ras-Gen

KRK

LK

LR

MDM2

MERCURY

MRT
Antikörper

abdominoperineale Rektumexstirpation

cyclin-dependent kinases; Cyclin-abhängige Kinase

Karzinoembryonales Antigen

Zentimeter

carcinom-specific survival; Karzinom-spezifisches Überleben

Computertomographie

Chemotherapie

Diaminobenzidin

Deutsche Forschungsgemeinschaft

disease free survival; krankheitsfreies Überleben

digital image analysis; digitales Bildanalysesystem

Desoxyribonukleinsäure

Familiäre adenomatöse Polyposis

fäkaler Okkultbluttest

5-Fluorouracil

German Rectal Cancer Study Group

Gray

hereditary non-polyposis colorectal cancer-Syndrome

Immunhistochemie

5-Jahres-Überlebensrate

Kilodalton

Kirsten-ras-Protoonkogen

kolorektales Karzinom

Lymphknoten

Lokalrezidiv

murine double minute 2

Magnetic Resonance Imaging and Rectal Cancer European Equivalence Study Magnetresonanztomographie 
OS

PE

PME

$\mathrm{RCT}$

rES

RT

TARR

TEM

TME

TNM

TRG

UICC

UMG

VIAS

WHO overall survival; Gesamtüberleben

Probeexzision

partielle mesorektale Exzision

Radiochemotherapie

rektale Endosonographie

Radiotherapie

tiefe anteriore Rektumresektion

transanale endoskopische Mikrochirurgie

totale mesorektale Exzision

Klassifikation maligner Tumore

Tumorregressionsgrad

Union internationale contre le cancer

Universitätsmedizin Göttingen

Ventana Image Analysis System

World Health Organization 


\section{Abbildungsverzeichnis}

Abbildung 1: Dritteleinteilung des Rektums

Abbildung 2: Stadien-adaptierte Therapie des Rektumkarzinoms mit kurativer Zielsetzung ............................ 12

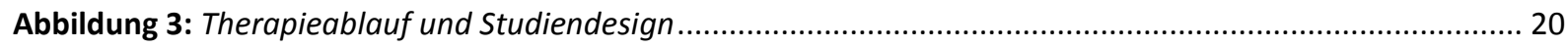

Abbildung 4: Ablauf der perioperativen Qualitätssicherung einer totalen mesorektalen Exzision mittels

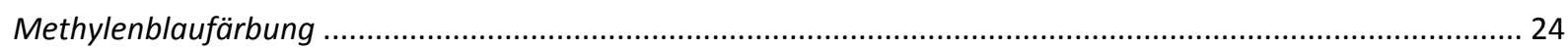

Abbildung 5: Übersicht über die Qualitätsgrade einer totalen mesorektalen Exzision ..................................... 25

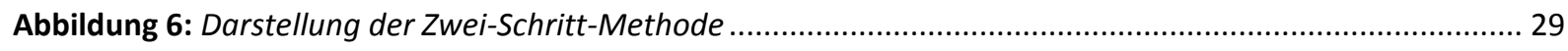

Abbildung 7: Chemische Reaktionen der verwendeten Enzyme …........................................................ 29

Abbildung 8: Färbeintensitäten am Beispiel p53-angefärbter Adenokarzinome des Rektums ........................... 37

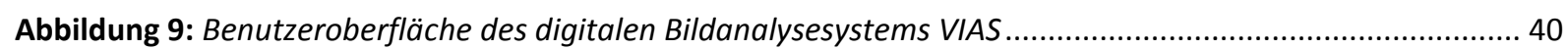

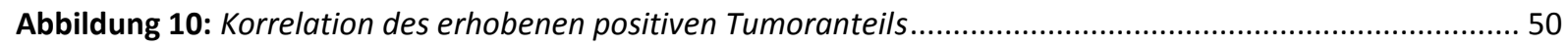

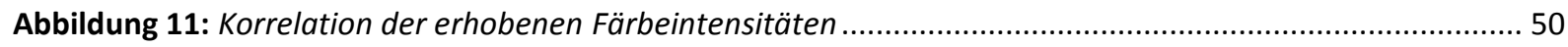

Abbildung 12: Gegenüberstellung des prätherapeutischen (PE) und des posttherapeutischen (Resektat)

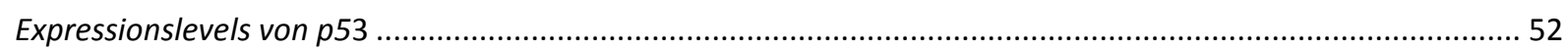

Abbildung 13: Korrelation des prätherapeutischen p53-Expressionslevels mit dem TRG .................................53

Abbildung 14: Korrelation des p53-Expressionslevels mit dem Metastasierungsstatus (M-Status) der

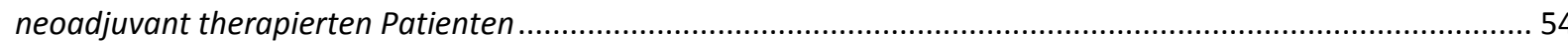

Abbildung 15: Kaplan-Meier-Kurven für das krankheitsfreie Überleben (DFS) und das Karzinom-spezifische Überleben (CSS)

Abbildung 16: Gegenüberstellung des prätherapeutischen (PE) und des posttherapeutischen (Resektat) Expressionslevels von Ki67 58

Abbildung 17: Korrelation des prä- und des posttherapeutischen Ki67-Expressionslevels mit dem TRG 59 Abbildung 18: Korrelation des posttherapeutischen Ki67-Expressionslevels mit dem Metastasierungsstatus (MStatus) der neoadjuvant therapierten Patienten 60

Abbildung 19: Kaplan-Meier-Kurven für das Karzinom-spezifische Überleben (CSS) in Abhängigkeit der prä- und posttherapeutischen Ki67-Expression 62 


\section{Tabellenverzeichnis}

Tabelle 1: TNM-Klassifikation nach Wittekind und Sobin, 2002

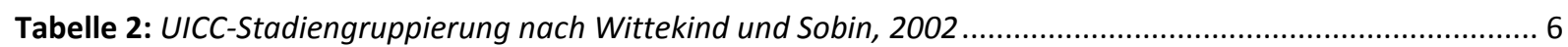

Tabelle 3: Übersicht der prätherapeutischen Staging-Ergebnisse ............................................................. 21

Tabelle 4: Klassifizierung des Tumorregressiongrades (TRG) nach neoadjuvanter Radio-/Chemotherapie ......... 27

Tabelle 5: Auflistung aller verwendeter Materialien und Substanzen, inkl. Angabe des Herstellers .................... 33

Tabelle 6: Übersicht über die zum Einsatz gekommenen Operationsverfahren und die Verteilung der Höhenlokalisationen der Rektumkarzinome

Tabelle 7: Übersicht über die klinikopathologischen Parameter aller Patienten, aufgeteilt nach verabreichter

Therapie

Tabelle 8: Übersicht über das Auftreten von Lokalrezidiven, dem Auffinden von Fernmetastasen und tumorbedingten Todesfällen im Nachbeobachtungszeitraum

Tabelle 9: Ergebnisse der immunhistochemischen Analyse für das Antigen p53.

Tabelle 10: Ergebnisse der immunhistochemischen Analyse für das Antigen Ki67

Tabelle 11: Übersicht über die aktuelle Studienlage zum Thema der p53-Expression in Adenokarzinomen des Rektums.

Tabelle 12: Übersicht über die aktuelle Studienlage zum Thema der Ki67-Expression in Adenokarzinomen des 


\section{Einleitung und Fragestellung}

Kolorektale Karzinome (KRK) stellen eine der häufigsten malignen Tumorerkrankungen in Europa und den Vereinigten Staaten von Amerika dar und zeigen eine seit mehr als drei Jahrzehnten andauernde Zunahme der Inzidenz (Husmann 2010). Prognosen sagen voraus, dass sich dieser Trend stetig fortsetzen wird, und es zu einer weiteren Progredienz der jährlichen Neuerkrankungen kommen wird (Husmann 2010). Allein in Niedersachsen erkrankten im Jahr 2008 insgesamt 6381 Menschen an einem malignen Tumor im Bereich des Dickdarms (Vohmann et al. 2011). Überdies stellen KRK bei beiden Geschlechtern die zweithäufigste Krebstodesursache in Deutschland dar (Husmann 2010, Vohmann et al. 2011).

Folglich handelt es sich beim KRK ohne Zweifel um eine bedeutende Erkrankung unserer Gesellschaft, sowohl aus medizinischer als auch aus sozioökonomischer Sichtweise. Aufgrund eines Anstiegs der durchschnittlichen Lebenserwartung und demographischer Veränderungen innerhalb Deutschlands wird dieser hohe Stellenwert auch zukünftig wachsen. Eine ausgereifte Früherkennung und die Weiterentwicklung der Stadienadaptierten Therapie sind unerlässlich, um dieser Entwicklung entgegentreten zu können. Die Etablierung eines individualisierten und Risiko-angepassten Therapieregimes kann zu einer Minimierung der therapieassoziierten Nebenwirkungen, aber vor allem auch zu einer Minimierung des Tumorrezidivrisikos führen. Dank neu entwickelter multimodaler Therapiestrategien konnte so die 5-Jahres-Überlebensrate (5-JÜR) von Patienten mit einem Rektumkarzinom in Deutschland in den letzten 30 Jahren von rund $45 \%$ auf $60 \%$ gesteigert werden (Husmann 2010, Sauer et al. 2012). Dieser Behandlungsfortschritt basiert auf einer stetigen Forschung und Weiterentwicklung der Therapiemöglichkeiten. Dem entgegengesetzt zeigen rund $30 \%$ aller Patienten trotz aller Fortschritte eine schlechte Therapieantwort auf die zur Verfügung stehenden Behandlungsmöglichkeiten und neigen zu einer frühen Fernmetastasierung. Diese Patienten könnten von einem intensivierten Therapiekonzept profitieren. Bislang ist jedoch nicht möglich, vor Einleitung der Therapie eine verlässliche Aussage über den Therapierespons zu treffen. Eine Zunahme der Individualisierung des Therapiekonzepts könnte den Behandlungserfolg weiterhin optimieren, die belastenden Nebenwirkungen der Therapie für den Patienten senken und 
demgemäß auch zu einer Minderung der ökonomischen Belastung für das Gesundheitssystem führen.

Ein grundlegender Baustein für die Möglichkeit einer individualisierten und gleichzeitig Risiko-adaptierten Tumortherapie stellt das genaue Wissen über die molekularbiologischen Eigenschaften des Karzinomgewebes dar. Neue Angriffspunkte für eine individualisierte Therapie liegen in der Anwendung moderner Therapiekonzepte, wie den Einsatz von Antikörpern (AK) gegen tumoreigene Proteine oder die Kombinationen verschiedener Zytostatika. Eine Umsetzung dieser Möglichkeiten fußt auf der umfassenden Kenntnis über die Tumorbiologie. Insofern sind eine bestmögliche Charakterisierung der intrazellulären Stoffwechselprozesse und Signalwege des Rektumkarzinoms und ein genaues Wissen über dessen zytologische Beschaffenheit unerlässlich.

\subsection{Epidemiologie kolorektaler Karzinome}

KRK stellen in Deutschland bei beiden Geschlechtern die zweithäufigste Malignomerkrankung dar, der Altersgipfel des Diagnosezeitpunktes liegt dabei zwischen dem 60. und 75. Lebensjahr (Liersch et al. 2007). Bei weniger als $10 \%$ der Patienten tritt ein maligner Dickdarmtumor vor Vollendung des 50. Lebensjahres auf (Fuchs et al. 2011). Im Jahr 2008 sind weltweit mehr als 1,2 Millionen Neuerkrankungen diagnostiziert worden und nach Schätzungen sind im gleichen Jahr global rund 608.700 Patienten an einem KRK verstorben (Jemal et al. 2011), davon rund 2635 innerhalb Niedersachsens (Vohmann et al. 2011). In Deutschland versterben jährlich rund 30.000 Menschen an einer malignen Entartung im Bereich des Dickdarms (Fuchs et al. 2011). Die Inzidenz KRK stellt sich in den verschiedenen Teilen der Erde heterogen dar. Die höchste Rate an Neuerkrankungen findet man in Industriestaaten (Australien, Nordamerika und Europa), die niedrigsten Raten in Afrika und Südzentral-Asien (Jemal et al. 2011).

Grundsätzlich sind Männer häufiger von malignen Tumoren des Dickdarms betroffen als Frauen (Fuchs et al. 2011). So sind 2004 in Deutschland rund 36.000 Frauen und rund 37.000 Männer bei steigender Inzidenz an Darmkrebs erkrankt (Husmann 2010).

Es ist von immenser Wichtigkeit, in welchem Erkrankungsstadium die Diagnosestellung erfolgt, da dies Prognose-entscheidend ist. Kann die Erkrankung in einem frühen Stadium (Stadium I/II nach Klassifikation der Union contre le cancer; UICC) diagnostiziert und der 
geeigneten Therapie zugeführt werden, liegt die 5-JÜR bei 85-90\% (Schmiegel et al. 2010, Fuchs et al. 2011). Erfolgt die Diagnosestellung erst im metastasierten Stadium, sinkt die Heilungsrate nach 5 Jahren trotz Therapie auf weniger als 10\% (Fuchs et al. 2011).

Bei 30-50\% aller KRK handelt es sich um Tumore, die im Bereich des Rektums lokalisiert sind (Liersch et al. 2007, Vohmann et al. 2011). Nach heutigem Wissensstand muss davon ausgegangen werden, dass es sich bei malignen Kolon- und Rektumtumoren um zwei eigenständige Entitäten handelt, die folgerichtig eigenständiger Therapiekonzepte bedürfen (Li und Lai 2009, Li et al. 2012, Hong et al. 2012).

\section{2 Ätiologie kolorektaler Karzinome}

Auf die Ätiologie KRK wirken sowohl exogene, als auch endogene Faktoren ein.

Als exogene Risikofaktoren werden bestimmte Ernährungs- und Lebensweisen eingestuft. So gilt ein hoher Konsum an Fleisch, Fett und Alkohol und eine unzureichende Versorgung mit Vitaminen und Ballaststoffen als negativer Prädiktor (Liersch et al. 2007, Vohmann et al. 2011). Körperliche Inaktivität und ein hoher sozioökonomischer Status begünstigen ebenso die Entstehung eines Dickdarmtumors. Als endogene Risikofaktoren betrachtet man heute das Vorhandensein von adenomatösen Polypen im Gastrointestinaltrakt, sowie chronisch entzündliche Darmerkrankungen wie Colitits ulcerosa oder Morbus Crohn. Des Weiteren tragen genetische Dispositionen, wie die Familiäre adenomatöse Polyposis (FAP) oder das hereditary non-polyposis colorectal cancer-Syndrome (HNPCC) zum Auftreten von KRK bei. Liegt der Entstehung eines KRK eine genetische Disposition zugrunde, treten maligne Tumore hereditär auf. Man geht davon aus, dass bei $10-15 \%$ aller Patienten mit einem malignen Tumor im Bereich des Dickdarms eine genetische Disposition vorliegt (Liersch et al. 2007). Aber auch bei sporadisch auftretenden KRK wird ein Entstehungsmechanismus auf genetischer Ebene in Betracht gezogen. Die Adenom-Karzinom-Sequenz nach Vogelstein beschreibt die Hypothese, dass sich maligne Neoplasien im Bereich des Kolons aus vorbestehenden benignen Adenomen entwickeln (Muto et al. 1975, Fearon und Vogelstein 1990). Dieser Karzinogenese gehen mehrere Mutationen, welche zu einer Aktivierung von Onkogenen und einer Inaktivierung von Tumorsuppressorgenen führen, voraus (Fearon und Vogelstein 1990). Hierbei spielt zum Beispiel der Verlust des Tumorsuppressors p53 und eine Mutation im k-ras-Gen eine entscheidende Rolle. Schätzungen sagen, dass zwischen dem 
Auftreten von Polypen und der Entstehung eines invasiven Karzinomwachstums bis zu 20 Jahre vergehen können. Anzumerken ist, dass die morphologische Charakteristik der Adenome einen wichtigen Einfluss auf den Krankheitsverlauf zu haben scheint. Breitbasig aufsitzende, villöse Adenome infiltrieren vergleichsweise frühzeitig das daruntergelegene Gewebe der Submukosa, als gestielt wachsende Polypen der Dickdarmschleimhaut. Gemäß dieser Hypothese werden Polypen der Dickdarmschleimhaut einer zeitnahen Polypektomie zugeführt, um das maligne Entartungsrisiko zu minimieren. Auf diesen Erkenntnissen begründet sich die Empfehlung einer regelmäßigen Koloskopie im Rahmen einer Krebsfrüherkennung ab dem 55. Lebensjahr. Ziel ist es auffällige Polypen frühestmöglich zu identifizieren und zu entfernen, um die Gefahr einer malignen Entartung zu senken (Schmiegel et al. 2010).

\subsection{Klassifikation des Rektumkarzinoms}

Rektumkarzinome werden mittels histopathologischer Sicherung anhand der TNMKlassifikation und UICC-Stadiengruppierung klassifiziert. Die geltenden Richtlinien zum Zeitpunkt der histopathologischen Aufarbeitung der in der vorliegenden Arbeit untersuchten Gewebeproben geben die Tabellen 1 und 2 wieder. Die aktuell gültige TNM-Klassifizierung und UICC-Einteilung ist zum Vergleich im Anhang (siehe Seite 85 und 86) eingefügt.

Die genaue Höhenlokalisation der Neoplasie bestimmt dabei die Unterscheidung zwischen einem Tumor des Rektums und einem Tumor des Kolons. Die Höhenlokalisation des unteren Tumorrandes muss mit einem starren Rektoskop ermittelt werden. Maligne Neubildungen, deren untere Tumorränder weiter als 16 Zentimeter $(\mathrm{cm})$ von der Anokutanlinie entfernt liegen, gelten als Kolonkarzinome. Innerhalb des Rektums werden Tumore weiterhin drei Rektumdritteln zugeordnet. Karzinome, welche bis $6 \mathrm{~cm}$ ab Anokutanlinie lokalisiert sind werden dem unteren Rektumdrittel zugeteilt. Das mittlere Rektumdrittel erstreckt sich von 6 bis $12 \mathrm{~cm}$ ab Anokutanlinie und Tumore, welche zwischen 12 und $16 \mathrm{~cm}$ beginnen, werden dem oberen Rektumdrittel zugeordnet (siehe Abbildung 1, Seite 5). Diese Zuordnung nimmt Einfluss auf die chirurgische Rektumresektion und wird aktuell auf ihren prognostischen Nutzen untersucht (siehe Kapitel 1.6, Seite 13). 


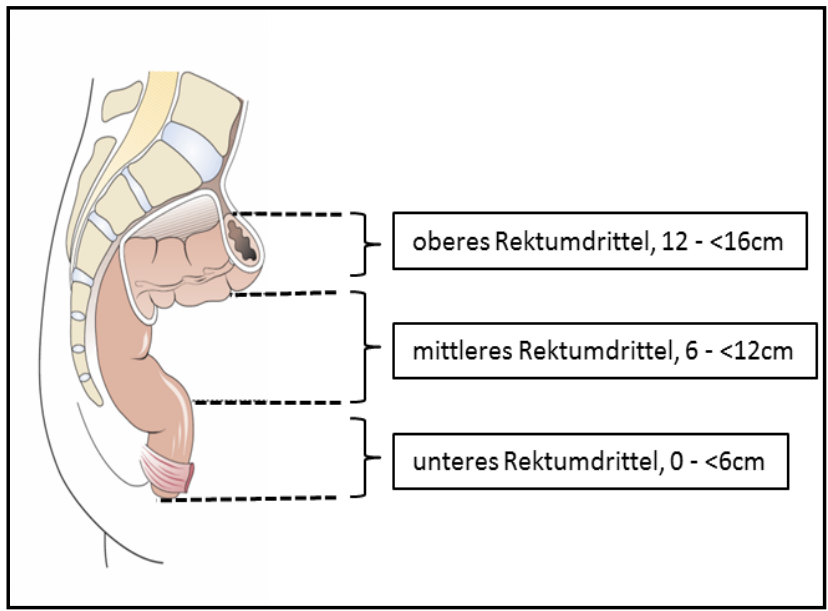

Abbildung 1: Dritteleinteilung des Rektums

Das untere Rektumdrittel beschreibt den Bereich von $<6 \mathrm{~cm}$ ab Anokutanlinie, das mittlere Rektumdrittel den Bereich von 6 $<12 \mathrm{~cm}$ und das obere Rektumdrittel den Bereich von $12-<16 \mathrm{~cm}$ ab Anokutanlinie. Die Höhenlokalisation muss immer mittels einer starren Rektoskopie bestimmt werden.

(Abbildung nach Liersch et al. 2007, Seite 48)

Die UICC-Stadieneinteilung erfolgt zunächst prätherapeutisch und wird anhand der klinischen (c) Ergebnisse der Staging-Untersuchungen (cUICC) bestimmt. Dieser Einschätzung der Krankheitsausbreitung kommt eine hohe Bedeutung zu, da sie therapieentscheidend ist. Die endgültige Festlegung des Krankheitsstadiums stellt das pathologisch ermittelte UICCStadium nach TNM (pUICC) dar. Das pUICC-Stadium wird postoperativ durch die histopathologische Aufarbeitung des Rektumresektats bestimmt und ist wegweisend für eine mögliche (adjuvante) Therapie. Aufbauend auf allen wichtigen Tumormerkmalen, wie dem Lymphknotenstatus (N-Status) oder dem Auffinden von Fernmetastasen kann jeder Tumor einem von fünf Stadien mit entsprechender Prognose zugeordnet werden (siehe Tabelle 2, Seite 6).

Der T-Status richtet sich nach der Invasionstiefe des Karzinoms in die Wandschichten des Rektums und nicht nach der Größe des Primärtumors (siehe Tabelle 1, Seite 6). Der Lymphknotenstatus wird durch die mikroskopische Untersuchung der chirurgisch entnommenen regionären Lymphknoten (LK) erhoben. Es ist darauf zu achten, dass ausreichend LK in die pathologische Aufarbeitung einbezogen werden. Heute wird empfohlen mindestens 12-14 regionäre LK histopathologisch zu untersuchen, um eine zuverlässige Aussage über die Tumorausbreitung treffen zu können (Hermanek 1995, Edge 2010, Wittekind und Meyer 2010). Als regionäre Lymphknotenstationen des Rektums gelten LK entlang den Aa. rectales superiores, mediae und inferiores, an der A. mesenterica inferior, an der A. iliaca interna, sowie mesorektale, lateral-sakrale und präsakrale LK. Werden Malignomzellen in LK anderer Stationen gefunden, zum Beispiel paraaortal, so gelten diese als Fernmetastasen. Der genauen Erfassung des $\mathrm{N}$-Status kommt eine immens hohe Bedeutung zu. Durch unsere Arbeitsgruppe innerhalb der klinischen Forschergruppe (KFO) 
179 konnte gezeigt werden, dass der Lymphknotenstatus einen erheblichen Einfluss auf die Langzeitprognose eines Patienten mit Rektumkarzinom nimmt (Sprenger et al. 2009).

Bevorzugte hämatogene Metastasierungsorte des Rektumkarzinoms stellen die Lunge (besonders Tumore im Bereich des unteren Rektumdrittels) und die Leber (Tumore im Bereich des mittleren und oberen Rektumdrittels), sowie angrenzende Organe wie das Ovar oder die Harnblase dar (Wittekind und Meyer 2010).

\begin{tabular}{|ll|}
\hline \multicolumn{1}{|c|}{ TNM-Klassifikation (Wittekind und Sobin, 2002) } \\
\hline T & Primärtumor \\
T0 & kein Anhalt für Primärtumor \\
Tis & $\begin{array}{l}\text { Carcinoma in situ; Infiltrationstiefe geht nicht über die Muscularis mucosae } \\
\text { hinaus }\end{array}$ \\
T1 & Tumor infiltriert die Submucosa, ohne Eindringen in die Muscularis propria \\
T2 & Tumor infiltriert die Muscularis propria \\
T3 & Tumor durchbricht die Muscularis propria und infiltriert die Subserosa / das \\
& pararektale Gewebe \\
T4 & Tumor infiltriert direkt angrenzende Organe und / oder durchbricht das \\
& viszerale Peritoneum \\
\hline N & regionäre Lymphknoten \\
N0 & keine Metastasen in regionären LK nachweisbar \\
N1 & Metastasen in 1-3 regionären LK nachweisbar \\
N2 & Metastasen in $\geq 4$ regionären LK nachweisbar \\
\hline M & Fernmetastasen \\
M0 & keine Fernmetastasen vorhanden \\
M1 & Fernmetastasen vorhanden \\
\hline
\end{tabular}

Tabelle 1: TNM-Klassifikation nach Wittekind und Sobin, 2002

Der T-Status beschreibt die Infiltrationstiefe des Tumors in die Wandstrukturen des Rektums. Der N-Status beschreibt den Befall regionärer LK und der M-Status gibt das Auftreten von Fernmetastasen wieder.

(Tabelle modifiziert nach Becker H et al. 2006, Seite 580)

Stadiengruppierung nach UICC (Wittekind und Sobin, 2002)

\begin{tabular}{|llll|}
\hline Stadium 0 & Tis & N0 & M0 \\
\hline Stadium I & T1, T2 & N0 & M0 \\
\hline Stadium II & T3, T4 & N0 & M0 \\
\hline Stadium III A & T1, T2 & N1 & M0 \\
& & & \\
Stadium III B & T3, T4 & N1 & M0 \\
& jedes T & N2 & M0 \\
& & & \\
\hline Stadium IV & Jedes T & Jedes N & M1 \\
\hline
\end{tabular}

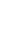

UICC-Stadiengruppierung nach Wittekind und Sobin, 2002

Anhand des TNM-Status des Tumors kann jedes Rektumkarzinom einem Stadium zugeordnet werden. Die Stadienzuordnung korreliert mit dem Fortschreiten der Erkrankung. 


\subsection{Diagnosesicherung und Staging des Rektumkarzinoms}

Maligne Tumore, welche sich im Bereich des Enddarms manifestieren, bleiben häufig lang unentdeckt. Dies liegt zum einem an einer unspezifischen Beschwerdesymptomatik, aber auch an einer Bagatellisierung eindeutiger Warnsignale. So werden in einer hausärztlichen Praxis vielfach Blutbeimengungen im Stuhl mit einem zusätzlich bestehenden Hämorrhoidalleiden erklärt, ohne dass ein Karzinomausschluss erfolgt. Die daraus resultierende Verzögerung der Diagnosestellung und Therapieeinleitung kann einen prognostischen Einfluss auf den Krankheitsverlauf nehmen. Demgemäß müssen Symptome, welche Hinweis auf ein Neoplasiewachstum im Kolon geben, zeitnah mittels einer kompletten Koloskopie abgeklärt werden. Als Warnsignal sollte jede Blutbeimengung im Stuhl (sowohl makroskopisch sichtbare, als auch ein positiver fäkaler Okkultbluttest (FOBT)), sowie Veränderungen der Defäkation, wie zum Beispiel paradoxer Stuhlgang, eine neu aufgetretene Sphinkterinsuffizienz oder Tenesmen angesehen werden. Eine ausführliche Anamneseerhebung und eine komplette körperliche Untersuchung stellen den Grundstein für alle folgenden Untersuchungen (Liersch et al. 2007, Bruns et al. 2010).

Ein sehr einfaches, schnelles und vor allem kostengünstiges Verfahren, um einen Überblick des distalen Rektums zu erhalten, stellt die digitale-rektale Untersuchung dar. Hierbei kann der Untersucher neben möglichen tiefsitzenden Tumoren (30-40\% aller Rektumkarzinome, Gaedcke et al. 2011) auch den Sphinktertonus orientierend beurteilen. Anhand der MasonKlassifikation kann eine erste Einschätzung über das Fortschreiten eines bestehenden Tumorwachstums getroffen werden. Dabei beurteilt der Untersucher die Verschieblichkeit der Neoplasie gegenüber dem umliegenden Gewebe (Mason 1976).

Epidemiologisch zeigt sich eine deutliche Zunahme der Inzidenz für Rektumkarzinome nach dem 50. Lebensjahr. Daher wird eine jährliche digitale Untersuchung des Rektums und die jährliche Durchführung eines FOBT ab dem 50. Lebensjahr für Patienten ohne erhöhtes Risiko empfohlen. Ab dem 55. Lebensjahr empfiehlt sich zusätzlich eine komplette Koloskopie, die bei unauffälligem Befund alle 10 Jahre wiederholt werden sollte (Bruns et al. 2010, Schmiegel et al. 2010).

Um bei Verdacht auf ein Rektumkarzinom die Diagnose zu sichern muss eine starre Rektoskopie erfolgen. Allein diese Untersuchung ermöglicht eine zuverlässig Messung der Distanz zwischen Anokutanlinie und Höhe des unteren Tumorunterrandes (Liersch et al. 2005, Schmiegel et al. 2010, Fuchs et al. 2011). Während der Rektoskopie werden 
Probeexzisionen (PE) entnommen, um die Dignität der Raumforderung histopathologisch zu klären. Dabei empfiehlt es sich, verschiedene Regionen des neoplastischen Gewebes zu biopsieren. Es besteht die Möglichkeit der Markierung der distalen Tumorregion mittels eines Goldclips. Dieser ist für die Planung des Strahlenfeldes unter Schonung der Sphinktermuskulatur bei Durchführung einer neoadjuvanten RCT von Bedeutung (Vorwerk et al. 2009).

Um die lokale Ausbreitung des Tumors und dessen Tiefeninfiltration in die Wandschichten des Rektums beurteilen zu können und damit eine Einschätzung des Erkrankungsstadiums zu treffen, ist eine rektale Endosonographie (rES) unabdingbar. Hierbei wird ein Rotorschallkopf endoluminal in das Rektum eingeführt. Diese Untersuchung ermöglicht eine genaue Beurteilung des Wachstumsverhaltens des Karzinoms, sowie eine Untersuchung regionaler LK hinsichtlich Metastasen und eine Beurteilung des Sphinkterapparates. Die rES in den Händen eines erfahrenen Untersuchers zeigt im Vergleich zu anderen bildgebenden Verfahren (Computertomographie (CT)/Magnetresonanztomographie (MRT)) die höchste Sensitivität und Spezifität bei der Beurteilung der Tiefeninfiltration des Tumors (Kwok et al. 2000, Liersch et al. 2005, Fuchs et al. 2011). Für die Erfassung des regionären Lymphknotenstatus eignet sich eine rektale Ultraschalluntersuchung, distale LK oder Fernmetastasen können jedoch nicht beurteilt werden. Zudem sollte die rES vor der bioptischen Gewebeentnahme erfolgen, da sich durch Biopsien regionale LK reaktiv vergrößern können. Folglich droht ein Overstaging des N-Status, sofern die rES innerhalb einer Woche nach bioptischer Sicherung des Rektumkarzinoms durchgeführt wird.

Weitere radiologische Bildgebungen des Beckens wie eine CT oder eine MRT sollten bei fortgeschrittenem Tumorwachstum (>UT2 oder $\mathrm{N}+$ ), stenosierend wachsenden Tumoren oder multiplem LK-Befall durchgeführt werden (Schmiegel et al. 2010). Beide Untersuchungen weisen jedoch eine geringere Spezifität und Sensitivität als die rES auf (Kwok et al. 2000).

In bis zu 5\% der Fälle liegt ein maligner Zweittumor im Bereich des Kolons vor, sodass stets eine komplette Koloskopie durchzuführen ist (Chen und Sheen-Chen 2000, Liersch et al. 2005, Schmiegel et al. 2010). Ist eine komplette Spiegelung des Dickdarms nicht möglich, sollte ein weiteres radiologisches Verfahren Einsatz finden (Schmiegel et al. 2010).

Nach histopathologischer Sicherung des Rektumkarzinoms schließt sich ein umfassendes Staging an, um den Ausbreitungsgrad der Tumorerkrankung zu erfassen. Diese 
Stadieneinteilung ist therapieentscheidend. Zu den Staging-Untersuchungen zählt eine perkutane Sonographie des Abdomens und eine Röntgenaufnahme des Thorax in zwei Ebenen. Ergebenen sich aus diesen Untersuchungen auffällige Befunde, werden weitere bildgebende Verfahren angeschlossen. Je nach Fall können zusätzliche Untersuchungen, wie eine gynäkologische oder urologische Inspektion notwendig werden (Schmiegel et al. 2010). Zu den intraoperativen Staging-Untersuchungen zählen eine Inspektion und Palpation der Leber, sowie eine direkten Sonographie des Organs (Schmiegel et al. 2010, Charnley et al. 1991).

Vor Therapieeinleitung hat eine Bestimmung des CEA-Werts zu erfolgen. Das Karzinoembryonale Antigen gilt heute als ein unabhängiger prognostischer Faktor (Chapman et al. 1998) und kann als Verlaufsparameter dienen, um Lokalrezidive (LR) zu detektieren.

\subsection{Stadien-adaptierte Therapie des Rektumkarzinoms}

Mit Einführung moderner Operationstechniken und einer neoadjuvanten RCT hat sich die Therapie des Rektumkarzinoms innerhalb der letzten zwei Jahrzehnte deutlich gewandelt (Gaedcke et al. 2011). Heutzutage erfolgt die Therapie Stadien-adaptiert (siehe Abbildung 2, Seite 12) und multimodal. Dabei umfasst die multimodale Therapie in kurativer Zielsetzung die chirurgisch-onkologische Resektion des Primärtumors, eine medikamentös-zytostatische Therapie zur Strahlensensibilisierung der Malignomzellen und eine Radiotherapie (RT) des kleinen Beckens (mit einer Gesamtdosis von bis zu 50,4 Gray (Gy)). Zielsetzung jeder onkologischen Rektumresektion ist, einen histopathologisch bestätigten RO-Status zu erreichen, auch wenn dies ein multiviszerales Vorgehen erforderlich machen sollte. Dabei wird das Ausmaß der chirurgischen Darmresektion durch die anatomischen Verhältnisse (zuund abführende Gefäße, regionäres Lymphabflussgebiet) vorgegeben. Es empfiehlt sich eine gleichzeitige Entnahme des Mesorektums, um eine Senkung der Lokalrezidivrate zu erreichen (Liersch et al. 2007, Schmiegel et al. 2010). Beim Rektumkarzinom gelten die gleichen onkologischen Resektionsprinzipien, die auch bei Karzinomen im Bereich des Kolons Anwendung finden. Dazu sind eine No-Touch-Isolations-Technik des Tumors, eine luminale Darmligatur (erfolgt proximal des tumortragenden Rektumabschnitts), eine zentrale Gefäßdissektion, eine lokoregionäre Lymphadenektomie, die Einhaltung eines ausreichenden Sicherheitsabstands und eine En-bloc-Resektion unabdingbar (Liersch et al. 
2007, Fuchs et al. 2011). Weiterhin müssen die autonomen Nerven (Plexus hypogastrici superiores et inferiores) im Operationsgebiet bestmöglich geschont werden, um die postoperativen Beeinträchtigungen (Blasen- und Sexualfunktionsstörrungen) für die Patienten so gering wie möglich zu halten.

\subsubsection{Therapie lokal begrenzter Rektumkarzinome (cUICC-I-Stadien)}

Lokal begrenzte Tumore, die keine LK-Invasion aufweisen (T1/2, N0, M0) werden kurativ rein chirurgisch therapiert, zytostatische Therapiemöglichkeiten finden keine Anwendung. Gut differenzierte Malignome (G1-2, sogenannte low-risk-Karzinome), deren Durchmesser maximal $3 \mathrm{~cm}$ beträgt, werden einer lokalen Vollwandexzision mittels transanalerendoskopischer Mikrochirurgie (TEM) zugeführt (Schmiegel et al. 2010). Diese rein lokale Resektion der Rektumwand wird durch ein geringes Risiko für einen LK-Befall (3-10\%) gerechtfertigt (Bruns et al. 2010). Weist der Tumor jedoch einen schlechten Differenzierungsgrad auf (G3-4, sogenannte high-risk-Karzinome), steigt das Risiko für eine stattgefundene lymphogene Metastasierung auf 10-20\% (Schmiegel et al. 2010). In diesen Fällen wird eine transabdominelle Resektion des Rektums, inklusive totaler mesorektaler Exzision (TME) empfohlen (Schmiegel et al. 2010).

\subsubsection{Therapie lokal fortgeschrittener Rektumkarzinome (cUICC-II/III-Stadien)}

Die Durchführung einer neoadjuvanten Radiochemotherapie (RCT) mit einer nachfolgenden tiefen anterioren Rektumresektion (TARR), inklusive einer TME gilt nach der aktuellen Studienlage als Therapie der Wahl für Adenokarzinome des Rektums im Stadium cUICC-II/III (des mittleren und unteren Drittels, Gaedcke et al. 2011, Glynne-Jones 2012). Die CAO/ARO/AIO-94-Studie der German Rectal Cancer Study Group (GRCSG) konnte belegen, dass die Einbindung einer neoadjuvanten RCT in das multimodale Therapiekonzept zu einer signifikanten Senkung der Lokalrezidivrate nach 5 Jahren und zu einer höheren Rate an R0Resektionen führt (Sauer et al. 2004, siehe Kapitel 1.6, Seite 13). Die Senkung der Lokalrezidivrate hat auch nach einem Nachbeobachtungszeitraum von mittlerweile 10 Jahren gegenüber den Patienten, die einer primären Operation zugeführt wurden, Bestand (Rödel C et al. 2012). Auch das Auftreten von toxischen Akut- und Langzeitnebenwirkungen ist bei einer neoadjuvanten RCT signifikant geringer (Sauer et al. 2004). 
Neben der Senkung der LR-Häufigkeit und einer höheren Rate an R0-Resektionen wird durch eine präoperative RCT auch bei tiefsitzenden Tumoren häufiger eine sphinktererhaltende Operation realisierbar. Verschiedene unabhängige Studien konnten zudem eine signifikant bessere Remissionsrate bei systemischer Behandlung mit 5-FU und gleichzeitiger Verabreichung von Folinsäure belegen (Petrelli et al. 1989, Poon et al. 1989). Laut der aktuellen CAO/ARO/AIO-04-Studie kann auch das FOLFOX-Schema zum Einsatz kommen (Schmiegel et al. 2010, siehe Kapitel 1.6, Seite 13). Es beinhaltet eine Kombination aus drei Wirkstoffen - 5-Fluorouracil (5-FU), Oxaliplatin und Folinsäure. Aktuell zeigen erste Studienergebnisse eine höhere Rate an Komplettremissionen (17\% gegenüber $13 \%$ bei einer neoadjuvanten Chemotherapie (CTX) mittels 5-FU) unter diesem Therapieregime (Rödel C et al. 2012, siehe Kapitel 1.6, Seite 13).

Die postoperative adjuvante Bestrahlung des kleinen Beckens mit Kombination einer zytostatischen Therapie wird nach den aktuellen Leitlinien durchgeführt bei Patienten mit einer R1-Resektion oder bei Patienten mit einem lokal fortgeschrittenen Rektumkarzinom, die keine neoadjuvante RCT erhalten haben (Gaedcke et al. 2012).

\subsubsection{Therapie des metastasierten Rektumkarzinoms (cUICC-IV-Stadium)}

Für Patienten, welche erst in einem fortgeschrittenen Erkrankungsstadium einer Therapie zugeführt werden, existieren keine feststehenden Therapieleitlinien. Jeder Krankheitsfall muss individuell über eine interdisziplinäre Tumorkonferenz entschieden und therapiert werden. Um Tumorkomplikationen zu vermeiden, kommt der chirurgischen Resektion des Primärtumors auch in diesem Fall eine hohe Bedeutung zu. Auch eine zytostatische Therapie kann in der palliativen Situation Anwendung finden, um eine weitere Tumorausdehnung einzuschränken (Fuchs et al. 2011). 


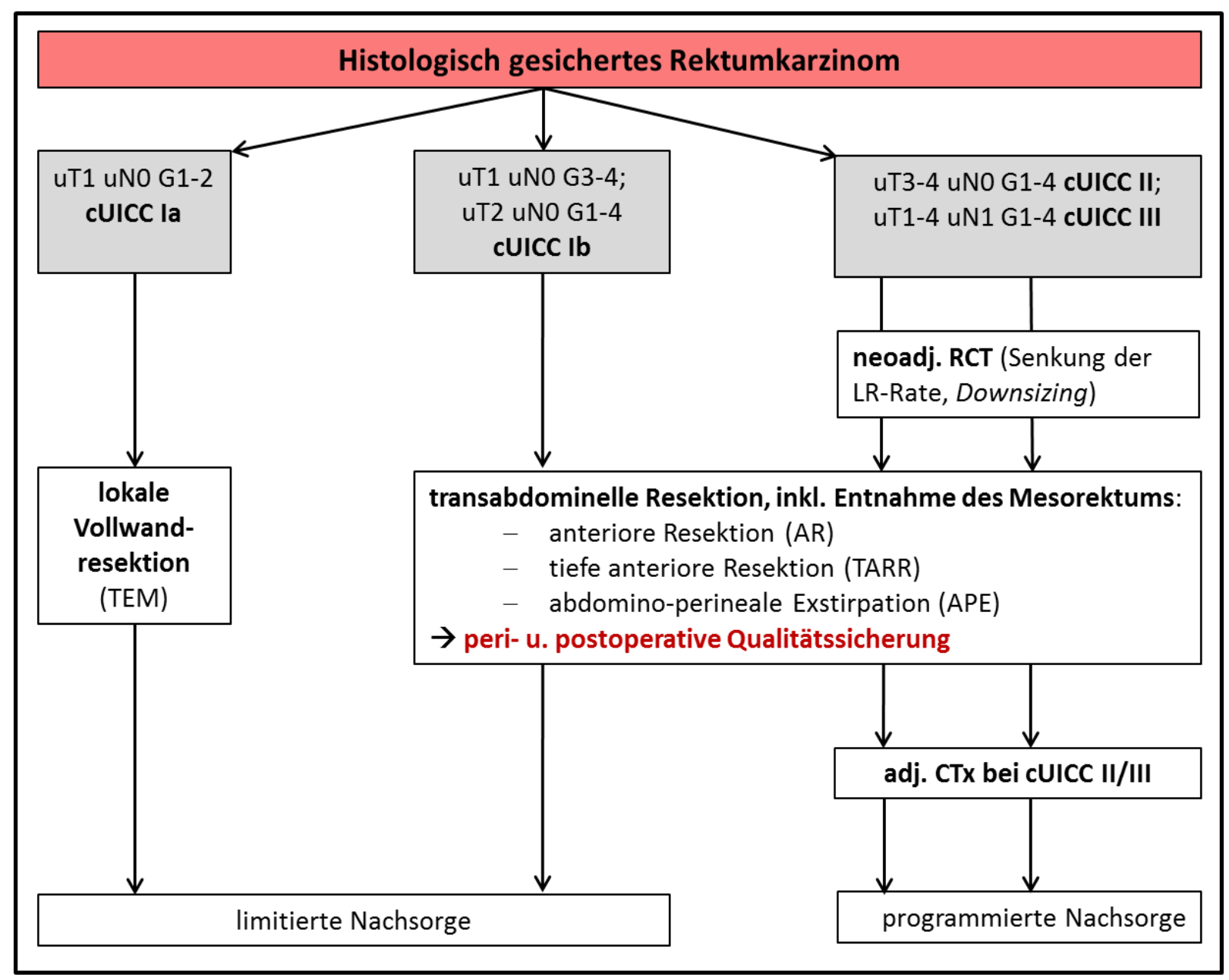

Abbildung 2: Stadien-adaptierte Therapie des Rektumkarzinoms mit kurativer Zielsetzung

Eine rein chirurgische Therapie erfolgt nur bei Tumoren im Stadium cUICC-la. Alle weiteren Stadien müssen einem multimodalen Therapiekonzept zugeführt werden. Dieses umfasst eine zytostatische Tumortherapie, eine Radiatio von 50,4 Gy des kleinen Beckens und die chirurgische Rektumresektion. Auch die Nachsorgeuntersuchungen gestalten sich abhängig vom Erkrankungsstadium.

Die chirurgische Rektumresektion umfasst derzeit immer eine begleitende Exzision des Mesorektums.

(Abbildung modifiziert nach Liersch et al. 2007, Seite 55) 


\section{6 Übersicht aktueller Studien zur Optimierung der multimodalen Therapie des lokal fortgeschrittenen Rektumkarzinoms}

Alle Patienten wurden im Rahmen der GRCSG oder analog der Therapieregime behandelt.

Die CAO/ARO/AIO-94-Studie, eine große Phase-III-Multicenterstudie, die deutschlandweit durchgeführt wurde, untersuchte die Fragestellung, ob eine neoadjuvante RCT Vorteile gegenüber einer adjuvanten Therapie aufweist (Studienprotokoll siehe Anhang c, Seite 86). Die Ergebnisse dieser Studie belegen, dass durch ein neoadjuvantes Therapiekonzept eine Senkung des Lokalrezidivrisikos auf die Hälfte erzielt werden kann. Adjuvant behandelte Patienten wiesen laut dieser Studie eine Lokalrezidivrate von $13 \%$ auf, demgegenüber steht eine Lokalrezidivrate von $6 \%$ in der neoadjuvanten Behandlungsgruppe (Sauer et al. 2004). Zusätzlich traten während der präoperativen Bestrahlung des kleinen Beckens signifikant weniger Akut- und Langzeittoxizitäten auf. Ein Einfluss auf das krankheitsfreie Überleben (disease free survival, DFS) oder das Gesamtüberleben (overall survival, OS) konnte nach einer Nachbeobachtungszeit von zehn Jahren nicht gezeigt werden (Sauer et al. 2004).

Auch nach erneuter Auswertung der Langzeitdaten (Median 134 Monate) konnte ein Persistieren der besseren lokalen Kontrolle durch eine neoadjuvante RCT gezeigt werden. Ein Effekt auf das OS oder auf die Rate der Fernmetastasierung zeigt sich auch bisher nicht (Sauer et al. 2012).

Die multizentrische CAO/ARO/AIO-04-Studie der GRCSG untersucht ebenfalls eine Verbesserung der systemischen Tumortherapie, um zukünftig eine weitere Prognoseverbesserung zu erzielen. In dieser Untersuchung wurde dem Prüfarm zusätzlich zu einer neodjuvanten RCT, bestehend aus 5-FU/Folinsäure, wie auch mit der postoperativen CTx, das Alkylanz Oxaliplatin verabreicht (FOLFOX-Schema, Studienprotokoll siehe Anhang d, Seite 87). Die Zugabe von Oxaliplatin zur systemischen Tumortherapie zeigt als ein erstes Ergebnis eine signifikant höhere Rate an Komplettremissionen (13\% bei Verabreichung des FOLFOX-Schemas gegen $17 \%$ bei RCT mittels 5-FU, $p<0,05$; Rödel $C$ et al. 2012). Ergebnisse über den primären Endpunkt dieser Studie, eine Verlängerung des DFS, stehen bislang noch aus und könnten durch Auswertung der Langzeit- und Überlebensdaten gewonnen werden (Glynne-Jones 2012).

Eine Studie zur primär operativen Therapie des Rektumkarzinoms stellt die DFG-geförderte GAST-05-Studie dar (Studienprotokoll siehe Anhang e, Seite 87). Diese untersucht die Fragestellung, ob Rektumkarzinome des oberen Rektumdrittels $(12-16 \mathrm{~cm})$ tatsächlich einer 
kompletten TME bedürfen. Diesbezüglich wird das onkologische Outcome hinsichtlich einer partiellen mesorektalen Exzision (PME) und einer TME verglichen. Sollten die Ergebnisse dieser Studie eine onkologische Gleichwertigkeit beider Operationsverfahren belegen, können funktionelle Vorteile bei Durchführung einer PME erwartet werden. Aktuelle Ergebnisse dieser Untersuchung stehen noch aus.

\subsection{Nachsorge und Prognose}

Die Prognose aller Rektumkarzinompatienten wird maßgeblich von dem primären Tumorstadium, sowie von der Qualität und Radikalität der Operation beeinflusst (Bruns et al. 2010). Weisen Patienten mit einem UICC-I-Rektumkarzinom eine tumorspezifische relative 5-JÜR von über $90 \%$ auf, liegt diese bei Patienten mit einem lokal fortgeschrittenen Rektumkarzinom (UICC-II/III) trotz erfolgter R0-Resektion wesentlich niedriger. Patienten mit einer disseminierten Erkrankung (UICC-IV) weisen eine OS nach 5-Jahren von knapp 10\% auf (Bruns et al. 2010).

Nach abgeschlossener Therapie in kurativer Zielsetzung ist eine engmaschige Nachsorge indiziert. Patienten, welche an einem Karzinom des Rektums erkrankt waren, zeigen ein erhöhtes Risiko für einen Zweittumor im Bereich des Dickdarms, ein LR oder für das Auftreten von Fernmetastasen für 5 Jahre nach Therapieabschluss. Dabei ist zu beachten, dass das Risiko mit dem Stadium des Primärtumors steigt und daher auch die Nachsorge Stadien-adaptiert verläuft (Schmiegel et al. 2010).

Bei Patienten, die an einem UICC-I-Tumor erkrankt waren und einer R0-Resektion zugeführt werden konnten, ist keine regelmäßige Nachsorge in den aktuellen Leitlinien verankert. Eine individuelle Entscheidung über die Notwendigkeit ist bei diesen Patienten zu treffen.

Eine regelmäßige Nachsorge wird bei Patienten mit erfolgreicher R0-Resektion in Tumorstadium UICC-II/III in den Leitlinien empfohlen, sofern sich bei Auftreten eines LR oder von Fernmetastasen therapeutische Konsequenzen ergeben (Schmiegel et al. 2010, Bruns et al. 2010). Die Nachsorge sollte eine regelmäßige körperliche Untersuchung, eine komplette Koloskopie, eine Abdomensonographie, eine Röntgenaufnahme des Thorax, sowie eine einmalige CT des Beckens 3 Monate nach Therapieabschluss umfassen (Bruns et al. 2010). 


\subsection{Prädiktive und prognostische Biomarker des Rektumkarzinoms}

Rund $45 \%$ aller Patienten, die an einem lokal-fortgeschrittenen Rektumkarzinom erkrankt sind, zeigen keine Tumorregression und keine Erniedrigung des T-Levels nach Verabreichung einer neoadjuvanten RCT und zählen somit zu den Non-Respondern beziehungsweise PoorRespondern (Kuremsky et al. 2009). Aktuell besteht nicht die Möglichkeit, vor Einleitung einer Therapie den individuellen Therapierespons abzuschätzen (Kuremsky et al. 2009). Verschiedene Biomarker könnten aufgrund ihrer Funktionsstellung im Zellzyklus und in Signalwegen Einfluss auf die Wirksamkeit einer systemischen Tumortherapie nehmen. Zum jetzigen Zeitpunkt ist kein etablierter Biomarker mit einem prädiktiven oder prognostischen Potential für das lokal fortgeschrittene Rektumkarzinom im klinischen Routineeinsatz verfügbar. Eine Übersicht über bisherige Studienergebnisse und die untersuchten Biomarker in lokal fortgeschrittenen Rektumkarzinomen gibt die Metaanalyse von Kuremsky et al. (2009). Zwei, basierend auf ihrer zellulären Funktion, vielversprechende Proteine stellen der Tumorsuppressor p53 und der Proliferationsmarker Ki67 dar. Trotz zahlreicher vorangegangener Studien konnte nicht eindeutig die Rolle der p53- oder Ki67-Expression im Adenokarzinom des Rektums geklärt werden (siehe Tabelle 11, Seite 70 und Tabelle 12, Seite 78).

Das Protein p53 gilt als der meistmutierte Tumorsuppressor in humanen Karzinomen und scheint bei der Entwicklung maligner Zelleigenschaften und der Tumorgenese beteiligt zu sein (Fearon und Vogelstein 1990, Hollstein et al. 1991, Levine et al. 1991, Kuremsky et al. 2009). Dieser Tumorsuppressor spielt eine entscheidende Rolle bei der Initialisierung der Zellapoptose und somit der Wirksamkeit von Desoxyribonukleinsäure(DNA)-schädigenden Agenzien (siehe Kapitel 2.5.1, Seite 34). So wurde in verschieden Studien belegt, dass das Expressionslevel von Wildtyp-p53 signifikanten Einfluss auf die Strahlensensibilität von Zellen nimmt (Clarke et al. 1993, Lowe et al. 1993 a, Lowe et al. 1993 b, Mcllwrath et al. 1994). In der Metaanalyse von Kuremsky et al. (2009) wurden 21 Studien ausgewertet, die die prädiktive und prognostische Bedeutung von p53 auf das Therapieansprechen und auf die Überlebensdaten von Rektumkarzinompatienten untersuchten. In 17 dieser Studien zeigt sich keine Korrelation zwischen der Expression von p53 und dem Erfolg einer zytostatischen Therapie beziehungsweise dem Outcome der Patienten (Kuremsky et al. 2009). Die restlichen vier Studien belegen eine signifikante Korrelation zwischen dem Expressionslevel von p53 im Tumorgewebe und dem Therapierespons neoadjuvant therapierter Patienten 
(Spitz et al. 1997, Luna-Perez et al. 1998, Esposito et al. 2001, Lin et al. 2006). Jedoch stellen sich die Ergebnisse dieser vier Untersuchungen sehr uneinheitlich dar und lassen keine sichere Aussage über den Nutzen von p53 als Biomarker zu (siehe Tabelle 11, Seite 70). Ki67, ein etablierter Marker für die Teilungsaktivität und Proliferation eines Gewebes, wurde schon in vorrangegangenen Studien als ein prädiktiver und prognostischer Marker im Rektumkarzinom herangezogen. Kuremsky et al. (2009) verglichen 13 Studien, welche diesen möglichen Nutzen untersuchten. Zwei Studien konnten einen Zusammenhang zwischen der Expression im prätherapeutischen Gewebe und dem histopathologisch erfassten Tumorregressionsgrad (TRG) belegen. Diese beiden Untersuchungen wurden an neoadjuvant behandelten Patientenkollektiven durchgeführt. Jakob et al. (2008) zeigen anhand ihrer Untersuchungen einen negativen Zusammenhang zwischen der Ki67-Expression und dem Ansprechen einer neoadjuvanten Therapie (gemessen am TRG). Dem entgegengesetzt zeigen Kim et al. (2001) einen höheren Ki67-Index bei Patienten, die eine komplette Tumorregression aufwiesen, als bei Non-Respondern. Die verbleibenden Untersuchungen konnten keinen signifikanten Zusammenhang erheben. Die Datenlage zum Nutzen des Proteins Ki67 als Biomarker ist also widersprüchlich.

Diese Metaanalyse zeigt auf, dass weder das prädiktive und prognostische Potential für den Tumorsuppressor p53 noch für den Proliferationsmarker Ki67 verlässlich geklärt ist. Weiterhin offenbart die Gegenüberstellung der einzelnen Studien eine mangelnde Standardisierung der Untersuchungsverfahren. Häufig wurden kleine Kollektive untersucht, welche zudem eine sehr heterogene Patientengruppe umfassten. Demzufolge könnte hierin eine Ursache für die widersprüchlichen Studienergebnisse liegen. Die Biomarkerexpression wurde in allen Studien mittels immunhistochemischer Färbeverfahren analysiert. Diese Methode eignet sich hervorragend, um die Proteinausstattung von Biomaterialien zu untersuchen. Jedoch erfolgt die Analyse der Färbeergebnisse häufig nach subjektiven Gesichtspunkten. Auch die durch fehlende Festlegung von standardisierten Analysekriterien entstehende hohe Interobservervariabilität erschwert die Vergleichbarkeit verschiedener immunhistochemischer Analysen untereinander und lässt die erfassten immunhistochemischen Daten anzweifeln (Seidal et al. 2001).

All diese Umstände legen eine erneute Untersuchung der Relevanz der Biomarkerexpression von p53 und Ki67 im lokal fortgeschrittenen Rektumkarzinom, anhand eines umfassenderen Patientenkollektivs unter standardisierten Therapiebedingungen nahe. Von noch größerer 
Bedeutung erscheint eine standardisierte und somit verlässliche Erfassung der immunhistochemischen Daten.

\subsection{Fragestellung und eigene Zielsetzung}

Die vorliegende Untersuchung wurde im Rahmen des Teilprojekts 5 der DFG(Deutsche Forschungsgemeinschaft)-geförderten klinischen Forschergruppe KFO 179: ,Biological Basis of Individual Tumor Response in Patients with Rectal Cancer' der Universitätsmedizin Göttingen (UMG) durchgeführt (siehe www.kfo179.de).

Alle Patienten, die in die Untersuchung eingeschlossen werden konnten, wurden unter standardisierten Bedingungen in der Abteilung für Allgemein- und Viszeralchirurgie der Universitätsmedizin Göttingen operiert. Die multimodale Therapie erfolgte in randomisierten, kontrollierten multizentrischen Phase-II/III-Studien oder analog zu deren Therapieregimen (siehe Kapitel 1.6, Seite 13). Nach den aktuellen Therapierichtlinien wird ab dem Stadium CUICC-II eine neoadjuvante RCT empfohlen. Postoperativ kann der Effekt der präoperativen Behandlung anhand des histopathologisch determinierten TRG eingeschätzt werden. Rund $11 \%$ unseres neoadjuvant behandelten Patientenkollektivs weisen einen TRG von 4 auf, jedoch zeigt der gleiche Prozentsatz ein sehr geringes Ansprechen auf die gleiche neoadjuvante Vorbehandlung (entsprechend TRG 1). Eine Ursache hierfür könnten interindividuelle Unterschiede innerhalb der Tumorbiologie sein. Genaue Kenntnis über das Biomarkerprofil von Tumorzellen aus Adenokarzinomen des Rektums kann die Grundlage für eine individualisierte Tumortherapie stellen.

Anhand von monozentrisch untersuchtem prätherapeutischem Gewebe und Gewebe des Rektumresektats, sowie der Erhebung der klinikopathologischen und Langzeit-Follow-upDaten unserer Patienten, wird in dieser Studie die Bedeutung der Expression der Biomarker p53 und Ki67 im Rektumkarzinom als prädiktiver und prognostischer Faktor untersucht.

Weiterhin wird innerhalb der vorliegenden Untersuchung eine Evaluation des digitalen Bildanalysesystems (digital image analysis, DIA) Ventana Image Analysis System - kurz VIAS genannt - durchgeführt (siehe Kapitel 2.6, Seite 36). Ziel ist es, dieses DIA zu etablieren, um eine standardisierte, hochsensitive und Observer-unabhängige Messung immunhistochemischer Daten zu ermöglichen. Dadurch wird eine Minimierung der Intraund Interobservervarianz erreicht. Nur eine valide und objektive Biomarkeranalyse ist 
verwertbar und kann zur Erforschung der Tumorbiologie des Rektumkarzinoms herangezogen werden. Um die erfassten Daten des DIA VIAS zu überprüfen, sind zwei verschiedene Verfahren zur Auswertung immunhistochemischer Präparate gegenübergestellt (alle vorhandenen Präparate wurden zuerst konventionell-manuell und danach mit Hilfe des DIA analysiert).

Folgende Fragen sollen in der vorliegenden Untersuchung geklärt werden:

1. Hat das Expressionslevel von p53 oder Ki67 in der prätherapeutischen Biopsie und/oder im posttherapeutischen Rektumresektat einen prädiktiven Wert bezüglich des Ansprechens auf eine RCT gemessen am Grad der Tumorregression und weiterer klinisch-pathologischer Parameter?

2. Hat das Expressionslevel von p53 oder Ki67 in der prätherapeutischen Probeentnahme und/oder im Rektumresektat einen prognostischen Stellenwert gemessen am DFS und am Karzinom-spezifischen Überleben (carcinom-specific survival, CSS)?

3. Kann aus Detektion von p53 und/oder Ki67 ein Nutzen für den klinischen Alltag gezogen werden?

4. Kann das Expressionslevel von p53 und/oder Ki67 zukünftig dazu beitragen, eine individualisierte Tumortherapie mit dem Ziel einer Prognoseverbesserung zu ermöglichen?

5. Wird durch Einsatz des DIA VIAS eine verlässliche Erfassung immunhistochemischer Daten ermöglicht? 


\section{Patienten, Material und Methodik}

\subsection{Patientenkollektiv}

Die vorliegende Untersuchung umfasst ein Patientenkollektiv von 225 Patienten, welche an einem lokal fortgeschrittenen (cUICC-II/III) Rektumkarzinom erkrankt sind. Alle Patienten sind im Zeitraum vom 26.01.1996 bis 26.01.2010 in der UMG, Abteilung für Allgemein- und Viszeralchirurgie unter der Leitung von Univ.-Prof. Dr. H. Becker operiert worden. Die Behandlung erfolgte im Zuge einer multimodalen Therapie orientierend an den aktuell gültigen Therapierichtlinien und im Rahmen von klinischen Studien, oder analog zu den Therapieregimen in Kooperation mit der Abteilung für Strahlentherapie und Radioonkologie (Leitung Prof. Dr. Dr. C. F. Hess) der UMG. Die Aufarbeitung der Resektate, deren histopathologische Diagnostik, sowie die Beurteilung des TRG erfolgten standardisiert in der Abteilung für Gastroenteropathologie durch Frau OÄ Dr. med. H. Rothe.

Alle Patienten, die in diese Analyse eingeschlossen wurden, waren ausführlich über den Inhalt und die Zielsetzung der Untersuchungen aufgeklärt worden. Von jedem Patienten liegt eine schriftliche Einwilligung über die Auswertung seiner klinischen Daten, die immunhistochemische Untersuchung des entnommenen und archivierten Biomaterials und die Erlaubnis zur Erhebung der krankheitsbezogenen Follow-up-Daten, im Rahmen der KFO 179, vor (www.kfo179.de).

Von 225 untersuchten Patienten sind 67 Personen weiblich (29,8\%) und 158 Personen männlich (70,2\%). Das durchschnittliche Alter zum Zeitpunkt der Operation lag bei 62 Jahren (62,38 +/- 9,95 Jahre; von 34 - 82 Jahre). Alle Operationsverfahren erfolgten standardisiert und orientierten sich stets an den onkologischen Operationsprinzipien (siehe Kapitel 1.5, Seite 9). Die multimodale Behandlung erfolgte im Rahmen von prospektiv randomisierten Studien der Phase-II/-III (CAO/AIO/ARO-94, CAO/AIO/ARO-04, CapOx; siehe Kapitel 1.6, Seite 13) oder analog zu diesen. Das Patientenkollektiv gliedert sich in drei Behandlungsgruppen auf. Zwei Gruppen erhielten eine neoadjuvante Therapie $(80,9 \%, n=182)$. Davon wurde eine Gruppe $(48,0 \%, n=108)$ mit einer systemischen 5-FU-Monotherapie als Radiosensitizer begleitend zur neoadjuvanten Bestrahlung behandelt. Die zweite Behandlungsgruppe $(32,9 \%, n=74)$ erhielt als neoadjuvante Behandlung eine Kombination von 5-FU und Oxaliplatin zur RT. Bei der Radiatio wurde eine Gesamtdosis von 50,4 Gy in 28 
Einzelfraktionen verabreicht. Die dritte Behandlungsgruppe $(19,1 \%, n=43)$ erhielt im Rahmen der CAO/AIO/ARO-94-Studie und der GAST-05-Studie eine primäre Resektion des Rektums und wurden adjuvant weiterbehandelt. Diese Patientenkohorte dient als Kontrollgruppe (siehe Tabelle 3, Seite 21; sowie Abbildung 3).

Intraoperativ offenbarte sich bei 13 Patienten $(5,8 \%)$ das Vorliegen einer okkult metastasierten Erkrankung. Der Großteil der Patienten $(54,2 \%, n=122)$ wies eine Tumorlokalisation im mittlerem Rektumdrittel auf (siehe Tabelle 3, Seite 21).

Zu der Verteilung der angewandten Operationstechniken siehe Kapitel 3.1.1 (Seite 42), sowie Tabelle 6 (Seite 43).

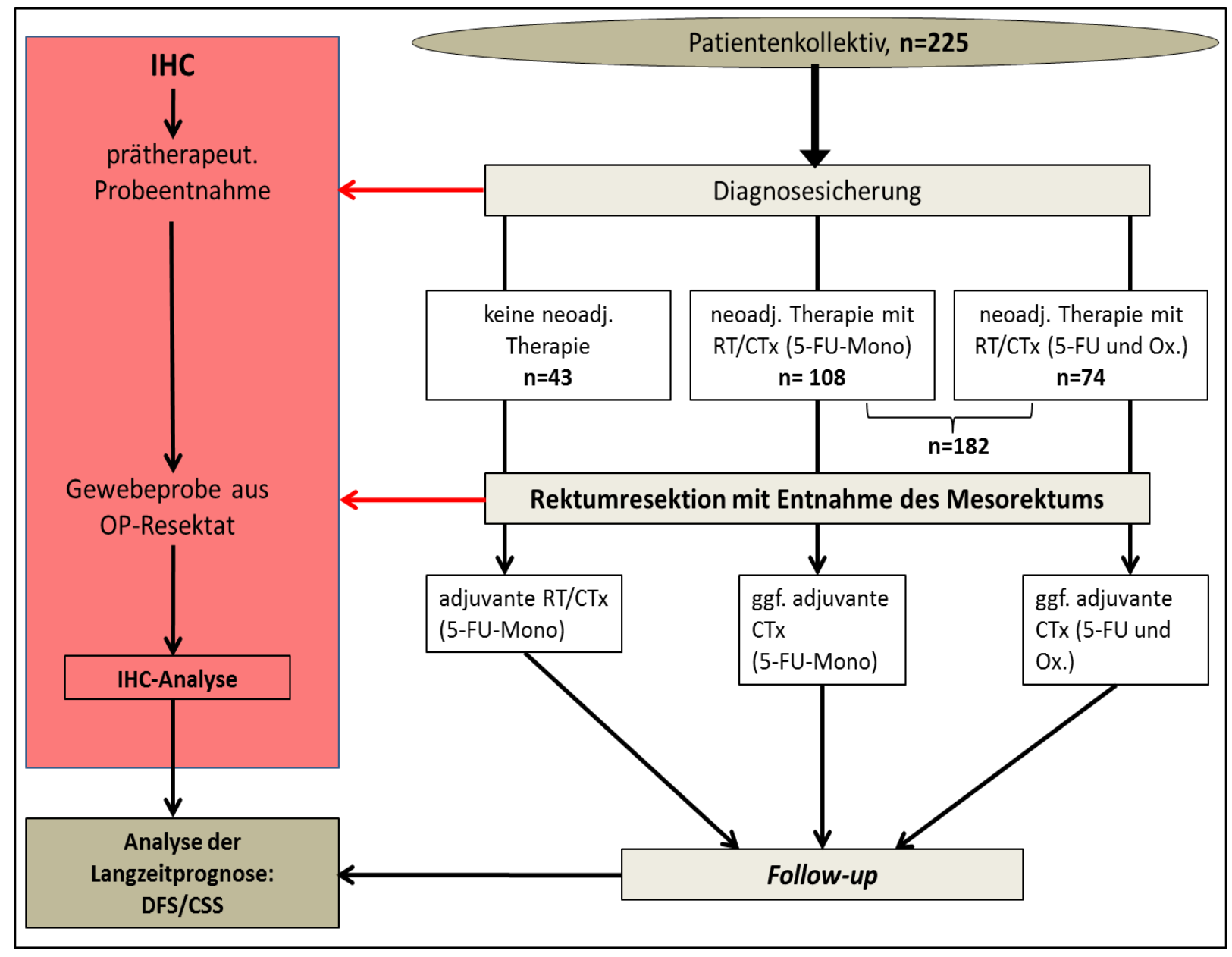

Abbildung 3: Therapieablauf und Studiendesign

Die Diagnosesicherung erfolgt histopathologisch. Das Patientenkollektiv $(n=225)$ teilt sich in 3 Behandlungsgruppen. Insgesamt erhielten 182 Patienten eine neodjuvante Therapie bestehend aus Radiatio des Beckens und eine begleitende CTx. Alle Patienten wurden im Rahmen einer multimodalen Therapie in der Universitätsmedizin Göttingen operiert.

(CSS -Karzinom-spezifisches Überleben, CTx - Chemotherapie, DFS - krankheitsfreie Überleben, 5-FU - 5-Fluorouracil, Ox. - Oxaliplatin, RT - Radiotherapie) 


\begin{tabular}{|c|c|c|c|c|c|c|c|}
\hline \multirow{2}{*}{$\begin{array}{l}\text { Neoadjuvante Therapie } \\
\text { Patientenzahl (N=225) }\end{array}$} & \multicolumn{2}{|c|}{ keine } & \multicolumn{2}{|c|}{$\begin{array}{c}\text { RCT } \\
\text { (5-FU-Mono) }\end{array}$} & \multicolumn{2}{|c|}{$\begin{array}{c}\text { intensivierte } \\
\text { RCT } \\
\text { (5-FU und } \\
\text { Oxaliplatin) }\end{array}$} & \multirow[t]{2}{*}{ p-Wert* } \\
\hline & 43 & $\%$ & 108 & $\%$ & 74 & $\%$ & \\
\hline \multicolumn{8}{|l|}{ Geschlecht } \\
\hline weiblich & \multicolumn{2}{|c|}{12} & \multicolumn{2}{|c|}{29} & \multicolumn{2}{|c|}{26} & \\
\hline männlich & \multicolumn{2}{|c|}{31} & \multicolumn{2}{|c|}{79} & \multicolumn{2}{|c|}{48} & \\
\hline \multicolumn{7}{|l|}{ Alter (zur OP, in Jahren) } & \\
\hline Min. - Max. & \multicolumn{2}{|c|}{$39-79$} & \multicolumn{2}{|c|}{$34-82$} & \multicolumn{2}{|c|}{$36-81$} & \\
\hline Mittelwert & \multicolumn{2}{|c|}{63,24} & \multicolumn{2}{|c|}{62,11} & \multicolumn{2}{|c|}{62,31} & \\
\hline \multicolumn{7}{|l|}{ Höhenlokalisation d. Tumors } & \multirow{4}{*}{0.04} \\
\hline unteres Rektumdrittel & 13 & 30,2 & 39 & 36,1 & 35 & 47,3 & \\
\hline mittleres Rektumdrittel & 23 & 53,5 & 63 & 58,3 & 36 & 48,6 & \\
\hline oberes Rektumdrittel & 7 & 16,3 & 6 & 5,6 & 3 & 4,1 & \\
\hline \multicolumn{7}{|l|}{ uT-Status } & \multirow{7}{*}{0.02} \\
\hline 0 & 0 & - & 0 & - & 0 & - & \\
\hline 1 & 0 & - & 0 & - & 0 & - & \\
\hline 2 & 6 & 14,0 & 3 & 2,8 & 2 & 2,7 & \\
\hline 3 & 35 & 81,4 & 97 & 89,8 & 68 & 91,9 & \\
\hline 4 & 1 & 2,3 & 8 & 7,4 & 4 & 5,4 & \\
\hline Keine Angabe mgl. & 1 & 2,3 & 0 & - & 0 & - & \\
\hline \multicolumn{7}{|l|}{ uN-Status } & \multirow{4}{*}{0.14} \\
\hline 0 & 16 & 37,2 & 30 & 27,8 & 18 & 24,3 & \\
\hline 1 & 26 & 60,5 & 78 & 72,2 & 56 & 75,7 & \\
\hline Keine Angabe mgl. & 1 & 2,3 & 0 & - & 0 & - & \\
\hline \multicolumn{7}{|l|}{ cUICC } & \multirow{7}{*}{0.05} \\
\hline 0 & 0 & - & 0 & - & 0 & - & \\
\hline I & 2 & 4,7 & 0 & - & 0 & - & \\
\hline II & 14 & 32,6 & 28 & 25,9 & 18 & 24,3 & \\
\hline III & 23 & 53,5 & 73 & 67,6 & 53 & 71,6 & \\
\hline IV & 3 & 7,0 & 7 & 6,5 & 3 & 4,1 & \\
\hline Keine Angabe mgl. & 1 & 2,3 & 0 & - & 0 & - & \\
\hline
\end{tabular}

\section{Tabelle 3: Übersicht der prätherapeutischen Staging-Ergebnisse}

Die Tabelle gibt eine Übersicht des Patientenkollektives wieder und stützt sich auf die Daten, die zum Zeitpunkt der Staging-Untersuchungen vorlagen. Die insgesamt 225 Patienten verteilen sich auf drei Behandlungsgruppen.

(cUICC - klinisches Erkrankungsstadium, 5-FU - 5-Fluorouracil, RCTx - Radiochemotherapie, uNStatus - endosonographisch-ermittelter regionärer LK-Status, UT-Status - endosonographischermittelte Tumorinvasionstiefe)

* p-Wert-Berechnung mit Chi-Quadrat-Test 


\subsection{Material}

\subsubsection{Gewebeproben}

Im Rahmen der vorliegenden Arbeit wurden prätherapeutische Tumorbiopsien und Proben, die dem Rektumresektat entstammen, immunhistochemisch analysiert (siehe Abbildung 3, Seite 20).

Zur Durchführung der immunhistochemischen Färbungen wurde das Tumormaterial im Rahmen der Routinediagnostik Formalin-fixiert und in Paraffin eingebettet (in der Abteilung für Pathologie der UMG).

Aus jeder vorliegenden Gewebeprobe wurden 2 Präparate gefertigt, um zwei etablierte Antigenfärbungen durchführen zu können - p53- und Ki67-Antigenfärbung. Die genaue Präparatanfertigung und die Färbemethoden sind in Kapitel 2.3 aufgeführt (siehe Seite 28). Jedes Präparat wurde zweimalig analysiert. Zuerst erfolgte die konventionell-manuelle Auswertung aller Präparate und danach schloss sich eine erneute Analyse mit Unterstützung des DIA an. Gewebeproben, die eine stark reduzierten Tumormasse und somit zu wenige eindeutig abgrenzbare Karzinomzellen enthalten haben, wurden nicht mit in die statistische Auswertung eingebracht (weniger als 50 Tumorzellen in den Präparaten der PE und weniger als 100 Tumorzellen in den Präparaten der Rektumresektate). Bei einigen Patienten lagen die prätherapeutischen PE zum Zeitpunkt der Analyse nicht vor (teilweise wurden diese außerhalb der UMG entnommen).

\subsubsection{Perioperative Qualitätskontrolle des Rektumresektats}

Bei dem multimodalen Behandlungskonzept des lokal fortgeschrittenen Rektumkarzinoms stellt die chirurgische Resektion des Tumors die wichtigste Therapiemethode dar (Liersch et al. 2009). Um eine onkologische Resektion zu gewährleisten, wird eine perioperative Qualitätskontrolle des Rektumresektats durchgeführt.

Die TME stellt bei Tumoren im Bereich des mittleren und des unteren Rektumdrittels die chirurgische Therapie der Wahl dar. Für Tumoren, welche im oberen Rektumdrittel lokalisiert sind, ist zum jetzigen Zeitpunkt noch unklar, ob eine PME onkologisch ausreichend ist. Die GAST-05-Studie soll klären, ob mit einer TME oder PME bessere Therapieerfolge erzielt werden können. 
Um die Qualität der mesorektalen Exzision frühestmöglich zu sichern, wird unmittelbar nach der Entnahme des Rektums eine erste Qualitätskontrolle nach etablierten Methoden durchgeführt (Sterk et al. 2000, Liersch et al. 2005). Mit Hilfe verdünnter Methylenblaulösung wird die Unversehrtheit der Hüllfaszie des Mesorektums überprüft. Zu diesem Zweck wird in dem nativen Rektumresektat die Arteria mesenterica inferior aufgesucht und freipräpariert. Danach erfolgt die Kanülierung dieser Arterie mit einer Knopfkanüle. Nach Fixierung der Kanüle werden $20 \mathrm{ml}$ Methylenblaulösung injiziert (siehe Abbildung 4, Seite 24). Infolgedessen färbt sich das Präparat an und selbst kleinste Verletzungen der mesorektalen Hüllfaszie werden durch Austritt des Farbstoffes sichtbar. Die komplette Phase des Anfärbens wird photographisch dokumentiert. Anhand des Farbstoffaustrittes kann die Qualität der TME eingestuft werden (Sterk et al. 2000, Hermanek et al. 2003, Liersch et al. 2005; siehe Abbildung 5, Seite 25):

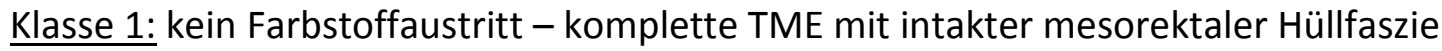
Klasse 2: punktförmige(r) Farbstoffaustritt(e) während/nach der Injektion - kleinste Inzisionen der mesorektalen Hüllfaszie; meist makroskopisch nicht sichtbar Klasse 3: flächenhafter Austritt des Farbstoffes - makroskopisch unvollständige TME

Es folgt die Dokumentation der Durchführung und des Ergebnisses der Qualitätssicherung. 


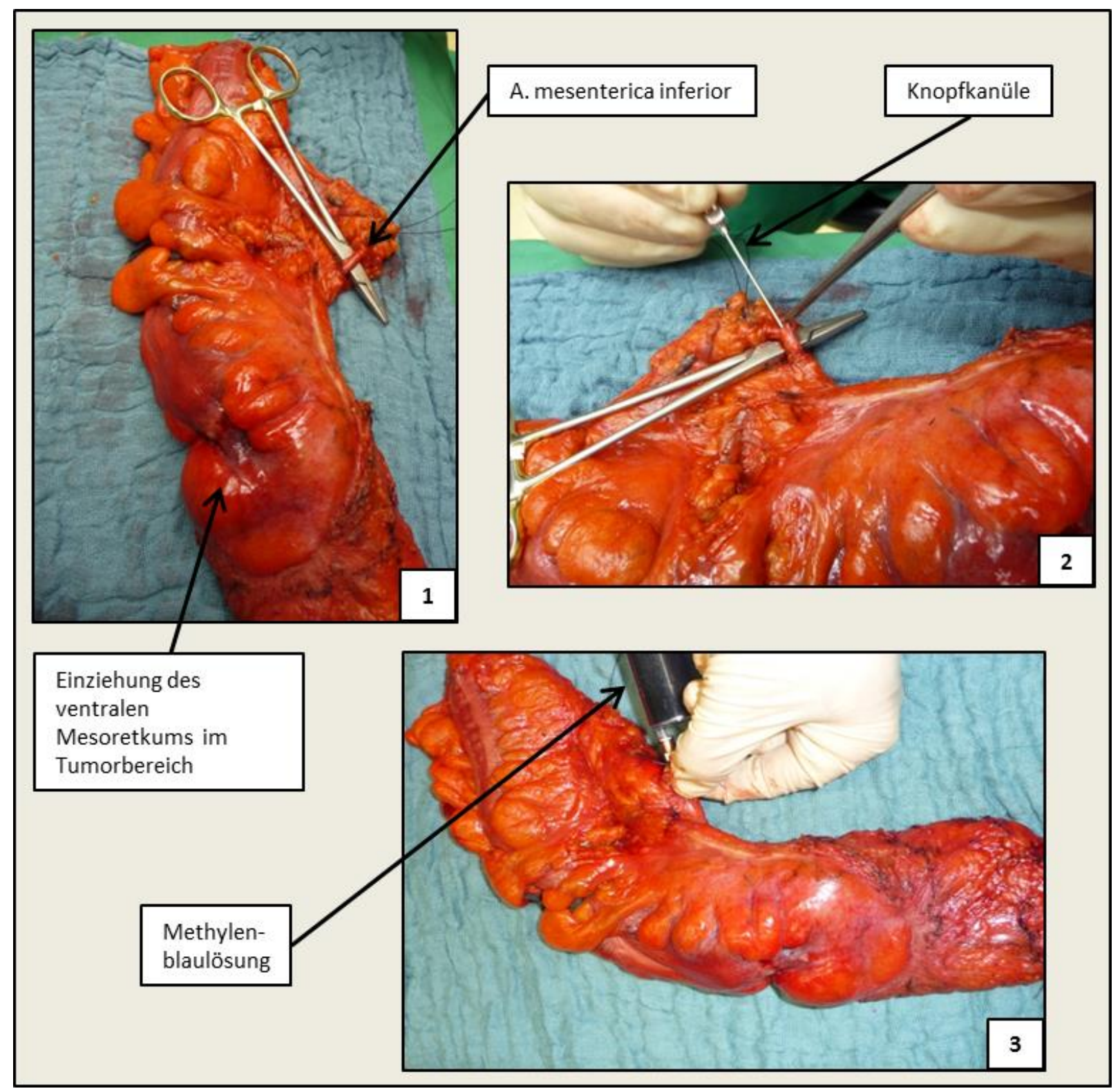

Abbildung 4: Ablauf der perioperativen Qualitätssicherung einer totalen mesorektalen Exzision mittels Methylenblaufärbung

1 - auffinden und freipräparieren der A. mesenterica inferior

2 - nach erfolgter Inzision der A. mesenterica inferior erfolgt die Kanülierung dieser (mittels einer Knopfkanüle)

3 - Fixierung der Knopfkanüle und anschließende Injektion der Methylenblaulösung (1 ml Methylenblau in $19 \mathrm{ml}$ Natriumchlorid-Lösung)

(Bilder freundlicherweise zur Verfügung gestellt von Dr. med. L. Conradi, Abteilung für Allgemein- und Viszeralchirurgie der UMG) 


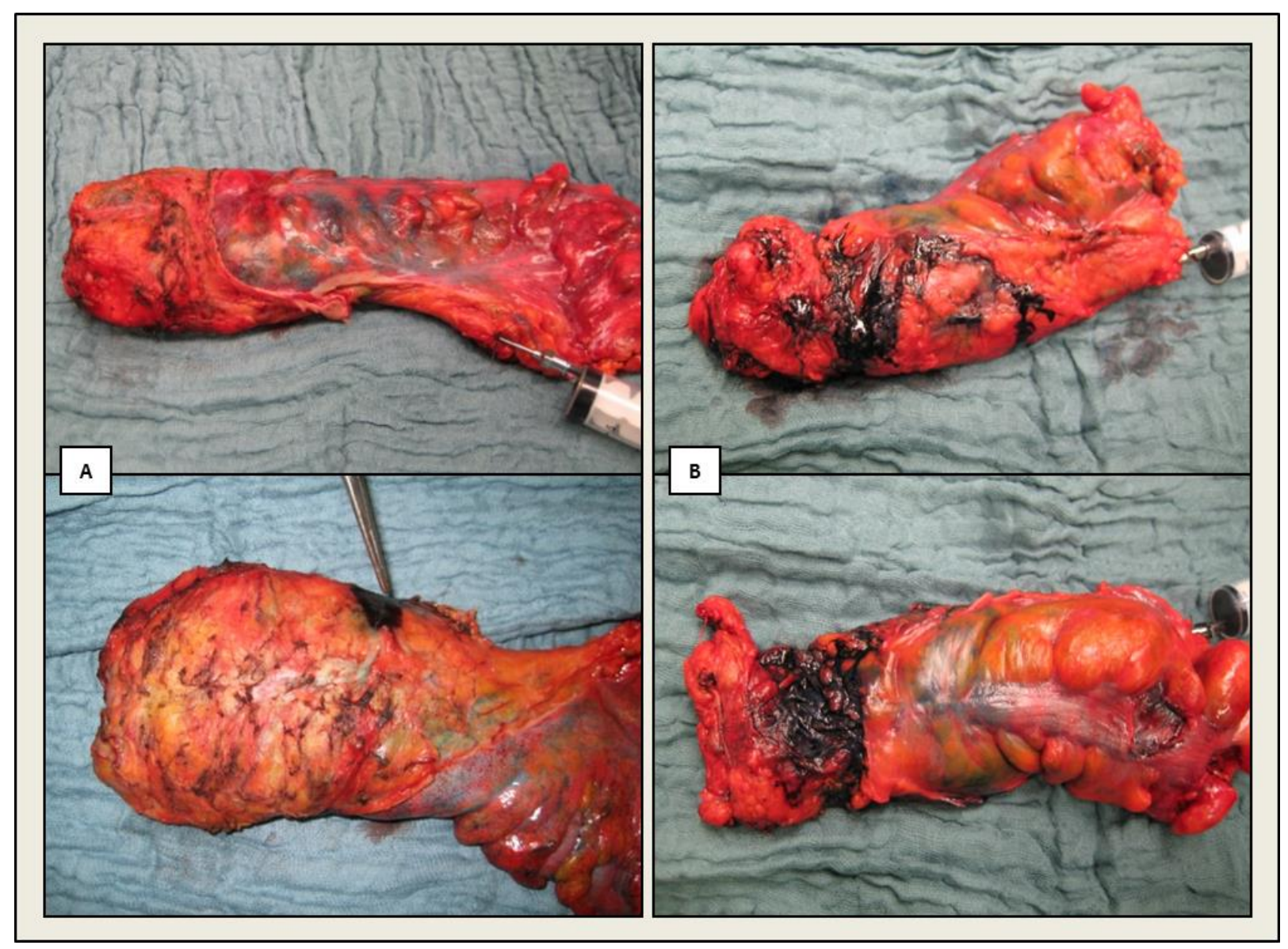

Abbildung 5: Übersicht über die Qualitätsgrade einer totalen mesorektalen Exzision

A - Klasse 1 - kein Farbstoffaustritt sichtbar, mesorektale Exzision erfolgte komplett, keine Verletzungen der mesorektalen Hüllfaszie

B - Klasse 3 - flächenhafter Farbstoffaustritt erkennbar, TME ist makroskopisch unvollständig und weist Defekte der mesorektalen Hüllfaszie auf

(Bilder freundlicherweise zur Verfügung gestellt von Dr. med. L. Conradi, Abteilung für Allgemein- und Viszeralchirurgie der UMG) 


\subsubsection{Postoperative Aufarbeitung und histopathologische Beurteilung des Resektats}

Unmittelbar nach Absetzen des Rektums und Kontrolle der mesorektalen Exzision mit Hilfe der Methylenblaufärbung wird das Resektat unversehrt und in nativem Zustand der Abteilung für Pathologie der UMG übergeben. Hier wird die histopathologische Aufarbeitung und anschließende Beurteilung des Karzinom-tragenden Gewebes durchgeführt.

Zuerst erfolgt eine makroskopische Begutachtung aller Hüllfaszien auf Intaktheit und Vollständigkeit, sowie eine Prüfung der kompletten mesorektalen Oberfläche, im Sinne einer weiteren Qualitätskontrolle. Eventuelle Defekte oder Tumorperforationen werden dokumentiert. Dabei wird die Qualität der TME nach den MERCURY-Kriterien ermittelt (M.E.R.K.U.R.Y. 2002). Hierbei werden 3 Qualitätsgrade unterschieden. Grad 1 (optimal) entspricht einer kompletten Resektion des Mesorektums mit intakter mesorektaler Hüllfaszie und nur geringgradigen Unebenheiten. Als Qualitätsgrad 2 (moderat) werden Resektate eingestuft, die mäßige Unregelmäßigkeiten an der Oberfläche aufweisen, jedoch die Muscularis propria des Rektums nicht sichtbar ist. Der Qualitätsgrad 3 (schlecht) umfasst Resektate mit größeren Defekten des Mesorektums, oder einer sichtbaren Muscularis propria. Dies geht meist mit einem massiven Methylenblauaustritt einher.

Zu Beginn der weiteren standardisierten Aufarbeitung wird das Resektat, sowie der Tumor ausgemessen und sein Abstand $\mathrm{zu}$ den Resektionsrändern (nach oral, aboral, zirkumferentiell) vermerkt. Es wird die Lage des Tumors in Bezug auf die peritoneale Umschlagsfalte dokumentiert. Das native Resektat wird ober- und unterhalb des tumortragenden Rektumabschnitts eröffnet. In diesem Zustand wird das Resektat aufgespannt und Formalin-fixiert (4\%, gepuffert, mind. 24 Stunden). Nach der Fixierung wird die mesorektale Oberfläche angefärbt und relevante Anteile des Tumor und des umgebenden Mesorektums in Paraffin eingebettet. Die Paraffineinbettung erfolgt nach Standard und automatisiert.

Die histopathologische Beurteilung nach aktuellen TNM/UICC-Richtlinien wird an Gewebeschnitten des in Paraffin eingelassenen Tumormaterials durchgeführt. Folgende Punkte werden begutachtet:

- Lokalisation des Tumors, Lokalisation zur peritonealen Umschlagsfalte (ober- oder unterhalb gelegen)

- Histologischer Tumortyp nach Klassifikation der World Health Organization (WHO)

- pT-Status - Tumorinvasionstiefe (T 1-4) 
- pN-Status - regionärer Lymphknotenstatus mit Angabe der Anzahl aller untersuchten LK und Anzahl der mit Tumorzellen befallenen LK (N 0-2)

- pM-Status - Existenz von Fernmetastasen (M 0/1)

- Grading - Differenzierungsgrad des Karzinomgewebes (G 0-4)

- R-Klassifikation - Beurteilung der Resektionsränder nach dem Vorhandensein von maligen Zellen mit Angabe des Abstands zwischen Tumor und Resektionsrand (R 0-2)

- CRM - zirkumferentieller Resektionsrand (CRM positiv/negativ)

- Blut-/Lymphgefäßinvasion (V 0/1; L 0/1)

- Beurteilung des TRG bei erfolgter neoadjuvanter RT/CTx (TRG 0-4)

Die Begutachtung des TRG erfolgt histopathologisch und erlaubt eine Einschätzung über das Ansprechen von Tumorgewebe auf eine präoperativ verabreichte RT/CTx und hat einen hohen prognostischen Stellenwert. Ein gutes Ansprechen auf eine neoadjuvante RCT spiegelt sich in einem hohen TRG wider. Der TRG wird in 5 Stufen (siehe Tabelle 4) klassifiziert (Dworak et al. 1997, Gavioli et al. 2000, Wittekind und Tannapfel 2003). In das Tumorregressionsgrading fließt unter anderen das enthaltene Tumorvolumen im Gewebe, sowie das Auffinden von Fibrosen, Nekrosen oder Granulationsgewebe ein (Dworak et al. 1997, Bruns et al. 2010).

\begin{tabular}{|c|l|}
\hline \multicolumn{2}{|c|}{ Tumorregressionsgrad nach Dworak } \\
\hline TRG 0 & $\begin{array}{l}\text { Keine Regression: keine Fibrosen im Präparat auffindbar } \\
\text { Minimale Regression: vitales Tumorgewebe dominiert, eindeutige Zeichen } \\
\text { radiogener fibrotischer Veränderungen/Vaskulopathie erkennbar (<25\% } \\
\text { der Tumormasse) } \\
\text { TRG 2 }\end{array}$ \\
TRG 3 & $\begin{array}{l}\text { Regression von 25-50\% der Tumormasse: Fibrosen überwiegen im Präparat, } \\
\text { leicht zu identifizierbare Tumorzellnester vorhanden } \\
\text { c >50\% der Tumormasse: dominante Fibrose im Präparat (>80\%), einzelne } \\
\text { schwer zu identifizierende Tumorzellen vorhanden } \\
\text { Komplette Regression: keine vitalen Tumorzellen nachweisbar, vollständige } \\
\text { TRG 4 }\end{array}$ \\
\hline
\end{tabular}

Tabelle 4: Klassifizierung des Tumorregressiongrades (TRG) nach neoadjuvanter Radio-/Chemotherapie

Der TRG wird histopathologisch im Rektumresektat bestimmt und dient einer frühzeitigen Abschätzung des Responses auf eine neoadjuvante RCT (Dworak et al. 1997, Gavioli et al. 2000). 


\subsection{Immunhistochemie und Anfertigung der Gewebeschnitte}

\subsubsection{Prinzip der immunhistochemischen Gewebeanfärbung}

Die immunhistochemische Anfärbung von Geweben beruht auf einer AntigenAntikörperbindung, welche mit Hilfe eines gekoppelten Detektionssystems dargestellt wird. Dabei wird die Affinität eines AK zu seinem Epitop genutzt.

Für die Untersuchungen der vorliegenden Arbeit wurde die Zwei-Schritt-Methode verwendet. Hierbei kommen zwei verschiedene AK zum Einsatz. Ein unkonjugierter Primärantikörper bindet direkt an das gesuchte Antigen im Gewebe. Der zweite AK trägt das Detektionssystem und ist als unspezifischer Sekundärantikörper gegen die AK-Art des Primärantikörpers gerichtet. Diese Methode bietet den Vorteil, dass mehrere Sekundärantikörper an einen Primärantikörper binden können und dadurch zu einer Verstärkung des Farbsignals und zu einer gesteigerten Sensitivität führen (siehe Abbildung 6, Seite 29).

Als Detektionssystem kommt in dieser Untersuchung ein an den Sekundärantikörper gekoppeltes Enzym zum Einsatz. Dieses Enzym wandelt ein zusätzlich zugegebenes Chromogen in einen Farbstoff um und markiert damit das Vorhandensein des gesuchten Antigens. Im Zuge unserer Versuchsreihen wurden zwei unterschiedliche Sekundärantikörper gegenübergestellt - Multimer-Ig_FastRed und Multimer-Ig_DAB. Diese verwendeten AK unterscheiden sich in ihrem gebundenen Enzym, woraus zwei verschiedenfarbige Färbeergebnisse resultieren.

Der AK Multimer-Ig_FastRed hat das Enzym Alkalische Phosphatase gekoppelt, woraus eine rote Anfärbung des gesuchten Antigens folgt. Dieses Enzym hydrolisiert Naphthol, welches als Substrat hinzugegeben wird zu Phenol und Phosphat. Es schließt sich eine zweite Reaktion an, in welcher sich das entstandene Phenol mit dem Chromogen Diazoniumsalz koppelt. Dieser Reaktion folgt ein roter, unlöslicher Azofarbstoff (siehe Abbildung 7Abbildung 7, Seite 29).

Der AK Multimer-Ig_DAB führt mit Hilfe des gekoppelten Enzyms Peroxidase zu einem braunen Färbeergebnis. Das Enzym oxidiert das hinzugefügte Chromogen mit Hilfe von Wasserstoffperoxid. Bei dem verwendeten Chromogen handelt es sich um Diaminobenzidin (DAB). Als Reaktionsprodukt bildet sich ein brauner, amorpher Farbstoff (siehe Abbildung 7, Seite 29). 


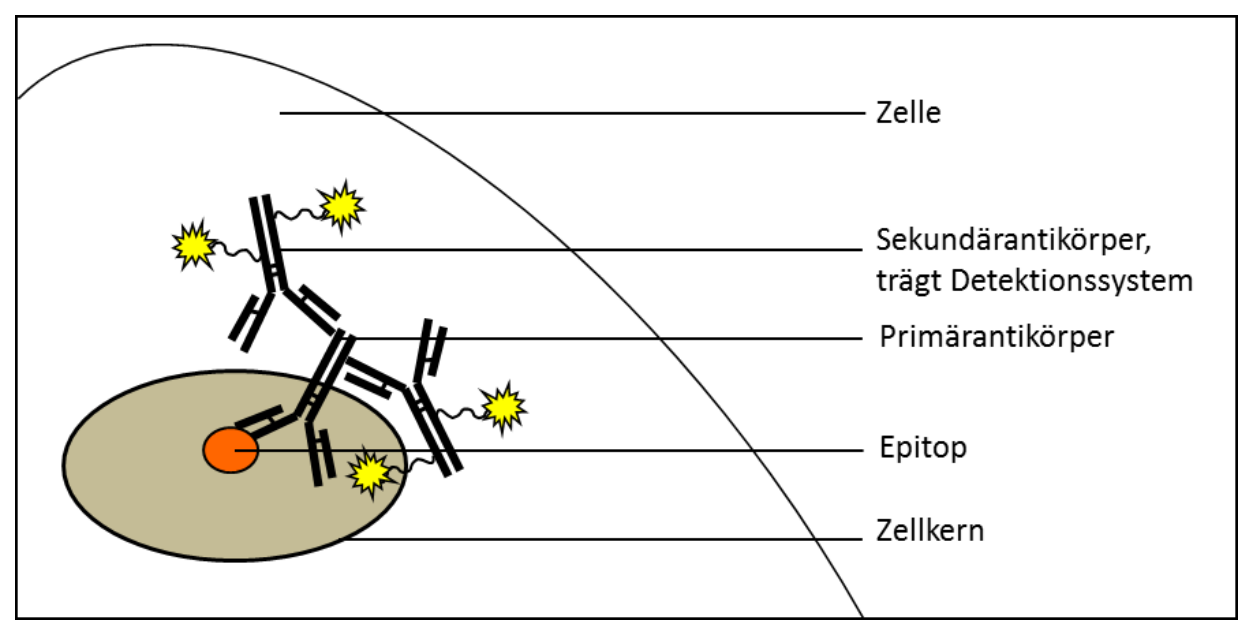

Abbildung 6: Darstellung der Zwei-Schritt-Methode

Über den unkonjugierten Primärantikörper binden mehrere Sekundärantikörper indirekt an das Epitop (in dieser Darstellung im Zellkern lokalisiert). Über ein Multimer sind mehrere Enzyme als Detektionssystem an den sekundären AK gekoppelt.
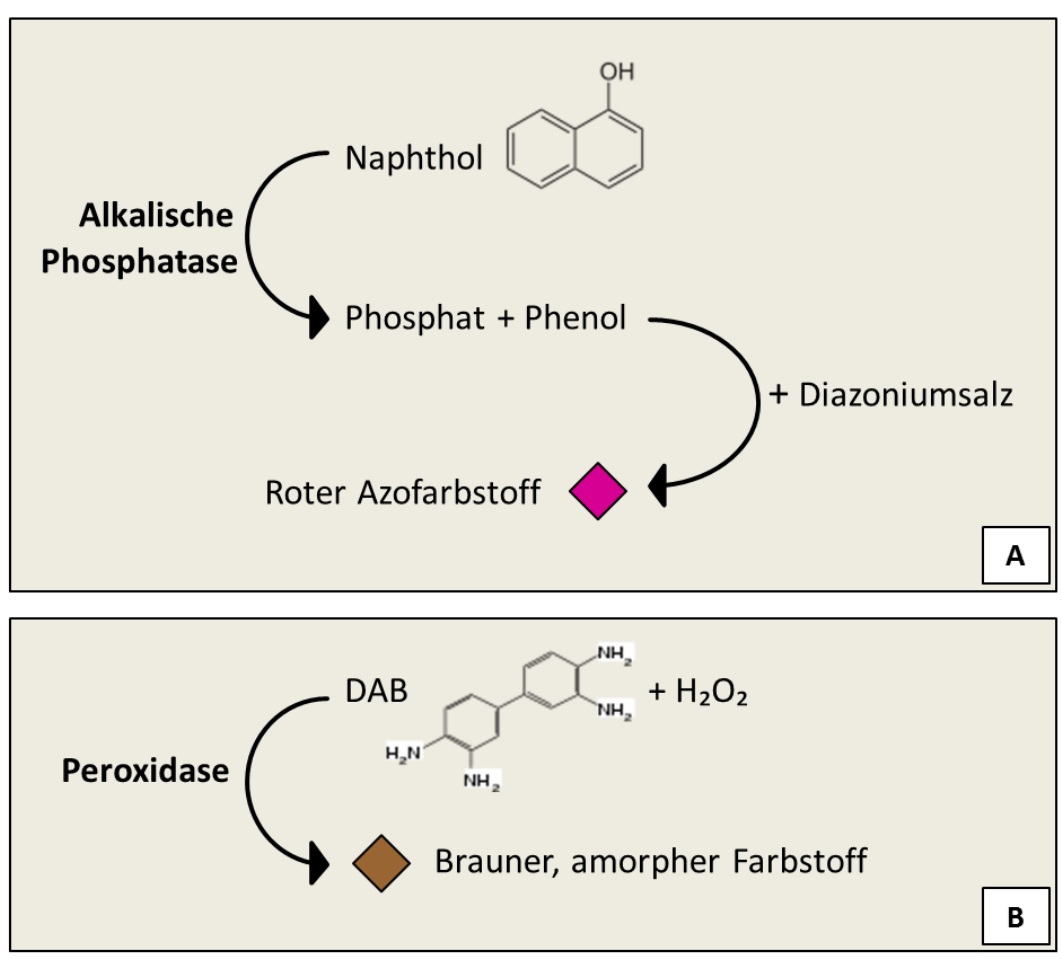

Abbildung 7: Chemische Reaktionen der verwendeten Enzyme A - Durch Hydrolyse von Naphthol mit Hilfe der alkalischen Phosphatase entsteht Phenol, welches mit dem Chromogen Diazoniumsalz gekoppelt einen roten Farbstoff bildet.

B - Die Peroxidase oxidiert DAB (Diaminobenzidin) mit Hilfe von Wasserstoffperoxid $\left(\mathrm{H}_{2} \mathrm{O}_{2}\right)$ zu einem braunen Farbstoff. 


\subsubsection{Schnittanfertigung}

Die Tumor-tragenden Paraffinblöcke, die im Rahmen der histopathologischen Begutachtung durch die Abteilung Pathologie der UMG angefertigt wurden, dienten als Untersuchungsmaterial. In diesen Blöcken ist Formalin-fixiertes (4\%ig, gepuffert, über 24 Stunden) und in Paraffin eingebettetes Tumormaterial enthalten. Zum einen entstammt das untersuchte Patientenmaterial aus einer prätherapeutischen Tumorbiopsie und zum anderem aus dem Rektumresektat.

Mittels eines Schlittenmikrotoms (siehe Tabelle 5, Seite 33) konnten aus den Paraffinblöcken etwa $2 \mu \mathrm{m}$ dicke Schnitte gefertigt werden, welche in einem Wasserbad auf adhäsive Objektträger aufgebracht wurden. Es schloss sich eine Trocknungsphase für rund 12 Stunden bei $37^{\circ} \mathrm{C}$ im Brutschrank an.

Danach konnten die Präparate standardisiert nach Färbeprotokoll gefärbt werden.

\subsubsection{Automatisierte Färbung}

Um die methodischen Unterschiede zwischen den einzelnen Präparaten so gering wie möglich zu halten und somit die Varianz zwischen den Präparaten zu senken, wurde der Färbeprozess mit Hilfe des Färbeautomats BenchMark XT von Ventana durchgeführt (siehe Tabelle 5, Seite 33). Der Einsatz maschineller Färbeautomaten kann, wie auch die Anwendung eines DIA eine Minimierung der Intra- und Interobservervariabilität bewirken. Der Prozess der immunhistochemischen Färbung wird stets standardisiert und mit gleichbleibend hoher Qualität durchgeführt. Bei manuellen Färbevorgängen können methodische Schwankungen zwischen einzelnen Präparaten auftreten, die eine konstante Analyse der immunhistochemischen Daten erschweren. Dadurch ist eine Vergleichbarkeit der Präparate untereinander nicht möglich.

Zuerst erfolgt die Antigenfreilegung, welche nach Gerätestandard durchgeführt wird. Dafür werden alle Präparate für 60 Minuten auf $100^{\circ} \mathrm{C}$ erhitzt. Hierbei kommt der Cell Conditioner von Ventana (siehe Tabelle 5, Seite 33) zum Einsatz.

Der AK Monoclonal Mouse Anti-Human-p53-Protein ist ein monoklonaler Mausantikörper, welcher in einer Verdünnung von 1:100 aufgetragen und für 32 Minuten bei $42^{\circ} \mathrm{C}$ inkubiert wird. Bei dem verwendeten AK Mouse Anti-Ki67 handelt es sich ebenfalls um einen 
monoklonalen Mausantikörper. Dieser wird in einer Verdünnung von 1:500 aufgetragen und anschließend für 32 Minuten bei $37^{\circ} \mathrm{C}$ inkubiert.

Um nach erfolgter Bindung des Primärantikörpers das gesuchte Antigen darzustellen, wird der Sekundärantikörper unter Verwendung eines Detektionskits aufgetragen. Für eine rote Färbung kam das ultraView Universal Alkaline Phosphatase Red Detection Kit zum Einsatz, für ein braunes Ergebnis das ultraView DAB Detection Kit (siehe Tabelle 5, Seite 33). Beide Kits enthalten Sekundärantikörper, die hochspezifisch gegen Maus- und Kaninchenantikörper sind und sind Biotin-frei. Nach Beendigung des Färbevorgangs werden alle Präparate gründlich gespült und mit Hilfe einer aufsteigenden Alkoholreihe und Xylol entwässert. Zuletzt werden die Objektträger mit einem Deckgläschen versehen.

\subsubsection{Probleme und Schwächen der quantitativen Immunhistochemie}

Bei der Immunhistochemie (IHC) handelt es sich um ein relativ kostengünstiges Verfahren, um Biomaterialien hinsichtlich ihrer Proteinausstattung zu untersuchen. Daraus resultiert ein breites Einsatzspektrum, sowohl in der klinischen Routinediagnostik, aber vor allem auch in der Forschung (Seidal et al. 2001). Einen besonders hohen Stellenwert findet die IHC in der spezifischen Tumordiagnostik und Tumorhistologie (Becker RL 1993). Jedoch erfolgte bis heute keine Standardisierung der Färbemethoden oder eine vereinheitlichte Festsetzung von Analysekriterien (Seidal et al. 2001). Erschwerend kommt hinzu, dass zu Beantwortung spezifischer Fragestellungen eine quantitative IHC unabdingbar ist (Becker RL 1993). So ist nicht die bloße Anwesenheit eines Antigens in einem Gewebe von Interesse, sondern vielmehr das Expressionslevel und Verteilungsmuster eines Proteins. Um dies beurteilen zu können, bedarf es ein hohes Maß an Genauigkeit, Präzision und Erfahrung (Taylor und Levenson 2006). Ein weiteres Problem stellt eine mögliche Voreingenommenheit, welche zu einer mangelnden Objektivität führt, dar (Becker RL 1993). So sind konventionell-manuelle Präparatanalysen sehr stark vom Betrachter abhängig und zudem schlecht reproduzierbar (Seidal et al. 2001). Methodische Unterschiede im Färbeprozess tragen ebenfalls wesentlich zu einer schwierigen Vergleichbarkeit verschiedener immunhistocheimscher Analysen bei. Annähernd jeder Faktor oder Parameter, welcher Einsatz in der Präparatanfertigung oder im Färbevorgang findet, nimmt Einfluss auf die Qualität des Färbeergebnisses (Grube 2004). So kann es bereits während der Gewebefixierung zu Veränderungen von Gewebeeigenschaften 
kommen, was anschließend zu Diskrepanzen im Ergebnis führt (Grube 2004). Besonders anfällig für diese Art von Beeinflussung sind manuelle Färbevorgänge. Hier können kleine Ungenauigkeiten bei der Fertigung der Präparate zu bedeutsamen Unterschieden in der Analyse und Interpretation von Gewebefärbungen führen. Aus diesen verschieden Problematiken ergibt sich die Tatsache, dass die meisten Diskrepanzen zwischen pathologischen Befunden auf Unterschieden in der Interpretation von Färbeergebnissen, sowie auf methodischen Unterschieden basieren (Seidal et al. 2001).

Resultierend aus diesen kritischen Umständen weisen immunhistochemische Analysen eine hohe Inter- und Intraobservervariabilität auf (Slodkowksa und Rojo 2011).

Eine Möglichkeit, diese Inter- und Intraobservervariabilität zu reduzieren, würde eine mehrmalige Befundung jedes Präparates von verschiedenen Pathologen darstellen. Jede erneute Begutachtung würde die Präzision erhöhen (Becker RL 1993). Jedoch ist dieses Vorgehen sehr teuer, zeitaufwendig und für den klinischen Alltag kaum praktikabel. Ein alternativer Lösungsvorschlag stellt den Einsatz von DIA dar. Diese stellen eine standardisierte Messung immunhistochemischer Daten anhand festgesetzter Analysekriterien sicher. Dadurch wird zuverlässig eine konstant hohe Präzision und Objektivität gewährleistet. Darüber hinaus ermöglichen diese Systeme eine gute Reproduzierbarkeit der immunhistochemischen Daten und unterstützen somit eine sicherere Diagnosestellung. Aus diesen Gründen wurde in dieser Arbeit der Einsatz des DIA VIAS evaluiert. 


\subsection{Verwendete Materialien}

Die folgende Tabelle führt alle verwendeten Materialen und Lösungen auf und beinhaltet die Angabe der Hersteller.

\begin{tabular}{|c|c|}
\hline Verwendete Materialien & Hersteller, Firma, etc. \\
\hline Adhäsive Objektträger Starfrost & $\begin{array}{l}\text { Engelbrecht Medizin\& Labortechnik GmbH, } \\
\text { Edermünde, Deutschland }\end{array}$ \\
\hline Ethanol $99 \%$ & Chemie Vertrieb, Hannover, Deutschland \\
\hline Deckgläser & $\begin{array}{l}\text { Gerhard Menzel GmbH, Braunschweig, } \\
\text { Deutschland }\end{array}$ \\
\hline Färbeautomat BenchMark XT & Ventana Medical Systems, Tucson, Arizona, USA \\
\hline Mikroskop Axio Imager II & Carl Zeiss Microlmaging GmbH, Deutschland \\
\hline Mikrotomklingen & pfm, Köln, Deutschland \\
\hline $\begin{array}{l}\text { Monoclonal Mouse Anti-Human } \\
\text { p53 Protein, Code-Nr. M } 7001\end{array}$ & Dako Cytomation, Glostrup, Dänemark \\
\hline $\begin{array}{l}\text { Monoclonal Mouse Anti -Human Ki-67, } \\
\text { Code-Nr. MSK018 }\end{array}$ & ZYTOMED Systems, Berlin, Deutschland \\
\hline Schlittenmikrotom Microm HM 430 & MICROM International, Walldorf, Deutschland \\
\hline $\begin{array}{l}\text { Substanzen für den Färbeautomat } \\
\begin{aligned} \text { BenchMark XT: } \\
-\quad \text { EZ Prep } \\
-\quad \text { LCS } \\
-\quad \text { Reaktion Buffer } \\
-\quad \text { CC1 (Cell Conditioner) } \\
-\quad \text { Antibody Diluent } \\
-\quad \text { Hämatoxylin II } \\
-\quad \text { Bluing Reagent }\end{aligned}\end{array}$ & Ventana Medical Systems, Tucson, Arizona, USA \\
\hline Wärmeschrank & Memmert GmbH, Schwabach, Deutschland \\
\hline $\begin{array}{l}\text { ultraView Universal Alkaline Phosphata } \\
\begin{array}{l}\text { Detection Kit, enthält: } \\
-\quad \text { Enhancer } \\
-\quad \text { Multimer Ig } \\
-\quad \text { Naphthol } \\
-\quad \text { Fast Red A / B }\end{array}\end{array}$ & $\begin{array}{l}\text { Ventana Medical Systems, Mannheim, } \\
\text { Deutschland }\end{array}$ \\
\hline $\begin{array}{l}\text { ultraView Universal DAB Detection Kit, } \\
-\quad \text { Inhibitor } \\
-\quad \text { Multimer Ig } \\
-\quad \text { DAB } \\
-\quad \mathrm{H}_{2} \mathrm{O}_{2} \\
-\quad \text { Copper }\end{array}$ & $\begin{array}{l}\text { Ventana Medical Systems, Mannheim, } \\
\text { Deutschland }\end{array}$ \\
\hline Ventana Image Analysis System (VIAS) & Ventana Medical Systems, Tucson, Arizona, USA \\
\hline Vitro Clud - Eindeckmittel & $\begin{array}{l}\text { R. Langenbrinck - Labor- und Medizintechnik, } \\
\text { Emmendingen, Deutschland }\end{array}$ \\
\hline Xylol & Mallinckrodt Baker B.V., Deventer, Niederlande \\
\hline
\end{tabular}

Tabelle 5: Auflistung aller verwendeter Materialien und Substanzen, inkl. Angabe des Herstellers 


\subsection{Die Zielantigene}

\subsection{1 p53}

Bei p53 handelt es sich um ein Phosphorprotein, welches in einem sehr niedrigen Level in den verschiedensten Zelltypen nachweisbar ist (Vogelstein und Kinzler 1992). Der Name dieses intrazellulären Proteins leitet sich von seiner Größe ab - 53 Kilodalton (kDa). Die höchste Konzentration des p53-Proteins findet sich im Zellkern. Diese nukleäre Lokalisation steht in enger Verbindung mit seiner Funktion. Das intrazelluläre p53-Protein spielt eine große Rolle bei der Zellzykluskontrolle (Vogelstein und Kinzler 1992) und ist als Tumorsuppressor in der Lage die Expression von proapoptotischen und DNAReparaturgenen zu erhöhen. Heute gilt p53 als essentiell für die Tumorsuppression. Hierbei fungiert das Phosphorprotein als Transkriptionsfaktor (Lane 1992) und steigert durch Sequenz-spezifische DNA-Bindung die Transkription verschiedener Zellproteine.

p53 selbst wird von dem TP53-Gen, welches auf dem kurzen Arm des Chromosoms 17 lokalisiert ist, codiert und in allen teilungsaktiven Zellen kontinuierlich neu synthetisiert. Unmittelbar nach der Transkription induziert die Ligase murine double minute 2 (MDM2) einen Ubiquitin-abhängigen Abbau von p53 im Proteasom der Zelle. Durch diesen Vorgang wird ein konstant niedriger Zellspiegel gesichert. Mittels eines Feedback-Mechanismus steigert p53 selbst die Transkription von MDM2 (Brown et al. 2009). Kommt es zu Zellstress und DNA-Schäden, zum Beispiel durch gentoxische Substanzen, wird das neu translatierte p53-Protein durch verschiedene Kinasen phosphoryliert. Infolgedessen entgeht das Protein seinem Abbau im Proteasom der Zelle und die intrazelluläre Konzentration steigt an. p53 kann nun intranukleär als Transkriptionsfaktor fungieren und die Expression verschiedener Gene stimulieren. $\mathrm{Zu}$ einem Arrest des Zellzyklus kommt es durch eine gesteigerte Expression von p21, welches die Cyclin-abhängige Kinase 4 (CDK) und CDK6 inhibiert. Die Apoptose kann durch die gesteigerte Transkription von Proteinen der Genfamilie Bcl-2 induziert werden.

p53 stellt den am häufigsten mutierten Tumorsuppressor in humanen Karzinomen dar (Kerns et al. 1992, Berns 2010). Eine Mutation in der Signalkaskade von p53 oder im Protein selbst kann zu einer Funktionseinschränkung oder gar zu dessen Funktionsverlust führen. Somit entfällt eine wichtige Kontrolle über den Zellzyklus und über das Zellwachstums. Die Zelle entwickelt ein neoplastisches Potential. In verschiedenen malignen Tumoren des 
Menschen konnte ein häufiges Vorliegen einer solchen Mutation nachgewiesen werden, zum Beispiel im nicht-kleinzelligen Bronchialkarzinom (Horio et al. 1993) oder bei Brustkrebs (Barbareschi et al. 1996, Jung et al. 2011). Auch bei der Entstehung von malignen Tumoren im Bereich des Dickdarms spielt ein Funktionsverlust von p53 laut der Adenom-KarzinomSequenz nach Vogelstein eine entscheidende Rolle (Fearon und Vogelstein 1990; siehe Kapitel 1.2, Seite 3). Außerdem ist bekannt, dass ein kongenitaler Defekt des TP53-Gens (LiFraumeni-Syndrom) mit einem sehr frühen Auftreten maligner Neoplasien verschiedener Gewebe vergesellschaftet ist. Betroffene Patienten weisen auch eine stark erhöhte Inzidenz gegenüber Tumoren des Gastrointestinaltrakts auf.

\subsubsection{Ki67}

Das Ki67-Protein ist ein intrazelluläres Protein, welches in allen proliferationsfähigen Geweben nachweisbar ist (Gerdes et al. 1983). Der Name dieses Proteins leitet sich von der Stadt $a b$, in welcher erstmalig ein AK gegen dieses bis dato unbekannte Protein entwickelt wurde - Kiel (Gerdes et al. 1983). Das Protein Ki67 gilt gemeinhin als Proliferationsmarker, da es in jeder Phase des Zellzyklus mit Ausnahme der G0-Phase exprimiert wird (Gerdes et al. 1984, Scholzen und Gerdes 2000). Ki67 lässt sich nicht in ruhenden oder ausdifferenzierten Zellen nachweisen, was dieses Protein zu einem exzellenten Marker für die Wachstumsfraktion eines Gewebes macht (Gerdes et al. 1983, Gerdes et al. 1984, Alison 1995, Scholzen und Gerdes 2000). Die Wachstumsfraktion stellt den Anteil der Zellen dar, welcher zur Proliferation befähigt ist (Alison 1995). Dabei kann keine Aussage über die Geschwindigkeit der Zellteilung oder deren Rate getroffen werden, lediglich der Zustand, dass sich die Zellen in einer Teilungsphase befinden, wird belegt (Scholzen und Gerdes 2000). Heute gilt es als erwiesen, dass der Einsatz eines Ki67-Antikörpers im Rahmen einer immunhistochemischen Untersuchung zur Abschätzung der Wachstumsfraktion in jedem humanem Gewebe herangezogen werden kann (Scholzen und Gerdes 2000). Genaue Erkenntnisse für die Bedeutung des Zellzyklus und über die exakte Funktionsweise des Ki67Proteins liegen noch nicht vor. Aber es gilt als unumstritten, dass dieses Protein sehr eng mit Zellproliferation verknüpft ist, selbst aber einer genauen Steuerung seiner eigenen Expression unterliegt (Scholzen und Gerdes 2000). Ein Problem bei der Untersuchung des Ki67-Proteins stellt seine einzigartige Struktur dar. Es konnte bislang kein anderes Zellprotein 
identifiziert werden, welches diesem ähnelt (Scholzen und Gerdes 2000). Die höchste Konzentration des Ki67-Proteins lässt sich im Zellkern nachweisen.

In verschiedenen malignen Neoplasien konnte sich das immunhistochemische Färbeverhalten des Ki67-Proteins als prognostischer Faktor etablieren. Unter anderem gilt das Ki67-Expressionslevel bei Mammakarzinomen (Seshadri et al. 1996, Rudolph et al. 1999), sowie bei bösartigen Tumoren der Prostata (Stattin et al. 1997, Borre et al. 1998) als unabhängiger Prognosefaktor. Der prognostische Nutzen beim KRK ist in der Literatur widersprüchlich belegt (siehe Tabelle 12, Seite 78).

\subsection{Immunhistochemische Analyse}

\subsubsection{Analyse der immunhistochemischen Färbung}

Die durchgeführten Färbungen stellen nukleäre Färbungen dar, daher wurde nur die Anfärbung der Zellkerne bei der Auswertung der IHC berücksichtigt. Mögliche Färbung von gesundem Gewebe oder unspezifische Hintergrundanfärbungen wurden vernachlässigt. Auch eine mögliche Anfärbung des Zytoplasmas wurde nicht mit in die Analysen einbezogen, da die Hauptlokalisation und der Wirkungsort von p53 und Ki67 intranukleär lokalisiert liegen.

Jedes Präparat wurde mittels zweier Auswertesysteme analysiert. Bei der konventionellmanuellen Auswertung der Färbeergebnisse wurde jedes Präparat hinsichtlich seines positiven Tumoranteils und seiner Färbeintensität beurteilt. Der positive Tumoranteil beschreibt den Prozentsatz der Tumorzellen, welche eine positive Anfärbung ihres Zellkerns aufweisen, bezogen auf den Gesamttumor. Die Färbeintensität stellt eine Beurteilung der Signalstärke der Zellkernfärbung dar. Jedes Präparat wurde hinsichtlich seiner Färbeintensität in vier Grade eingeteilt werden. Die Färbeintensität 0 entspricht keiner sichtbaren Anfärbung der Zellkerne innerhalb des Tumorgewebes. Die höchste Färbeintensität Grad 3 klassifiziert eine sehr intensive Anfärbung der Zellkerne (siehe Abbildung 8, Seite 37). Hat ein Präparat eine starke Heterogenität hinsichtlich der Färbeintensität aufgewiesen, so wurde die höchste messbare Intensität notiert. Gab es uneinheitlich angefärbte Tumoranteile, so wurde die überwiegend vorliegende Färbeintensität vermerkt. 
Nach der konventionell-manuellen Auswertung wurden alle Präparate erneut mit dem DIA VIAS analysiert. Hierbei wurden ebenfalls der prozentuale Anteil der positiven Tumorzellen und eine Einschätzung der vorliegenden Intensität der Kernfärbung dokumentiert (siehe Kapitel 2.6.3, Seite 38).

Für alle prätherapeutisch entnommenen Probenentnahmen wurde eine Mindestzellzahl von 50 auswertbaren Tumorzellen festgelegt. Für die Objekte der Tumorresektate lag eine Mindestzellzahl von 100 gut erkennbaren Tumorzellen zugrunde. Konnte diese Zellzahl nicht erreicht werden, wurde das Präparat bei der statistischen Auswertung nicht berücksichtig.

Die Auswertung der immunhistochemischen Parameter erfolgte stets verblindet und ohne Kenntnis der klinischen oder pathologischen Patientendaten.

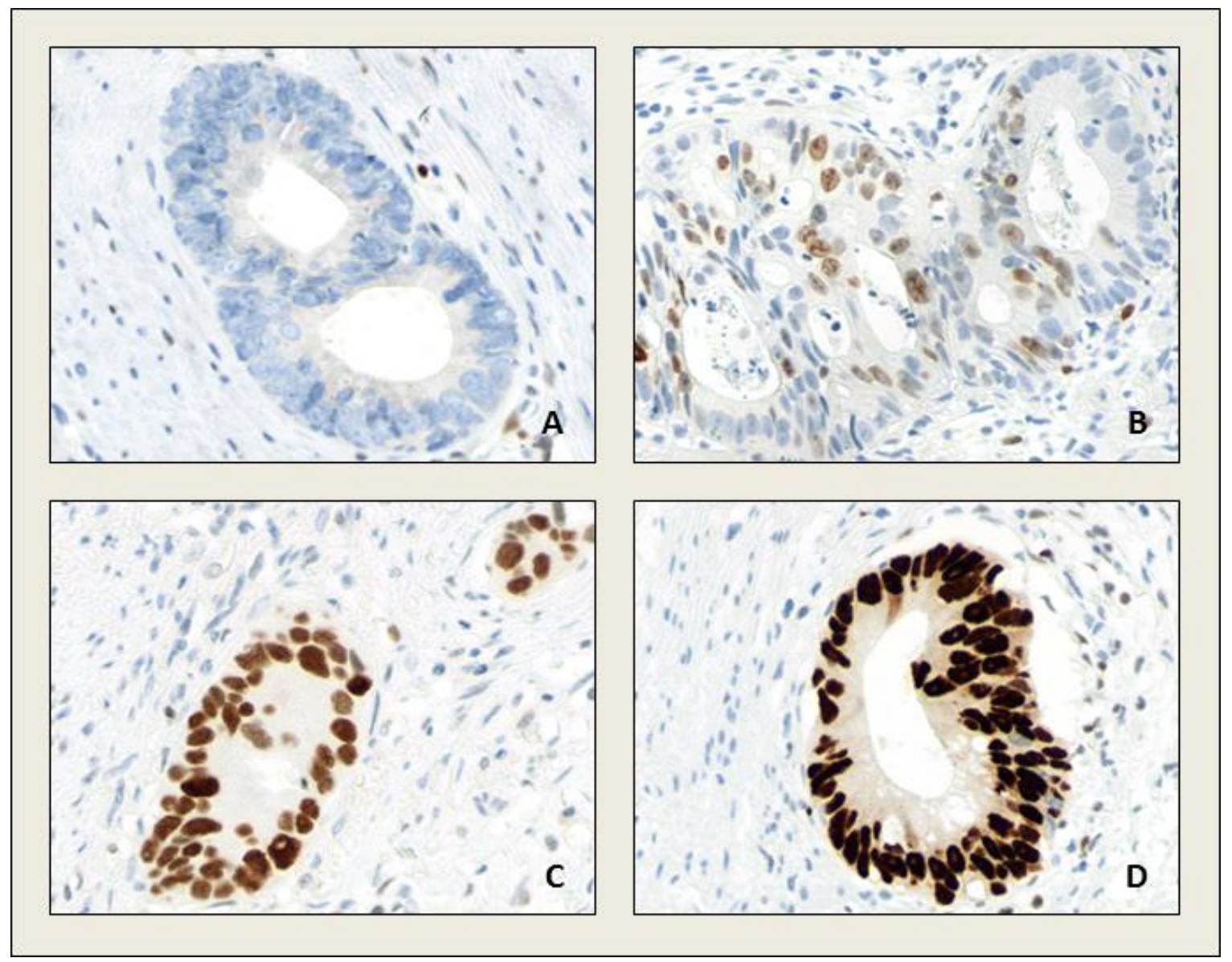

Abbildung 8: Färbeintensitäten am Beispiel p53-angefärbter Adenokarzinome des Rektums A - keine sichtbare Anfärbung der Zellkerne im Tumorzellverband B - schwache Anfärbung (einige Zellkerne lassen eine schwache Braunfärbung erkennen) C - moderate Anfärbung (Zellkerne zeigen eine gut sichtbare Braunfärbung) D - intensive Anfärbung (sehr starke Braunfärbung der Zellkerne)

Die abgebildeten Präparate entstammen Rektumresektaten und sind mittels DAB angefärbt. 


\subsubsection{Konventionell-manuelle Auswertung der immunhistochemischen Färbung}

Die Auswertung jedes einzelnen Präparats erfolgte nach einem festgelegten Ablauf und ohne Kenntnis der Patientenidentität oder der klinischen Daten. Alle Präparate wurden hinsichtlich ihres positiven Tumoranteils und der Intensität der Anfärbung untersucht (siehe Kapitel 2.6.1, Seite 36).

Zu Beginn wurde jedes Präparat bei 2,5-facher Vergrößerung durchgemustert, um die vollständige Tumorausdehnung zu erfassen, alle vorhandene Tumoranteile zu registrieren und die Qualität des Färbeergebnisses zu überprüfen. Es schloss sich eine Musterung des Gewebes mit 10-facher Vergrößerung an, um auch kleinere Tumorzellverbände zu identifizieren. Bei 40-facher Objektivvergrößerung wurden verschiedene repräsentative Gewebestellen zur immunhistochemischen Analyse aufgesucht. Um den prozentualpositiven Tumoranteil zu ermitteln wurden in mindestens 5 Tumorbereichen mehr als 100 Adenokarzinomzellen ausgezählt. Dabei wurde beachtet, dass diese Zellen klar voneinander abgrenzbar und die Zellkerne im Ganzen ohne Überlappungen sichtbar sind. Die Färbeintensität wurde ebenfalls bei 40 -facher Vergrößerung registriert. Hierfür wurde die Intensität der Zellkernfärbung anhand definierter Beispielbilder in 4 Grade eingeteilt (siehe Abbildung 8, Seite 37).

Stichprobenartig wurden in regelmäßigen Abständen Objektträger von einem zweiten unabhängigen Beobachter ausgewertet. Von jedem Präparat wurden digitale Fotografien der ausgewerteten Tumorregionen angefertigt.

Alle gewonnenen Daten wurden sorgfältig dokumentiert.

\subsubsection{Auswertung der immunhistochemischen Färbung mit Hilfe des digitalen}

\section{Bildanalysesystems VIAS}

Die immunhistochemische Analyse aller Präparate mit Hilfe des DIA fand im Anschluss an die konventionell-manuelle Auswertung statt. Die Erfassung der immunhistochemischen Daten erfolgte verblindet und ohne Kenntnis der klinikopathologischen Daten.

VIAS stellt ein DIA dar und setzt sich aus einem Mikroskop mit einer angeschlossen digitalen Farbkamera, einem Computer und einer Bildanalysesoftware zusammen. Mit Hilfe der digitalen Farbkamera wird der Objektträger eingelesen und mittels der Software digitalisiert wiedergegeben. Eine genaue Betrachtung des Gewebes ist bei 20-facher 
Objektivvergrößerung möglich. Der Betrachter wählt die repräsentativen Tumorbereiche aus, die in die immunhistochemische Analyse einbezogen werden sollen. Innerhalb der ausgewählten Tumorbereiche kommt es, anhand ihrer Zellmorphologie, zu einer automatischen Erfassung der Karzinomzellen. Die erfassten Tumorzellen werden im Bildausschnitt markiert (siehe Abbildung 9Abbildung 9, Seite 40). Dem Observer unterliegt es, diese Auswahl zu überprüfen und gegebenenfalls manuell zu korrigieren (siehe Abbildung 9, Seite 40). Die korrekte Auswahl der Tumorbereiche liegt also in jedem Falle in der Verantwortung des Betrachters. Es können beliebig viele Tumorregionen in die immunhistochemische Analyse einbezogen werden.

Anhand des heterogenen Färbeverhaltens zwischen Zellkernen, die eine Antigenexprimierung aufweisen, und dem umliegenden Gewebe erfolgt eine automatische Erfassung der immunhistochemischen Daten. Positive Zellkerne sind mit DAB markiert und weisen eine braune Farbgebung auf. Die Gegenfärbung aller Zellkerne erfolgt während des automatisierten Färbeprozesses mit Hämatoxylin und führt zu einem blauen Erscheinungsbild der nicht Antigen-tragenden Zellkerne.

Die Bildanalysesoftware zählt alle Zellkerne der ausgewählten Tumorregionen. Weiterhin wird der positive Tumoranteil erfasst und als Prozentwert (0-100\%) wiedergegeben. Die Färbeintensität wird als ein Scorewert analysiert. Dieser setzt sich aus den Färbeintensitäten aller registrierten Zellkerne zusammen, ähnlich dem bekannten Remmele-Score. Der Remmele-Score errechnet sich aus der Färbeintensität und dem Prozentsatz der positiven Zellen (Remmele und Stegner 1987).

Zu Beginn der Analyse wurden alle Präparate mit kleinster Mikroskopvergrößerung überblickt, um das komplette Karzinomgewebe einzusehen. Bei 20-facher Vergrößerung wurden anschließend mindesten fünf verschiedene repräsentative Tumorregionen ausgewählt. Es wurde darauf geachtet, dass in jedem Präparat mindestens 500 Karzinomzellen (wenn im Tumorschnitt vorhanden) registriert wurden.

Alle gewonnenen Daten wurden sorgfältig dokumentiert. 

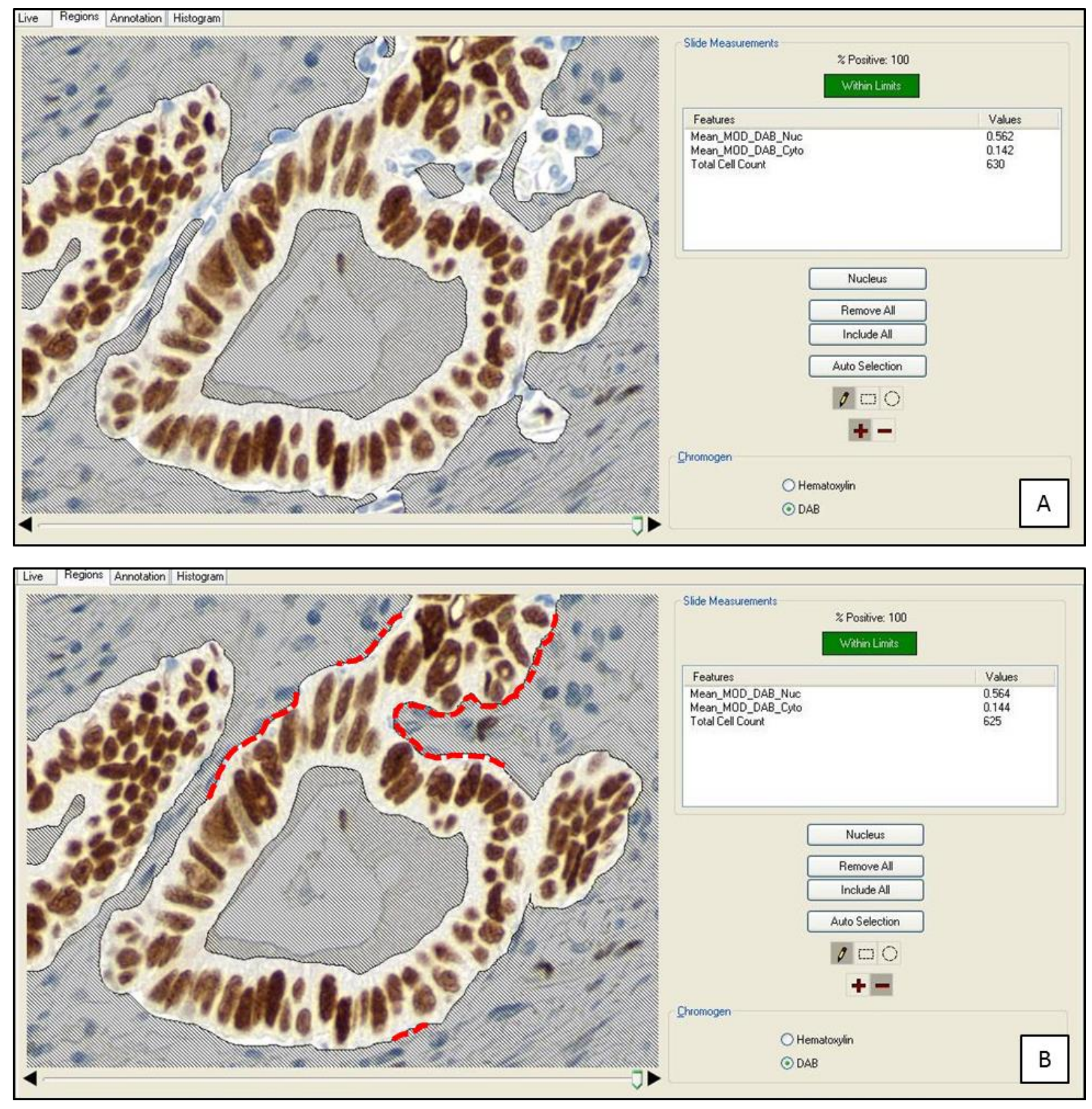

Abbildung 9: Benutzeroberfläche des digitalen Bildanalysesystems VIAS

A - automatisch erfasste Auswahl der Karzinomzellen

B - manuell korrigierte Auswahl des Tumorbereiches; markiert mit einer roten Linie

Das gezeigte Präparat enststammt einem Rektumresektat und ist mit DAB gefärbt, 20-fache Vergrößerung. 


\subsection{Statistische Analyse}

Die statistischen Analysen wurden in Kooperation mit Univ.-Prof. Dr. Tim Beißbarth, Abteilung für Medizinische Statistik UMG (Leiter Univ.-Prof. Dr. Tim Friede) durchgeführt. Bei den statistischen Berechnungen sowie bei der Erstellung der Graphiken fand das Statistikprogramm $R$ Anwendung (URL http://www.r-project.org, Version 2.14.2).

Um die Häufigkeitsunterschiede zwischen den klinikopathologischen Parametern innerhalb der Behandlungsgruppen zu vergleichen, wurde der Chi-Quadrat-Test eingesetzt.

Für die Erhebung einer Varianzanalyse zwischen den immunhistochemischen Daten und den klinikopathologischen Parametern der Patienten wurde der Kruskal-Wallis-Test herangezogen. Hierbei handelt es sich um einen nichtparametrischen Test, der bei unabhängigen Stichproben Anwendung findet (Trampisch et al. 1997). Um die erhobenen Daten der IHC mit den klinikopathologischen Patientendaten zu korrelieren, wurde der Rangkorrelationskoeffizient Kendall's Tau berechnet. Diese Korrelationsanalyse erlaubt eine Überprüfung des statistischen Zusammenhangs zweier Merkmale.

Die Überlebensdaten in Abhängigkeit einer Überexpression der Biomarker p53 bzw. Ki67 wurden mittels Kaplan-Meier-Kurven dargestellt. Der p53-Überexpression liegt dabei ein Cut-off-Level von $\geq 10 \%$ positivem Tumoranteil (orientierend an der aktuellen Literatur) und der Ki67-Überexpression ein Cut-Off-Level $\geq 25 \%$ positivem Tumoranteil zu Grunde. Um den gesamten Verlauf der Überlebenskurven vergleichen zu können, wurde der Logrank-Test eingesetzt (Hilgers et al. 2007). Dieser stellt einen nichtparametrischen Test dar und kann bei zwei oder mehr unverbundenen Stichproben eingesetzt werden. Der statistische Zusammenhang zwischen der Biomarkerexpression und dem DFS, bzw. dem CSS wurden mittels des Cox-Regression-Models bestimmt.

Allen statistischen Berechnungen liegt ein 5\%-Signifikanzniveau zu Grunde. 


\section{Ergebnisse}

\subsection{Ergebnisse der multimodalen Therapie}

Die Daten der immunhistochemischen Analyse wurden verblindet erhoben und anschließend mit den klinikopathologischen Parametern der Patienten verglichen. Im Folgenden sind die Ergebnisse der statistischen Analyse vorgestellt und für jede Behandlungsgruppe separat aufgelistet. Die Erhebung der Follow-up-Daten der Patienten erfolgte im Rahmen der strukturierten Tumornachsorge zunächst halbjährlich und nach Ablauf von zwei Jahren jährlich. Diese umfasst die Dokumentation des Auftretens eines LR, das Auffinden von Fernmetastasen und die Erfassung tumorbedingter Todesfälle. Der Nachbeobachtungszeitraum zum Ende der vorliegenden Studie umfasst einen Median von 49 Monaten.

\subsubsection{Operationsverfahren}

Die Resektion des Rektums zielte bei allen Patienten, die in diese Untersuchung einbezogen wurden, auf eine vollständige Kuration ab. Dabei wurde stets eine R0-Resektion angestrebt, auch wenn bei organüberschreitendem Tumorwachstum ein multiviszerales Vorgehen erforderlich wurde. Die Operation erfolgte bei 43 Patienten (19,1\% des Patientenkollektivs) primär. Die restlichen 182 (80,9\% des Patientenkollektivs, N=225) Patienten erhielten die Rektumresektion nach neoadjuvanter Therapie mit Bestrahlung des kleinen Beckens und begleitender CTx.

Die Operationstechniken, die am häufigsten zum Einsatz kamen, stellen die tiefe anteriore Rektumresektion und die abdominoperineale Rektumexstirpation (APE) dar. Die APE ist bei tiefsitzenden Tumoren des unteren Rektumdrittels notwendig, bei denen es aus onkologischer Sicht nicht möglich ist, einen $2 \mathrm{~cm}$ großen Sicherheitsabstand zum aboralen Tumorrand zu gewährleisten und gleichzeitig eine Sphinktererhaltung durchzuführen. Insgesamt wurde bei 61 Patienten (27,1\% des Patientenkollektives) eine APE durchgeführt (siehe Tabelle 6, Seite 43). In der primär operierten Behandlungsgruppe musste bei $61,5 \%$ $(n=8)$ aller Patienten, die eine Tumorlokalisation im unteren Rektumdrittel aufwiesen eine APE durchgeführt werden. In der Behandlungsgruppe, welche eine 5-FU-Monotherapie und RT als präoperative Behandlung erhielt, wurden $89,7 \%(n=35)$ der Patienten mit einem 
tiefsitzendem Rektumkarzinom einer APE zugeführt. Dem gegenüber konnten in der Kohorte, die eine intensivierte neoadjuvante RCT mit 5-FU und Oxaliplatin erhalten haben, die Hälfte aller Patienten $(51,4 \%, n=18)$ trotz eines tiefsitzenden Rektumkarzinoms Kontinenz-erhaltend therapiert werden.

Die meist gewählte Operationstechnik stellt die TARR dar, die bei 68\% ( $n=153)$ des Patientenkollektivs Anwendung fand (siehe Tabelle 6). Bei elf Patienten (4,9\%) wurde eine patientenbezogene alternative Operationsmethode, wie eine Diskontinuitätsoperation nach Hartmann mit TME durchgeführt.

Es zeigt sich ein signifikanter Unterschied in der Verteilung der Höhenlokalisation des Tumors auf die Behandlungsgruppen. Dies begründet sich in der Leitlinien-gerechten Therapie, bei der Patienten, die ein Rektumkarzinom im oberen Rektumdrittel aufweisen, keiner neoadjuvanten Therapie zugeführt werden müssen.

\begin{tabular}{|c|c|c|c|c|c|c|c|}
\hline \multirow{2}{*}{$\begin{array}{l}\text { Neoadjuvante Therapie } \\
\text { Patientenzahl }(\mathrm{N}=225)\end{array}$} & \multicolumn{2}{|c|}{ keine } & \multicolumn{2}{|c|}{$\begin{array}{c}\text { RCT } \\
\text { (5-FU-Mono) }\end{array}$} & \multicolumn{2}{|c|}{$\begin{array}{l}\text { intensivierte } \\
\text { RCT } \\
\text { (5-FU und } \\
\text { Oxaliplatin) }\end{array}$} & \multirow[t]{2}{*}{ p-Wert* } \\
\hline & 43 & $\%$ & 108 & $\%$ & 74 & $\%$ & \\
\hline \multicolumn{7}{|l|}{ Operationsverfahren } & \multirow{4}{*}{0.31} \\
\hline TARR & 32 & 74,4 & 67 & 62,0 & 54 & 73,0 & \\
\hline APE & 8 & 18,6 & 35 & 32,4 & 18 & 24,3 & \\
\hline andere & 3 & 7,0 & 6 & 5,6 & 2 & 2,7 & \\
\hline \multicolumn{7}{|l|}{ Höhenlokalisation d. Tumors } & \multirow{4}{*}{0.04} \\
\hline unteres Rektumdrittel & 13 & 30,2 & 39 & 36,1 & 35 & 47,3 & \\
\hline mittleres Rektumdrittel & 23 & 53,5 & 63 & 58,3 & 36 & 48,6 & \\
\hline oberes Rektumdrittel & 7 & 16,3 & 6 & 5,6 & 3 & 4,1 & \\
\hline
\end{tabular}

Tabelle 6: Übersicht über die zum Einsatz gekommenen Operationsverfahren und die Verteilung der Höhenlokalisationen der Rektumkarzinome

Bei allen drei Behandlungsgruppen stellt die am häufigsten angewendete OP-Technik die TARR mit Entnahme des Mesorektums dar. Über die Hälfte aller Rektumkarzinome $(54,2 \%, n=122)$ zeigten eine Lokalisation im mittleren Rektumdrittel.

${ }^{*}$ p-Wert-Berechnung mit Chi-Quadrat-Test 


\subsubsection{Histopathologische Tumorstadien und lokales Tumoransprechen}

Die Ergebnisse der histopathologischen Aufarbeitung der Rektumresektate, welche nach onkologischen Prinzipien reseziert wurden sind in Tabelle 7 (siehe Seite 46) zusammengefasst.

In jeder Behandlungsgruppe konnte in über $90 \%$ der Fälle eine R0-Resektion erreicht werden. Die Kohorte, welche eine primäre Resektion des Rektums erfahren hat, zeigt die höchste Rate an R1-Resektionen (7\% der 43 Patienten). In beiden Behandlungsgruppen, welche einer präoperativen RCT zugeführt wurden, wurde nur bei 0,9-2,7\% der Patienten keine komplette Tumorfreiheit (entsprechend R1/2-Resektion) durch die operative Therapie erzielt.

In der primär operierten Behandlungsgruppe zeigten 67,4\% ( $n=29)$ der Patienten einen Tumordurchbruch durch die Muscularis propria mit Infiltration der Subserosa oder des perirektalen Gewebes (pT3-Status). Ein Eindringen des Karzinoms bis in die Muscularis propria (pT2-Status) konnte bei $11(25,6 \%)$ der 43 Patienten ermittelt werden. Lediglich bei zwei untersuchten Patienten (4,7\%) zeigte sich in dieser Kohorte eine Begrenzung des Tumors auf die Submucosa (pT1-Status). Ein Patient (2,3\%) wies zum Operationszeitpunkt bereits eine multiviszerale Tumorausbreitung auf. Dem entgegengesetzt konnte bei den neoadjuvant vorbehandelten Kohorten in rund $10-15 \%$ der Fälle ( $n=10$ bzw. $n=11$ ) im Rektumresektat kein vitales Tumorgewebe aufgefunden werden (entsprechend ypT0, TRG4). Dennoch wiesen leider insgesamt 10 Patienten der neoadjuvanten Behandlungsgruppen (5,5\% bzw. 5,4\%) zum Operationszeitpunkt auch nach Verabreichung einer präoperativer RCT einen ypT4-Tumor auf. In beiden neoadjuvanten Patientengruppen konnte bei einem Großteil der Resektate eine Tumorinfiltration mit Durchbrechung der Muscularis propria, entsprechend einem ypT3-Status, festgestellt werden $(50,9 \%, n=55 ; 45,9 \%, n=34$; siehe Tabelle 7, Seite 46).

Es zeigt sich ein signifikanter Unterschied bei der Verteilung des pathologischen Nodalstatus auf die Behandlungsgruppen $(p=0,02)$. In der primär operierten Kohorte konnte bei rund 49\% der Patienten ( $n=21$ ) ein pNO-Status ermittelt werden. In über 65\% der Fälle zeigte sich ein negativer Nodalstatus bei Patienten, welche präoperativ eine RCT erhalten haben. Dabei wiesen 71 (65,7\%) Patienten der 5-FU-Mono-Kohorte und 53 (71,6\%) der Patienten, welche zusätzlich Oxaliplatin verabreicht bekamen, keinen Lymphknotenbefall im Rektumresektat auf. Die niedrigste Rate an einem Befall von vier oder mehr LK, entsprechend ypN2-Status, 
zeigte sich ebenfalls bei den Patienten, denen eine intensivierte CT mit Oxaliplatin verabreicht wurde. Lediglich 6 der 74 Patienten (8,1\%) wiesen laut histopathologischem Befund einen ypN2-Status auf (siehe Tabelle 7, Seite 46). Diese deutet daraufhin, dass eine Beeinflussung des pN-Status durch das Therapieregime besteht.

Ein intraoperativer Metastasenfund bei primär operierten Patienten, die beim präoperativen Staging als negativ eingestuft wurde, führt zu einer Rate an Fernmetastasen von $11,6 \%(n=5)$ in dieser Kohorte. Bei beiden neoadjuvant therapierten Kollektiven wurde ebenfalls bei einigen Patienten zum Operationszeitpunkt das Vorhandensein von Metastasen diagnostiziert. Diese Patienten mit einem M1-Status konnten entweder bei den vorangegangenen Staging-Untersuchungen nicht detektiert werden oder es kam zu einer Progredienz der Erkrankung unter der neoadjuvanten Therapie. So wurden bei 7,4\% bzw. bei 8,1\% der Fälle wurden zum Zeitpunkt der Operation Fernmetastasen diagnostiziert.

Aus den vorangegangen Daten ergibt sich, eine Verteilung der pUICC-Stadien wie folgt: die primär operierten Patienten befanden sich zu 37,2\% $(n=19)$ und damit vorherrschend im Stadium pUICC-III. Patienten, welche als Chemotherapeutikum nur 5-FU erhalten haben, befanden sich zum überwiegenden Teil $(32,4 \%, n=34)$ im Stadium ypUICC-II. Nach Verabreichung einer intensivierten RCT, wies der Großteil der Behandlungsgruppe das Stadium ypUICC-I auf $(32,4 \%, n=24)$. Ein Downstaging des ypUICC-Stadiums durch Verabreichung einer neoadjuvanten Therapie konnte bei einigen Patienten beobachtet werden. Nach erfolgter präoperativer Bestrahlung des kleinen Beckens mit begleitender CTx zeigte sich insgesamt bei 39,6\% ( $n=72$, der 182 neoadjuvant therapierten Personen) der Patienten ein Stadium ypUICC-0/I. Innerhalb der Behandlungsgruppe, welche eine 5-FUMonotherapie erhalten hat, zeigte sich eine Rate von 9,3\% der Patienten, die ein ypUICC-0 aufweisen $(n=10)$. Eine höhere Rate an Rektumresektaten, die kein vitales Tumorgewebe enthalten haben, konnte nach zusätzlicher Gabe von Oxaliplatin beobachtet werden. Hier lag der Prozentsatz von Patienten mit dem Stadium ypUICC-0 bei 14,9\% $(n=11)$.

Eine Komplettremission des Tumors (entsprechend TRG 4) zeigten 9,3\% ( $n=10)$ der Fälle, innerhalb der Kohorte, welche eine Monotherapie mit 5-FU erhalten hat. Eine TRG4 durch die präoperative zytostatische Therapie konnte bei $12,2 \% \quad(n=9)$ der intensiv chemotherapierten Patienten erzielt werden (siehe Tabelle 7, Seite 46). In keiner der beiden neoadjuvanten Behandlungsgruppen war ein komplettes Versagen der präoperativen RCT (entsprechend TRG 0) beobachtet worden. 


\begin{tabular}{|c|c|c|c|c|c|c|c|}
\hline \multirow{2}{*}{\begin{tabular}{|l|} 
Neoadjuvante Therapie \\
Patientenzahl $(\mathrm{N}=225)$ \\
\end{tabular}} & \multicolumn{2}{|c|}{ keine } & \multicolumn{2}{|c|}{$\begin{array}{c}\text { RCT } \\
\text { (5-FU-Mono) }\end{array}$} & \multicolumn{2}{|c|}{$\begin{array}{l}\text { intensivierte } \\
\text { RCT } \\
\text { (5-FU und } \\
\text { Oxaliplatin) }\end{array}$} & \multirow[t]{2}{*}{ p-Wert* } \\
\hline & 43 & $\%$ & 108 & $\%$ & 74 & $\%$ & \\
\hline \multicolumn{7}{|l|}{ R-Status } & \multirow{4}{*}{0.10} \\
\hline RO & 40 & 93 & 107 & 99,1 & 72 & 97,3 & \\
\hline R1 & 3 & 7 & 1 & 0,9 & 1 & 1,35 & \\
\hline R2 & 0 & - & 0 & - & 1 & 1,35 & \\
\hline \multicolumn{7}{|l|}{ (y)pTNM-Status } & \multirow{6}{*}{0.17} \\
\hline 0 & 0 & - & 10 & 9,3 & 11 & 14,9 & \\
\hline 1 & 2 & 4,7 & 10 & 9,3 & 9 & 12,2 & \\
\hline 2 & 11 & 25,6 & 27 & 25,0 & 16 & 21,6 & \\
\hline 3 & 29 & 67,4 & 55 & 50,9 & 34 & 45,9 & \\
\hline 4 & 1 & 2,3 & 6 & 5,5 & 4 & 5,4 & \\
\hline \multicolumn{7}{|l|}{ (y)pN-Status } & \multirow{4}{*}{0.02} \\
\hline 0 & 21 & 48,8 & 71 & 65,7 & 53 & 71,6 & \\
\hline 1 & 10 & 23,3 & 25 & 23,2 & 15 & 20,3 & \\
\hline 2 & 12 & 27,9 & 12 & 11,1 & 6 & 8,1 & \\
\hline \multicolumn{7}{|l|}{ (y)pM-Status } & \multirow{3}{*}{0.69} \\
\hline 0 & 38 & 88,4 & 100 & 92,6 & 68 & 91,9 & \\
\hline 1 & 5 & 11,6 & 8 & 7,4 & 6 & 8,1 & \\
\hline \multicolumn{7}{|l|}{ (y)pUICC-Stadium } & \multirow{6}{*}{0.13} \\
\hline 0 & 0 & - & 10 & 9,3 & 11 & 14,9 & \\
\hline 1 & 10 & 23,3 & 27 & 25,0 & 24 & 32,4 & \\
\hline II & 12 & 27,9 & 35 & 32,4 & 16 & 21,6 & \\
\hline III & 16 & 37,2 & 28 & 25,9 & 19 & 25,7 & \\
\hline IV & 5 & 11,6 & 8 & 7,4 & 4 & 5,4 & \\
\hline \multicolumn{7}{|l|}{$\begin{array}{l}\text { Tumorregressionsgrad } \\
\text { (n. Dworak) }\end{array}$} & \multirow{6}{*}{0.47} \\
\hline 0 (keine Regression) & & & 0 & - & 0 & - & \\
\hline 1 (<25\% Regression) & & & 11 & 10,1 & 9 & 12,1 & \\
\hline 2 (<50\% Regression) & & & 26 & 24,1 & 11 & 14,9 & \\
\hline 3 (>50\% Regression) & & & 61 & 56,5 & 45 & 60,8 & \\
\hline 4 (komplette Regr.) & & & 10 & 9,3 & 9 & 12,2 & \\
\hline
\end{tabular}

Tabelle 7: Übersicht über die klinikopathologischen Parameter aller Patienten, aufgeteilt nach verabreichter Therapie

Der R-Status, pTNM-Status sowie der TRG wurden histopathologisch erhoben.

*p-Wert-Berechnung mit Chi-Quadrat-Test 


\subsection{Fernmetastasen, Lokalrezidive und tumorbedingte Todesfälle im}

\section{Nachbeobachtungszeitraum}

Alle Patienten wurden im Zeitraum vom 26.01.1996 bis 26.01.2010 in der UMG, Abteilung für Allgemein- und Viszeralchirurgie unter der Leitung von Univ.-Prof. Dr. H. Becker einer Resektion des Rektums unterzogen.

Der Nachbeobachtungszeitraum beträgt im Median 49 Monate (5 bis 164 Monate). Die längste Nachbeobachtungszeit zeigt sich bei den Patienten, die einer primären Resektion des Rektums unterzogen wurden. Das Patientenkollektiv, das eine intensivierte RCT erhalten hat, zeigt die kürzeste Follow-up-Zeit.

Im Nachbeobachtungszeitraum trat bei $11,6 \%(n=5)$ der Patienten der primär operierten Kohorte ein LR auf. Fünf Patienten (4,6\%), die mit einer präoperativen 5-FU-Mono RCT therapiert wurden, erfuhren ein LR während des Nachbeobachtungszeitraumes. Die niedrigste Lokalrezidivrate weist die Behandlungsgruppe auf, welche einer intensivierten RCT unterzogen wurde. Hier zeigte sich lediglich bei $2,7 \%(n=2)$ der Patienten ein erneutes lokales Tumorwachstum (siehe Tabelle 8, Seite 48).

In jeder Behandlungsgruppe zeigt sich eine ähnlich hohe Rate an Fernmetastasen. Bei elf Patienten, die primär operiert wurden, traten Fernmetastasen im Zeitraum der Nachbeobachtung auf. Diese machen 25,6\% $(n=11)$ der Kohorte aus. Am häufigsten fanden sich bei diesem Patientenkollektiv pulmonale Tumorabsiedlungen. Bei rund dem gleichen Prozentsatz traten Fernmetastasen in den neoadjuvanten Behandlungsgruppen auf. Die Kohorte, welche ausschließlich eine 5-FU-Monotherapie erhielt zeigt bei $25 \%(n=27)$ der Patienten und die Kohorte der intensiv chemotherapierten Patienten zeigt bei $24,3 \%(n=18)$ Fernmetastasen.

Der höchste Prozentsatz an tumorbedingten Todesfällen zeigte sich in der adjuvant radiochemotherapierten Patientengruppe $(18,6 \%, n=8)$. Weniger tumorbedingte Todesfälle im Nachbeobachtungszeitraum traten in beiden neoadjuvant behandelten Patientenkollektiven auf. Dabei zeigte sich die niedrigste Rate $(13,5 \%, n=10)$ bei Verabreichung einer CT, bestehend aus 5-FU und Oxaliplatin (siehe Tabelle 8, Seite 48). 


\begin{tabular}{|c|c|c|c|c|c|c|c|}
\hline \multirow{2}{*}{$\begin{array}{l}\text { Neoadjuvante Therapie } \\
\text { Patientenzahl }(\mathrm{N}=225)\end{array}$} & \multicolumn{2}{|c|}{ keine } & \multicolumn{2}{|c|}{$\begin{array}{c}\text { RCT } \\
\text { (5-FU-Mono) }\end{array}$} & \multicolumn{2}{|c|}{$\begin{array}{c}\text { intensivierte RCT } \\
\text { (5-FU und } \\
\text { Oxaliplatin) }\end{array}$} & \multirow[t]{2}{*}{ p-Wert* } \\
\hline & 43 & $\%$ & 108 & $\%$ & 74 & $\%$ & \\
\hline \multicolumn{7}{|l|}{ Rezidive } & \multirow{3}{*}{0.10} \\
\hline $\mathrm{Ja}$ & 5 & 11,6 & 5 & 4,6 & 2 & 2,7 & \\
\hline Nein & 38 & 88,4 & 103 & 95,4 & 72 & 97,3 & \\
\hline \multicolumn{7}{|l|}{ Fernmetastasen } & \multirow{6}{*}{0.77} \\
\hline Hepar & 2 & 4,65 & 6 & 5,6 & 3 & 4,0 & \\
\hline Lunge & 4 & 9,3 & 7 & 6,5 & 2 & 2 & \\
\hline Hepar u. Lunge & 2 & 4,65 & 2 & 1,8 & 2 & 2,7 & \\
\hline Andere & 3 & 7,0 & 12 & 11,1 & 11 & 14,9 & \\
\hline Nein & 32 & 74,4 & 81 & 75,0 & 56 & 75,7 & \\
\hline \multirow[t]{2}{*}{ Tumorbedingte Todesfälle } & & & & & & & \multirow{2}{*}{0.14} \\
\hline & 8 & 18,6 & 17 & 15,7 & 10 & 13,5 & \\
\hline \multicolumn{7}{|l|}{ Follow-up-Zeit } & \\
\hline Median in Monaten & \multicolumn{2}{|c|}{$\begin{array}{c}108 \\
(51-164)\end{array}$} & \multicolumn{2}{|c|}{$\begin{array}{c}42 \\
(5-150)\end{array}$} & \multicolumn{2}{|c|}{$\begin{array}{c}36 \\
(10-148)\end{array}$} & \\
\hline
\end{tabular}

Tabelle 8: Übersicht über das Auftreten von Lokalrezidiven, dem Auffinden von Fernmetastasen und tumorbedingten Todesfällen im Nachbeobachtungszeitraum

Die höchste Rate an Lokalrezidiven und tumorbedingten Todesfälle findet sich innerhalb der Kontrollgruppe (keine neoadjuvante Therapie). Die niedrigste Rate an LR, Fernmetastasen und tumorbedingten Todesfällen zeigt sich nach Verabreichung einer neoadjuvanten intensivierten RCT.

*p-Wert-Berechnung mit Chi-Quadrat-Test

\subsection{Ergebnisse der Gegenüberstellung zweier immunhistochemischer}

\section{Analyseverfahren}

Um die mit dem DIA VIAS erhobenen immunhistochemischen Daten mit den Daten der konventionell-manuellen Auswertung zu vergleichen, wurden alle vorhandenen Präparate mittels beider Verfahren verblindet analysiert. Die erhobenen Datensätze wurden einer Korrelationsanalyse unterzogen.

Insgesamt wurden 772 Präparate, entstammend den prätherapeutischen PE und den Rektumresektaten, mittels eines DAB-gekoppelten Sekundärantikörper gefärbt und ausgewertet. Von diesen 772 Präparaten wurde in 384 Präparaten das Antigen p53 und in 388 Präparaten das Antigen Ki67 gefärbt.

Korreliert man den prozentual positiven Tumoranteil, welcher konventionell-manuell und mit DIA-Unterstützung erfasst wurde, so ergibt sich ein Koeffizient von $>0,9$. Dieser Korrelationskoeffizient lässt sich bei beiden Antigenfärbungen (siehe Abbildung 10, Seite 50) 
im Tumorgewebe der Resektate, sowie auch im Gewebe der Probenentnahmen wiederfinden. Es zeigt sich also eine sehr starke Korrelation zwischen den mittels beiden Analyseverfahren erfassten positiven Tumoranteilen.

Da mit dem Programm VIAS eine durchschnittliche Färbeintensität aller gezählten Zellkerne ermittelt wird (ähnlich dem Remmele-Score), wurde auch aus den konventionell-manuell erfassten Daten der Remmele-Score erhoben. Dieser ergibt sich aus dem Prozentsatz der positiven Zellkerne und der Färbeintensität, wiedergegeben auf einer Skala von 0-12 (Remmele und Stegner 1987). Für beide Antigenfärbungen konnte bei der Korrelation des konventionell-manuell erfassten und des Software-gestützt erhobenen Scores ein Koeffizient von $>0,9$ ermittelt werden (siehe Abbildung 11, Seite 50). Es zeigt sich also auch bei der Gegenüberstellung der erfassten Färbeintensitäten eine sehr starke Korrelation zwischen beiden Analyseverfahren.

Es wurden weiterhin zwei der gebräuchlichsten Sekundärantikörper gegenübergestellt. Beide dieser AK tragen ein Enzym, welches nach Bindung und Zugabe eines Chromogens zu einer Anfärbung des Gewebes führt. Der AK Multimer-lg_FastRed führt zu einem roten Färbeergebnis und der Sekundärantikörper Multimer-Ig_DAB zu einem braunen Färbeergebnis (siehe Kapitel 2.3, Seite 28). Das DIA VIAS wertet lediglich DAB-gefärbte Präparate aus. Um eine Vergleichbarkeit der Sekundärantikörper zu gewährleisten, wurden die konventionell-manuell erhobenen immunhistochemischen Daten beider Sekundärantikörper gegenübergestellt. Es zeigt sich sowohl für die erfasste Intensität der Anfärbung, als auch für den erhobenen positiven Tumoranteil ein Korrelationskoeffizient von $\geq 0,8$, sodass auch hier eine sehr starke Korrelation zu finden ist. Es kann von einer Vergleichbarkeit beider Sekundärantikörper ausgegangen werden. 

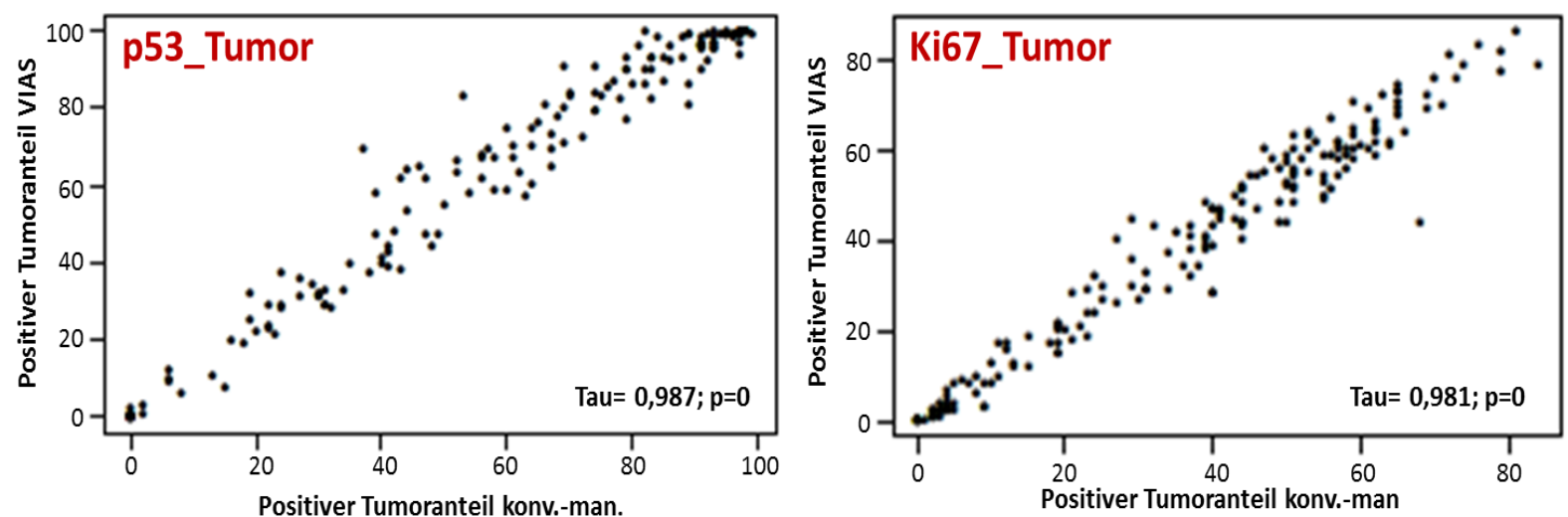

Abbildung 10: Korrelation des erhobenen positiven Tumoranteils

Die Graphen zeigen eine Gegenüberstellung des positiven Tumoranteils in Prozent, welcherkonventionell- manuell (Positiver Tumoranteil konv.-man.) oder mit Unterstützung des DIA (Positiver Tumoranteil VIAS) erhoben wurde. Die Daten wurden in Präparaten des residuellen Tumors erhoben.

tau $=0,987$ bzw. tau $=0,981$
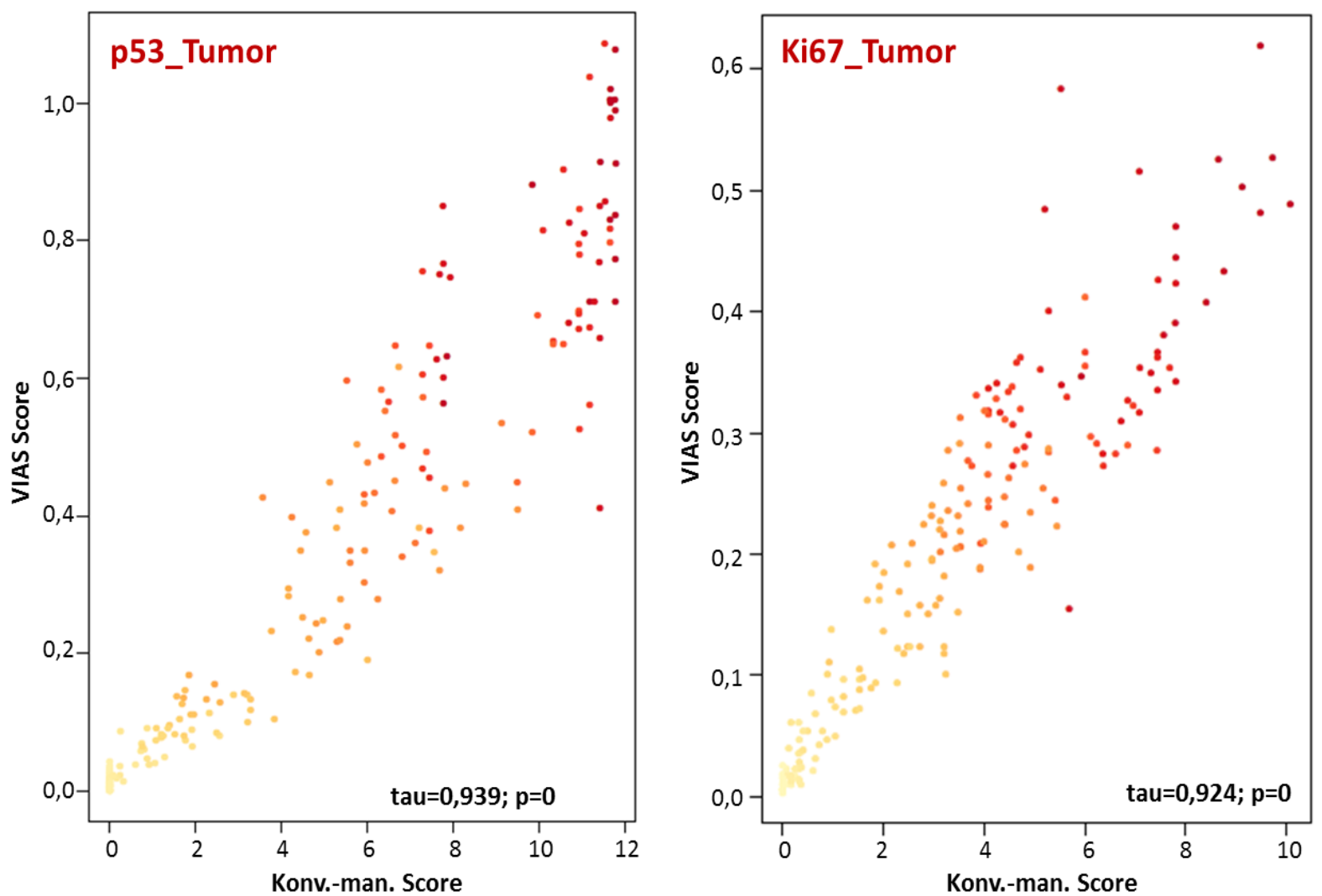

Abbildung 11: Korrelation der erhobenen Färbeintensitäten

Die Graphen zeigen eine Gegenüberstellung der mit Hilfe des DIA erhobenen Intensität (VIAS Score) und des errechneten Remmele-Score aus den konventionell-manuell erfassten Daten (konv.-man. Score). Die Daten wurden in Präparaten des residuellen Tumors gewonnen.

tau $=0,939$ bzw. tau=0,924 


\subsection{Auswertung der Expression von p53}

\subsubsection{Das Expressionslevel von p53}

Aus allen prätherapeutisch entnommen PE, sowie aus Gewebeproben der Rektumresektate, wurde das Expressionslevel von p53 bestimmt. Da der Vergleich der zwei Analyseverfahren immunhistochemischer Daten eine sehr stark positive Korrelation der erhobenen Datensätze belegen konnte (siehe Kapitel 3.3, Seite 48), beziehen sich alle nachfolgenden Statistiken auf die mit Hilfe des DIA VIAS erhobenen Werte.

Die Tabelle 9 (siehe Seite 52) zeigt einen Überblick über die erfassten positiven Tumoranteile in den PE und in den Rektumresektaten, sowie den prozentualen Anteil an Präparaten, die immunhistochemisch eine p53-Überexpression aufweisen. Die prätherapeutische und posttherapeutische Verteilung des DIA-erfassten Färbeintensitäts-Scores wird für die einzelnen Behandlungsgruppen in Abbildung 12 (siehe Seite 52) dargestellt.

In dieser Untersuchung konnte kein signifikanter Unterschied zwischen dem prätherapeutischem Expressionslevel und dem Expressionslevel von p53 nach Therapieabschluss mit Verabreichung einer neoadjuvanten RCT ermittelt werden (siehe Abbildung 12, Seite 52). Sowohl die erfasste Färbeintensität, als auch die Anzahl an Präparaten mit einer p53-Überexpression zeigen eine konstante Verteilung innerhalb der Behandlungsgruppen. Orientierend an der aktuellen Studienlage (siehe Tabelle 11, Seite 70) wurde das Cut-Off-Level für das Vorliegen einer Überexpression des p53-Proteins im Adenokarzinom des Rektums ab einen positiven Tumoranteil von $\geq 10 \%$ festgesetzt. Prätherapeutisch wurde in jeder Behandlungsgruppe ein sehr hoher Anteil an Präparaten, die eine Überexpression aufweisen $(80,6 \%$ bis $93,3 \%)$ detektiert. Innerhalb der Kontrollgruppe wurde in $82,9 \%$ der Präparate, die dem Rektumresektat entstammen, das Vorliegen einer p53-Überexpression erfasst. Folglich zeigt sich in dieser Kohorte während des Therapieverlaufes eine Abnahme des Anteils an Gewebeproben, die den Tumorsuppressor p53 überexprimieren. In beiden Behandlungsgruppen, die vor der Rektumresektion einer RCT zugeführt wurden, zeigt sich ein gleichbleibend hoher Anteil an Präparaten, die eine erhöhte Expression von p53 aufweisen (siehe Tabelle 9, Seite 52). 

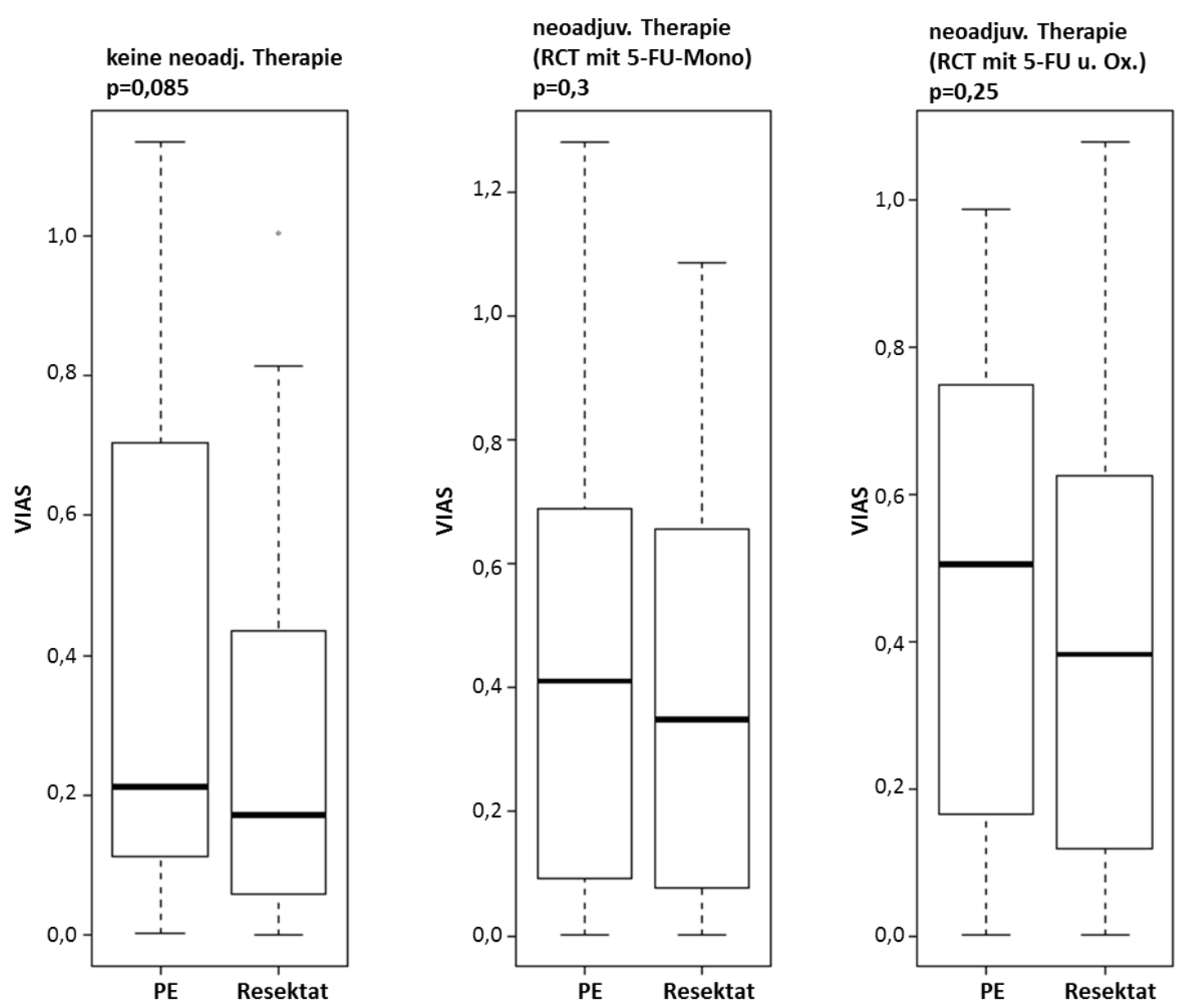

Abbildung 12: Gegenüberstellung des prätherapeutischen (PE) und des posttherapeutischen (Resektat) Expressionslevels von p53

In keiner Behandlungsgruppe lässt sich im Vergleich ein Unterschied zwischen prä- und posttherapeutischer p53-Expression feststellen.

\begin{tabular}{|cccc|}
\hline Neoadjuvante Therapie & $\begin{array}{c}\text { keine } \\
\text { (Kontrollgruppe) }\end{array}$ & $\begin{array}{c}\text { RCT } \\
\text { (5-FU-Mono) }\end{array}$ & $\begin{array}{c}\text { intensivierte RCT } \\
\text { (5-FU und } \\
\text { Oxaliplatin) }\end{array}$ \\
\hline Patientenzahl (N=225) & 43 & 108 & 74 \\
\hline p53-Expression in der PE (\%) & $0-100$ & $0-100$ & $0-100$ \\
Min.-Max. & 67,0 & 63,3 & 70,7 \\
Mittelwert & 93,3 & 80,6 & 87,9 \\
\hline Überexpression ( $\geq 10 \%)$ & & & \\
p53-Expression im Resektat (\%) & $0-100$ & $0-100$ & $0-100$ \\
Min.-Max. & 52,2 & 60,2 & 60,1 \\
Mittelwert & 82,9 & 79,1 & 88,1 \\
\hline Überexpression ( $\geq 10 \%)$ & & & \\
\hline
\end{tabular}

Tabelle 9: Ergebnisse der immunhistochemischen Analyse für das Antigen p53

Die Tabelle zeigt den mit Hilfe des DIA ermittelten positiven Tumoranteil in Prozent (innerhalb der einzelnen Behandlungsgruppen) und den prozentualen Anteil an Präparaten, die eine p53-Expression von $\geq 10 \%$ aufweisen (entsprechend einer Überexpression des p53-Proteins). 


\subsubsection{Korrelation des prätherapeutischen Expressionslevels von p53 mit dem TRG}

Um das prädiktive Potential von p53 im lokal fortgeschrittenen Rektumkarzinom aufzudecken wurde das Expressionslevel der prätherapeutischen PE mit dem histopathologisch ermittelten TRG korreliert. Insgesamt konnten die immunhistochemischen Daten der prätherapeutischen Biopsien von 160 neoadjuvant therapierten Patienten in diese Berechnung einbezogen werden (von einigen Patienten lag keine prätherapeutsiche Tumorbiopsie vor, andere konnten aufgrund eines zu geringen Tumoranteils nicht mit in die Auswertung einbezogen werden).

Bei den vorliegenden Berechnungen ließ sich kein Hinweis für einen Zusammenhang zwischen dem prätherapeutischem p53-Expressionslevel und dem Tumoransprechen auf eine lokale Therapie erfassen ( $p>0,05)$. Es zeigt sich bei jedem TRG eine vergleichbare $p 53-$ Expression (entsprechend dem positivem Tumoranteil, siehe Abbildung 13). Eine Korrelationsberechnung der erfassten Färbeintensitäten mit dem TRG ergab ebenfalls keinen Zusammenhang.

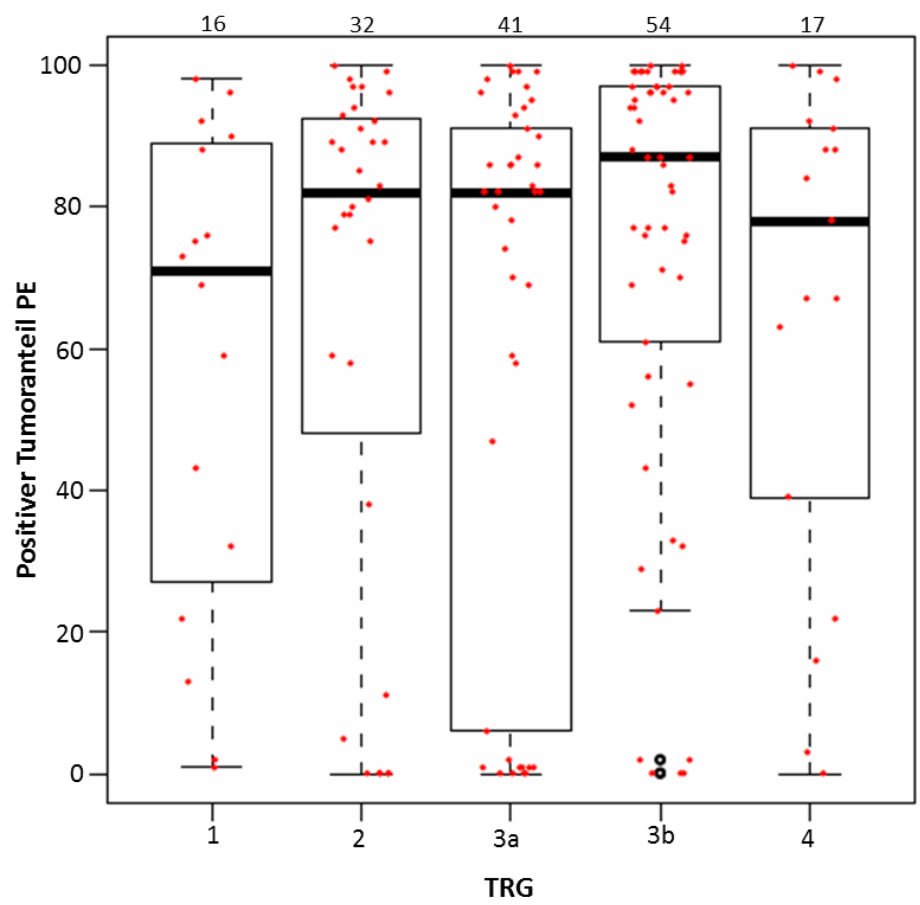

Abbildung 13: Korrelation des prätherapeutischen p53Expressionslevels mit dem TRG

Es zeigt sich kein signifikanter Zusammenhang zwischen dem prätherapeutisch erfassten positiven Tumoranteil und dem Tumoransprechen auf eine lokale Therapie (TRG).

Kruskal-Wallis-Test: $p=0,252 ;$ Kendall's Tau: 0,089, $p=0,139$ 


\subsubsection{Korrelation des Expressionslevels von p53 mit dem Nodalstatus und dem Auftreten von Fernmetastasen}

Um einen Zusammenhang zwischen dem Expressionsmuster von p53 im Tumorgewebe und dem N-Status/M-Status zu identifizieren, wurde eine Korrelationsanalyse zwischen dem erhobenen positiven Tumoranteil, dem Nodalstatus und dem Auftreten von Fernmetastasen durchgeführt. Insgesamt konnten für diese Berechnungen die prätherapeutischen immunhistochemischen Daten von 160 neoadjuvant therapierten Patienten und die posttherapeutischen immunhistochemischen Daten von 151 neoadjuvant therapierten Patienten herangezogen werden.

Die Korrelation des positiven Tumoranteils mit dem Nodalstatus ergab weder für die p53Expression in der PE, noch im residuellen Tumor einen Zusammenhang. Das Expressionslevel von p53 zeigt zwischen den nodal-negativen Patienten und den Patienten mit histopathologisch gesichertem Befall der regionären LK keinen signifikanten Unterschied.

Des Weiteren zeigt die Korrelationsanalyse des positiven Tumoranteils mit dem Auftreten von Fernmetastasen im Nachbeobachtungszeitraum keinen Zusammenhang $(p>0,05)$. Es zeigt sich kein unterschiedliches Expressionslevel von p53 im Tumorgewebe von Patienten, die metastasenfrei sind und denen, die im Nachbeobachtungszeitraum Tumorabsiedlungen aufweisen (siehe Abbildung 14Abbildung 15).
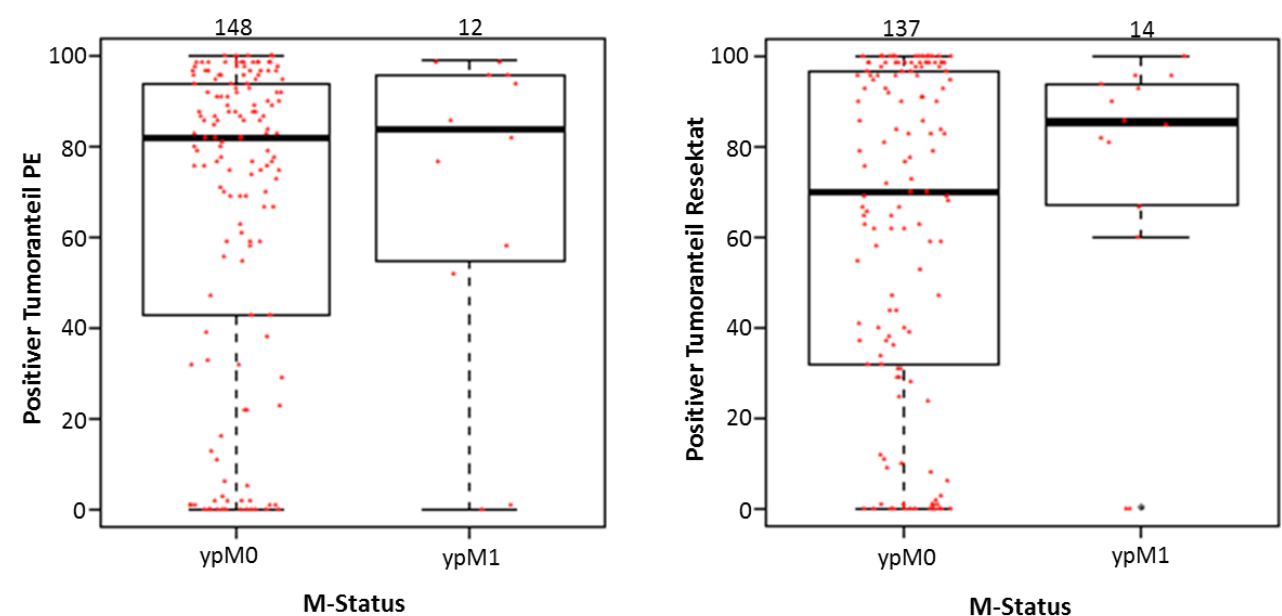

Abbildung 14: Korrelation des p53-Expressionslevels mit dem Metastasierungsstatus (MStatus) der neoadjuvant therapierten Patienten

Es zeigt sich weder für den prätherapeutischen positiven Tumoranteil (Positiver Tumoranteil $\mathrm{PE}$ ), noch für den positiven Tumoranteil des residuellen Tumors (Positiver Tumoranteil Resektat) ein Zusammenhang mit dem Auftreten von Fernmetastasen (ypM1).

PE - Kruskal-Wallis Test: $p=0,717$; Kendall's Tau: $0,024, p=0,717$

Resektat - Kruskal-Wallis-Test: $p=0,583$; Kendall's Tau: 0,037, $p=0,583$ 


\subsubsection{Korrelation des Expressionslevels von p53 mit dem krankheitsfreien Überleben und dem Karzinom-spezifischen Überleben}

Das erhobene p53-Expressionslevel wurde bei allen Patienten mit dem DFS und dem CSS korreliert. Ziel dieser Berechnungen war es, den prognostischen Nutzen des Tumorsuppressors p53 unabhängig des Therapieschemas zu untersuchen. Die Patienten wurden in eine Beobachtungsgruppe mit einem normalen p53-Expressionslevel $(<10 \%$ der Tumorzellen weisen eine Anfärbung des Zellkerns auf) und in eine Beobachtungsgruppe mit einer p53-Überexpresssion ( $\geq 10 \%$ der Tumorzellen zeigen eine nukleäre Anfärbung) geteilt. Insgesamt konnte das posttherapeutische p53-Expressionslevel von 192 Patienten aus allen Behandlungsgruppen einbezogen werden. Bei 158 dieser Patienten (82,3\%) wurde durch die immunhistochemische Analyse das Vorhandensein einer Überexpression des untersuchten Tumorsuppressorproteins p53 festgestellt. Die ermittelten Kaplan-Meier-Kurven scheinen darauf hinzudeuten, dass Patienten, welche keine erhöhte Expression von p53 im Gewebe der Rektumresektate aufweisen, ein besseres DFS haben, als Patienten mit einer p53Überexpression. Jedoch unterscheiden sich die Endpunkte beider Graphen nicht signifikant ( $p=0,196$; siehe Abbildung 15, Seite 56). Das CSS wird ebenfalls nicht durch das posttherapeutische Expressionslevel von p53 beeinflusst (siehe Abbildung 15, Seite 56).

Die Erhebung der Kaplan-Meier-Kurven mit der prätherapeutisch erfassten p53-Expression zeigte keine Einflussnahme auf das DFS oder das CSS.

Betrachtet man das DFS der primär operierten Patienten scheint das Vorliegen einer p53Überexpression im Rektumresektat ein negativer Prädiktor zu sein. Im kompletten Nachbeobachtungszeitraum von über 120 Monaten zeigt die Patientengruppe mit einem normalen p53-Expressionslevel kein Ereignis. In der Patientengruppe, die eine Überexpression von p53 im Gewebe des Rektumresektats zeigt, weisen zum Ende des Nachbeobachtungszeitraums rund ein Drittel (35\%) der Patienten ein Ereignis auf. Dieser Effekt stellt sich jedoch aufgrund der geringen Fallzahl (7 Patienten mit einer normalen und 34 Patienten mit einer Überexpression von $p 53)$ als nicht signifikant dar $(p=0,117)$. 

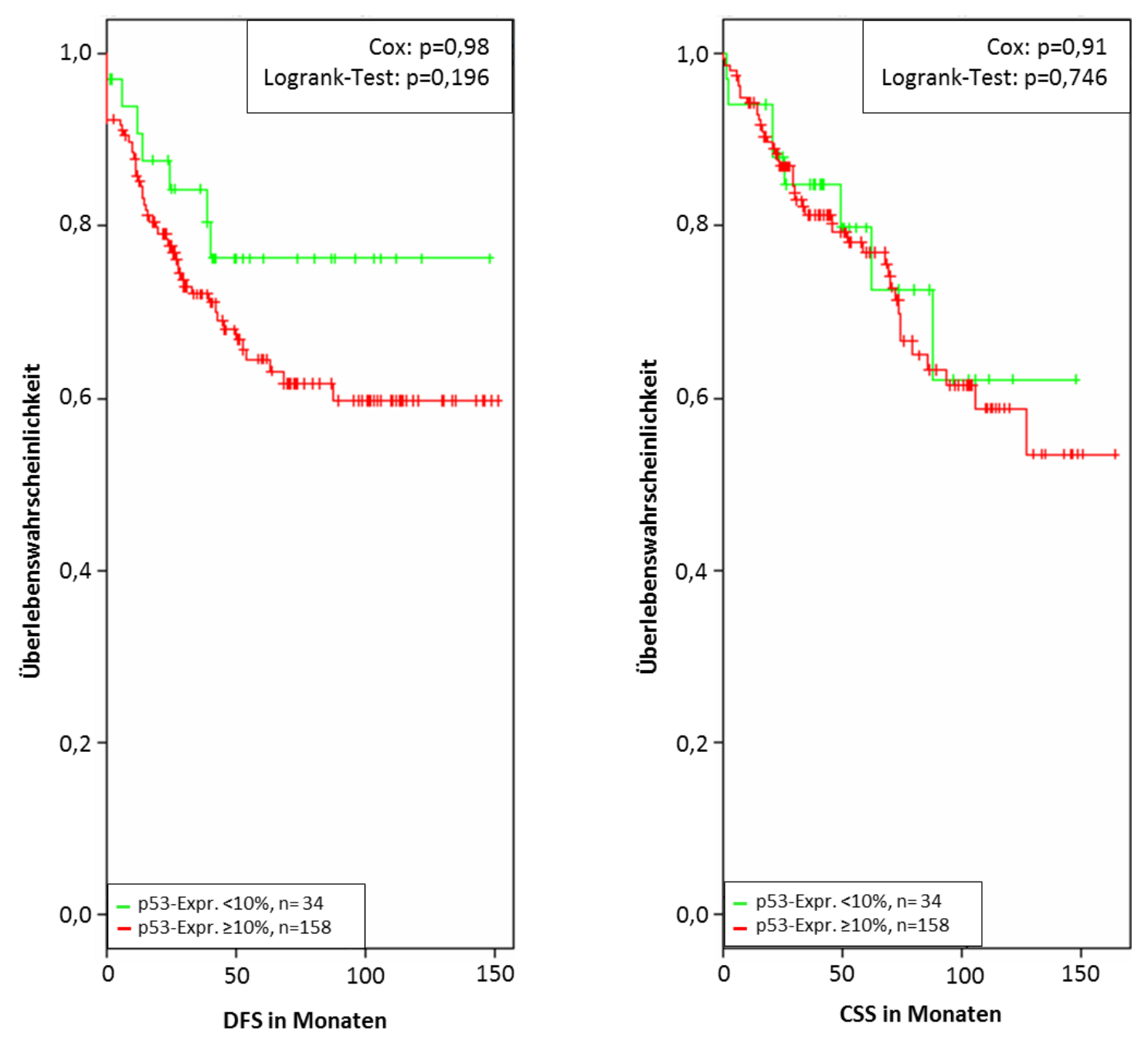

Abbildung 15: Kaplan-Meier-Kurven für das krankheitsfreie Überleben (DFS) und das Karzinom-spezifische Überleben (CSS)

Es wird in grün/rot die Wahrscheinlichkeit, dass Patienten mit einer normalen/erhöhten Expression von p53 eine Zeit (in Monaten) überleben, gezeigt. Die Ereignisse beider Beobachtungsgruppen scheinen sich im Trend des DFS zu unterscheiden. Dieser Effekt ist jedoch statistisch nicht signifikant.

Die Kurven beider Beobachtungsgruppen in Bezug auf das CSS verlaufen ähnlich.

Die hier dargestellten immunhistochemischen Daten wurden aus residuellem Tumor nach Therapieabschluss gewonnen. 


\subsection{Auswertung der Expression von Ki67}

\subsubsection{Das Expressionslevel von Ki67}

Analog zur statistischen Auswertung des p53-Expressionslevels, stützten sich die nachfolgenden statistischen Berechnungen auf die immunhistochemischen Daten, die mit Hilfe des DIA erfasst wurden.

Die prä- und posttherapeutischen Score-Werte, die die Färbeintensität widerspiegeln und innerhalb der einzelnen Behandlungsgruppen erfasst wurden, zeigt die Abbildung 16 (siehe Seite 58). Eine Übersicht über die durchschnittlich ermittelten positiven Tumoranteile und den Anteil an Präparaten, die eine Ki67-Überexpression aufwiesen gibt die Tabelle 10 (siehe Seite 58).

Ein konstantes Ki67-Expressionslevel vor Therapiebeginn und nach der Rektumresektion zeigt sich in der primär operierten Behandlungsgruppe. Diese Kohorte dient als Kontrollgruppe. In den beiden Patientenkollektiven, die einer neoadjuvanten RCT zugeführt wurden, zeigt sich ein signifikanter Unterschied zwischen dem prätherapeutischem und dem posttherapeutischem Ki67-Expressionslevel. Beide Kohorten weisen eine Downregulation der Proteinexpression nach neoadjuvanter zytostatischer Therapie auf. So zeigt sich ein signifikant niedrigeres Ki67-Expressionslevel im residuellen Tumorgewebe im Vergleich zum prätherapeutisch erfassten Level (siehe Abbildung 16, Seite 58).

Das Cut-Off-Level für das Vorliegen einer Ki67-Expression wurde vor Beginn der immunhistochemischen Analysen ab einem positiven Tumoranteil von $\geq 25 \%$ festgelegt. In allen Behandlungsgruppen zeigt prätherapeutisch ein annähernd gleich hoher Anteil an Präparaten eine Proteinüberexpression (90,3-92,5\% der Präparate). Postoperativ weist die Kontrollgruppe ebenfalls diesen Anteil an Ki67-Überexpressionen auf (92,9\% der Präparate). Eine starke Abnahme der Rate an posttherapeutischen Überexpressionen zeigt sich innerhalb beider neoadjuvant therapierter Patientenkollektive. Die Behandlungsgruppe mit einer 5-FU-Monotherapie begleitend zur RT zeigt in 62,6\% der Präparate des residuellen Tumors eine Überexpression. Innerhalb der Kohorte, die begleitend 5-FU und Oxaliplatin zur RT erhalten hat, zeigt sich in 54,2\% der Resektatpräparate eine Überexpression von Ki67. Diese Behandlungsgruppe weist also den geringsten Anteil an posttherapeutischer Ki67Überexpressionen auf (siehe Tabelle 10, Seite 58). 

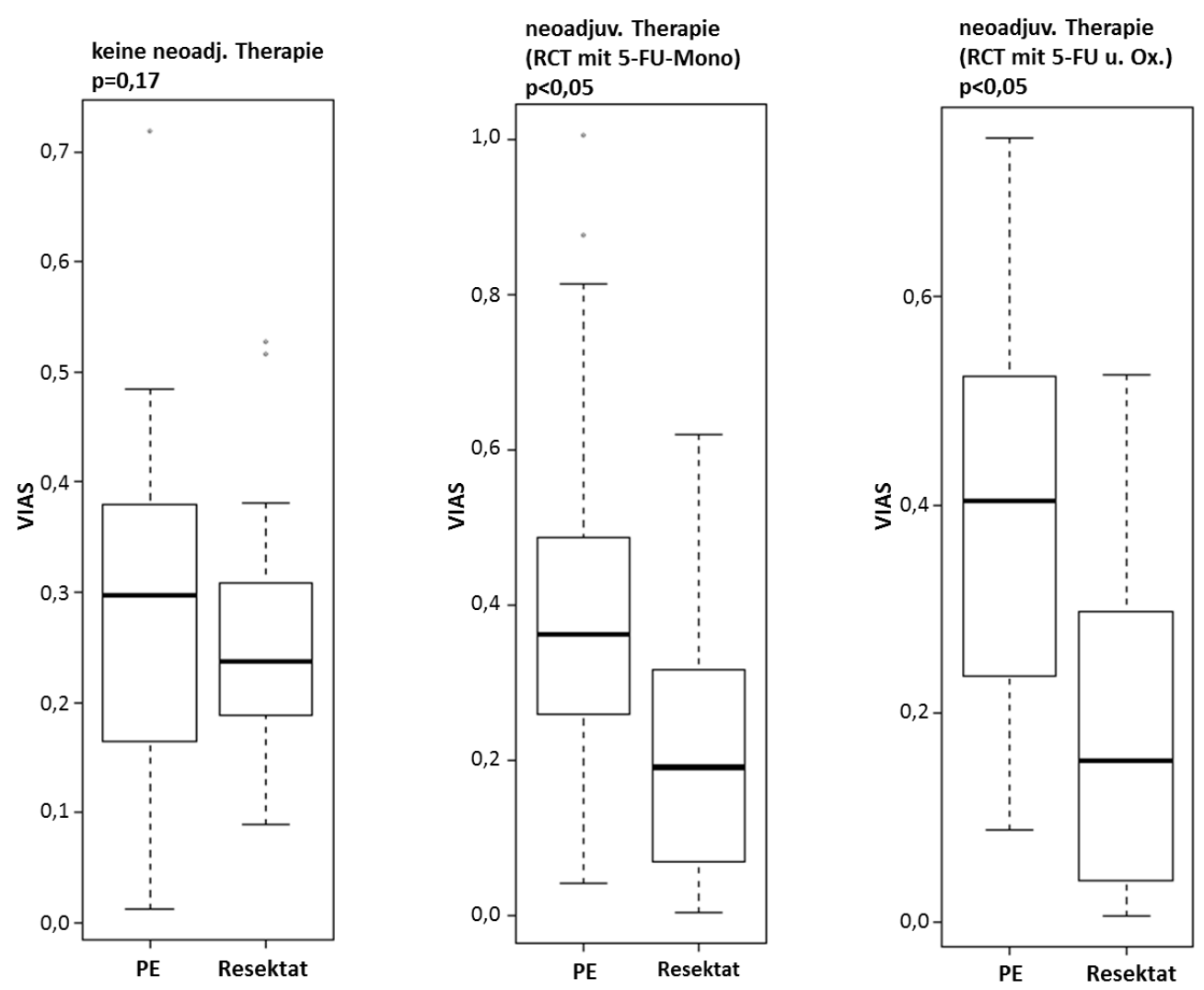

Abbildung 16: Gegenüberstellung des prätherapeutischen (PE) und des posttherapeutischen (Resektat) Expressionslevels von Ki67

Innerhalb der neoadjuvant therapierten Kohorten lässt sich ein signifikanter Unterschied des prä(PE)- und des posttherapeutischen (Resektat) Ki67-Expressionslevels messen $(p<0,05)$.

Innerhalb der Kontrollgruppe (keine neoadjuvante Therapie) zeigt sich eine gleichbleibende Proteinexpression.

\begin{tabular}{|cccc|}
\hline Neoadjuvante Therapie & $\begin{array}{c}\text { keine } \\
\text { (Kontrollgruppe) }\end{array}$ & $\begin{array}{c}\text { RCT } \\
\text { (5-FU-Mono) }\end{array}$ & $\begin{array}{c}\text { intensivierte RCT } \\
\text { (5-FU und } \\
\text { Oxaliplatin) }\end{array}$ \\
\hline Patientenzahl (N=225) & 43 & 108 & 74 \\
\hline Ki67-Expression in der PE (\%) & $0-77$ & $8-96$ & $17-93$ \\
\hline Min.-Max. & 50,0 & 57,8 & 59,6 \\
Mittelwert & 90,3 & 90,4 & 92,5 \\
\hline Überexpression ( $\geq 25 \%)$ & & & \\
\hline Ki67-Expression im Resektat (\%) & $21-86$ & $0-83$ & $0-81$ \\
\hline Min.-Max. & 49,1 & 36,8 & 31,9 \\
Mittelwert & 92,9 & 62,6 & 54,2 \\
\hline Überexpression ( $\geq 25 \%)$ & &
\end{tabular}

\section{Tabelle 10: Ergebnisse der immunhistochemischen Analyse für das Antigen Ki67}

Diese Tabelle zeigt den erfassten positiven Tumoranteil und den Anteil an Präparaten mit einer Ki67Überexpression. In der Kontrollgruppe (keine neoadjuvante Therapie) zeigt sich ein gleichbleibend hoher Anteil an Präparaten mit einer Ki67-Überexpression. In beiden neoadjuvant behandelten Patientenkollektiven zeigt sich eine starke Abnahme der posttherapeutischen Rate an Präparaten mit einer Ki67-Überexpresission. 


\subsubsection{Korrelation des Expressionslevels von Ki67 mit dem TRG}

Die gemessenen prä- und posttherapeutischen Expressionslevel des Proliferationsmarkers Ki67 aus den Präparaten der neoadjuvant vorbehandelten Patientengruppen wurden mit dem TRG korreliert.

Insgesamt konnte das prätherapeutische Expressionslevel aus 159 PE in diese Analyse einbezogen werden. Es stellt sich kein statistischer Zusammenhang zwischen der prätherapeutischen Ki67-Expression und dem Ansprechen auf eine lokale Tumortherapie dar (siehe Abbildung 17). Im Gegensatz hierzu zeigt sich ein signifikanter Zusammenhang zwischen der posttherapeutischen Proteinexpression im residuellen Tumorgewebe und dem TRG (siehe Abbildung 17). Für diese Korrelationsanalyse konnten die Ki67-Expressionsdaten von 150 Gewebeproben, gewonnen nach Beendigung der Therapie, einbezogen werden. Aus der Korrelationsanalyse lässt sich entnehmen, dass Patienten, die einen sehr guten Therapierespons (entsprechend TRG 3b) aufweisen, eine signifikant niedrigere Ki67Expression im Gewebe des residuellen Tumors zeigen (siehe Abbildung 17).
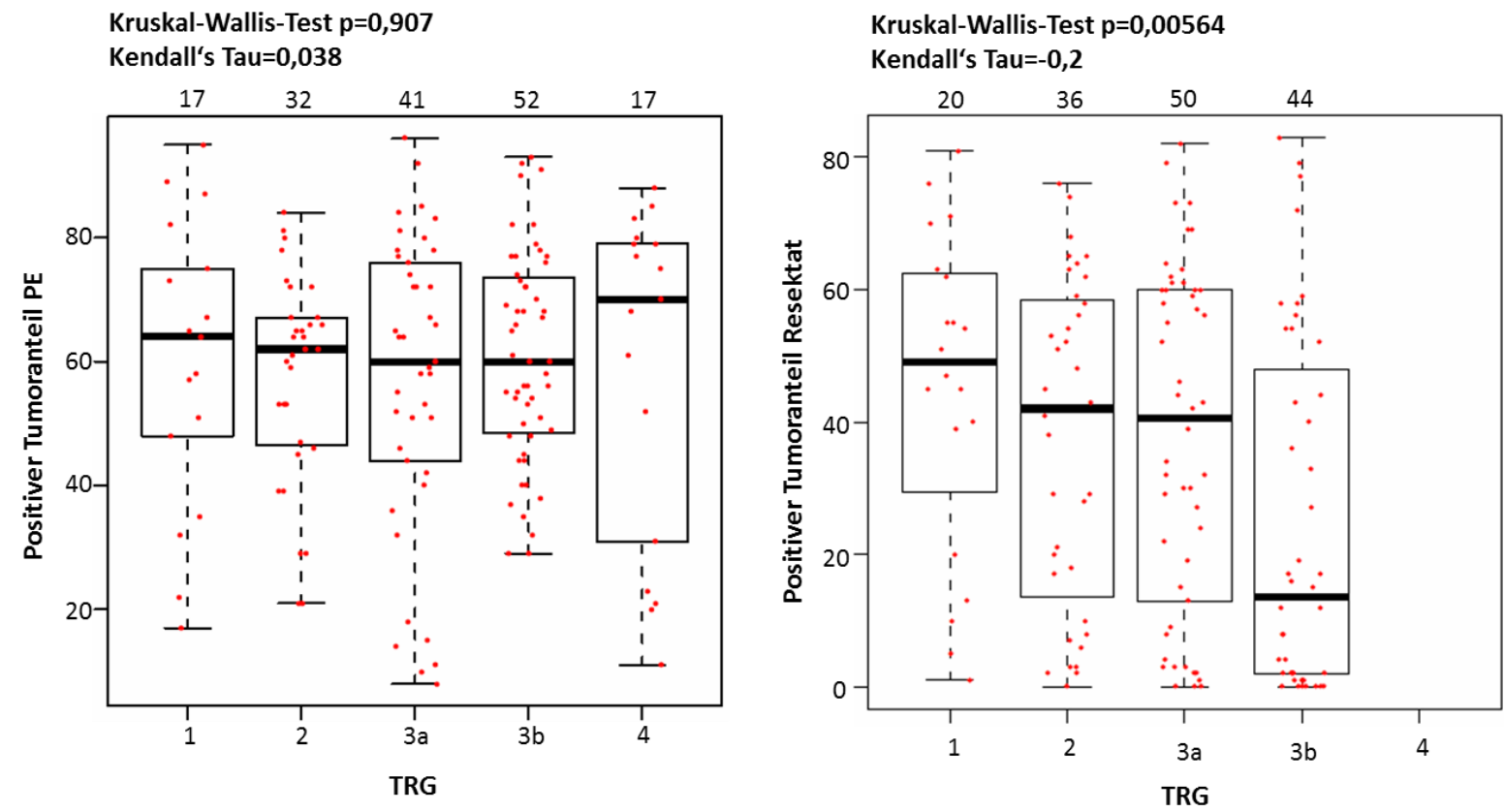

Abbildung 17: Korrelation des prä- und des posttherapeutischen Ki67-Expressionslevels mit dem TRG

Das Ki67-Expressionslevel des residuellen Tumorgewebes (positiver Tumoranteil Resektat) korreliert signifikant mit dem histopathologisch ermittelten Tumorregressionsgrad (TRG; $p<0,05)$.

Entgegengesetzt zeigt die prätherapeutisch erfasste Ki67-Expression (Positiver Tumoranteil $P E)$ keinen statistischen Zusammenhang mit dem TRG $(p>0,05)$. 


\subsubsection{Korrelation des Expressionslevels von Ki67 mit dem Nodalstatus und dem Auftreten} von Fernmetastasen

Die erfassten prä- und posttherapeutischen Ki67-Expressionslevel wurden mit dem Nodalstatus der Patienten korreliert. Die immunhistochemischen Daten von 190 Präparaten der PE und von 192 Präparaten der Rektumresektate sind in diese Berechnungen eingegangen. Es zeigt sich kein statistischer Zusammenhang zwischen dem Expressionsmuster des Zellproteins Ki67 und dem Befall regionärer LK mit Tumorabsiedlungen $(p>0,05)$.

Weiterhin wurde eine Korrelationsanalyse der Ki67-Expression mit dem M-Status der Patienten durchgeführt. Es zeigt sich der Trend, dass eine hohe Ki67-Expression im residuellen Tumorgewebe mit einer höheren Rate an Fernmetastasen einhergeht $(p<0,1$; siehe Abbildung 18). Bei insgesamt 14 der 150 neoadjuvant radiochemotherapierten Patienten wurden innerhalb des Nachbeobachtungszeitraumes Fernmetastasen diagnostiziert (siehe Abbildung 18).

Das prätherapeutische Ki67-Expressionslevel zeigt keine Korrelation mit dem M-Status der neoadjuvant therapierten Patientengruppen $(p>0,05)$.

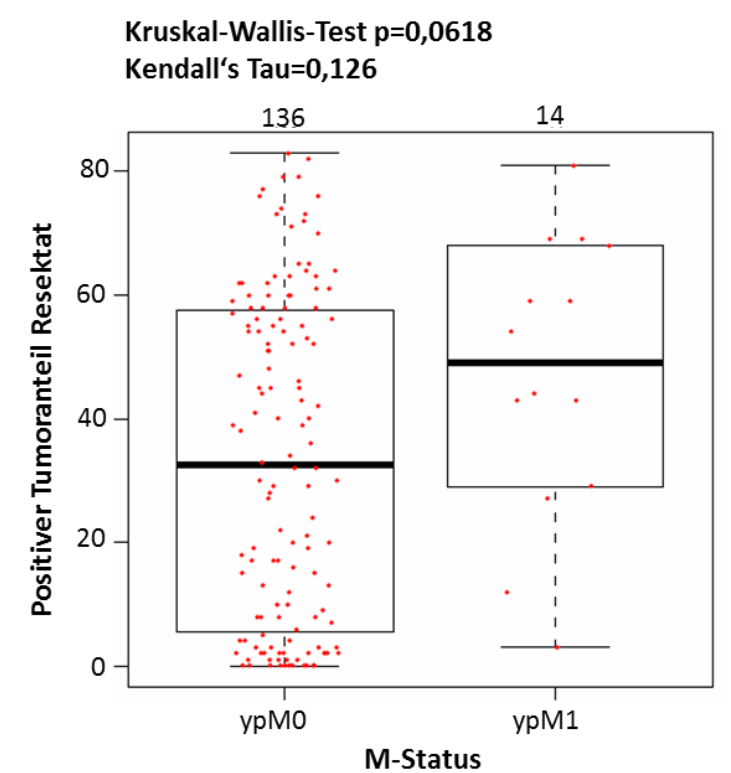

Abbildung 18: Korrelation des posttherapeutischen Ki67-Expressionslevels mit dem Metastasierungsstatus (M-Status) der neoadjuvant therapierten Patienten

Es zeigt sich, dass eine hohe Ki67-Expression im residuellen Tumor (Positiver Tumoranteil Resektat) nach neoadjuvanter RCT mit dem Auffinden von Fernmetastasen assoziiert zu sein scheint $(p=0,0681)$. 


\subsubsection{Korrelation des Expressionslevels von Ki67 mit dem krankheitsfreien Überleben und dem Karzinom-spezifischen Überleben}

Die immunhistochemisch ermittelte prä- und posttherapeutische Ki67-Expression wurde mit dem DFS und dem CSS korreliert, um ein therapieunabhängiges prädiktives oder prognostisches Potential des Proliferationsmarkers Ki67 aufzudecken. Für diese Berechnungen sind die Patienten in zwei Beobachtungsgruppen, entsprechend der Expressionsstärke des Proliferationsmarkers Ki67, eingeteilt. Patienten, welche einen positiven Tumoranteil von $<25 \%$ aufwiesen, werden einem normalen Ki67-Expressionslevel zugeordnet. Zeigte sich in der IHC in $\mathbf{2 5 \%}$ der Tumorzellkerne eine Anfärbung, liegt bei diesen Patienten eine Ki67-Überexpression vor. Diese Grenze findet regelmäßig als Cut-Off für die Ki67-Expression in Studien Anwendung (siehe Tabelle 12, Seite 78).

Es zeigte sich bei der Analyse der Überlebenswahrscheinlichkeit, in Einbeziehung des gesamten Patientenkollektivs, keine statistische Abhängigkeit des DFS oder des CSS mit dem Expressionsmuster von Ki67.

Bei der Berechnung der Überlebenswahrscheinlichkeiten der neoadjuvant therapierten Patientenkollektive konnten prätherapeutisch $14(8,8 \%)$ von insgesamt 159 Patienten in die Kohorte mit einer normalen Ki67-Expression einbezogen werden. Posttherapeutisch zeigten 62 (41,3\%) der insgesamt 150 Patienten ein normales Ki67-Expressionslevel im Gewebe des residuellen Tumors. Dabei ergibt sich, dass weder das DFS noch das CSS durch eine erhöhte beziehungsweise normale prä- oder posttherapeutische Expression von Ki67 signifikant beeinflusst werden. Bei Betrachtung der Kaplan-Meier-Kurve, welche das CSS in Abhängigkeit der gemessenen Ki67-Expression im residuellen Tumorgewebe darstellt, scheint es einen Überlebensvorteil innerhalb der Gruppe mit einem niedrigen Expressionslevel zwischen dem 20. Und 80. Nachbeobachtungsmonat zu geben. Allerdings unterscheiden sich die Endpunkte (>120 Monate) beider Graphen nicht (siehe Abbildung 19, Seite 62). 

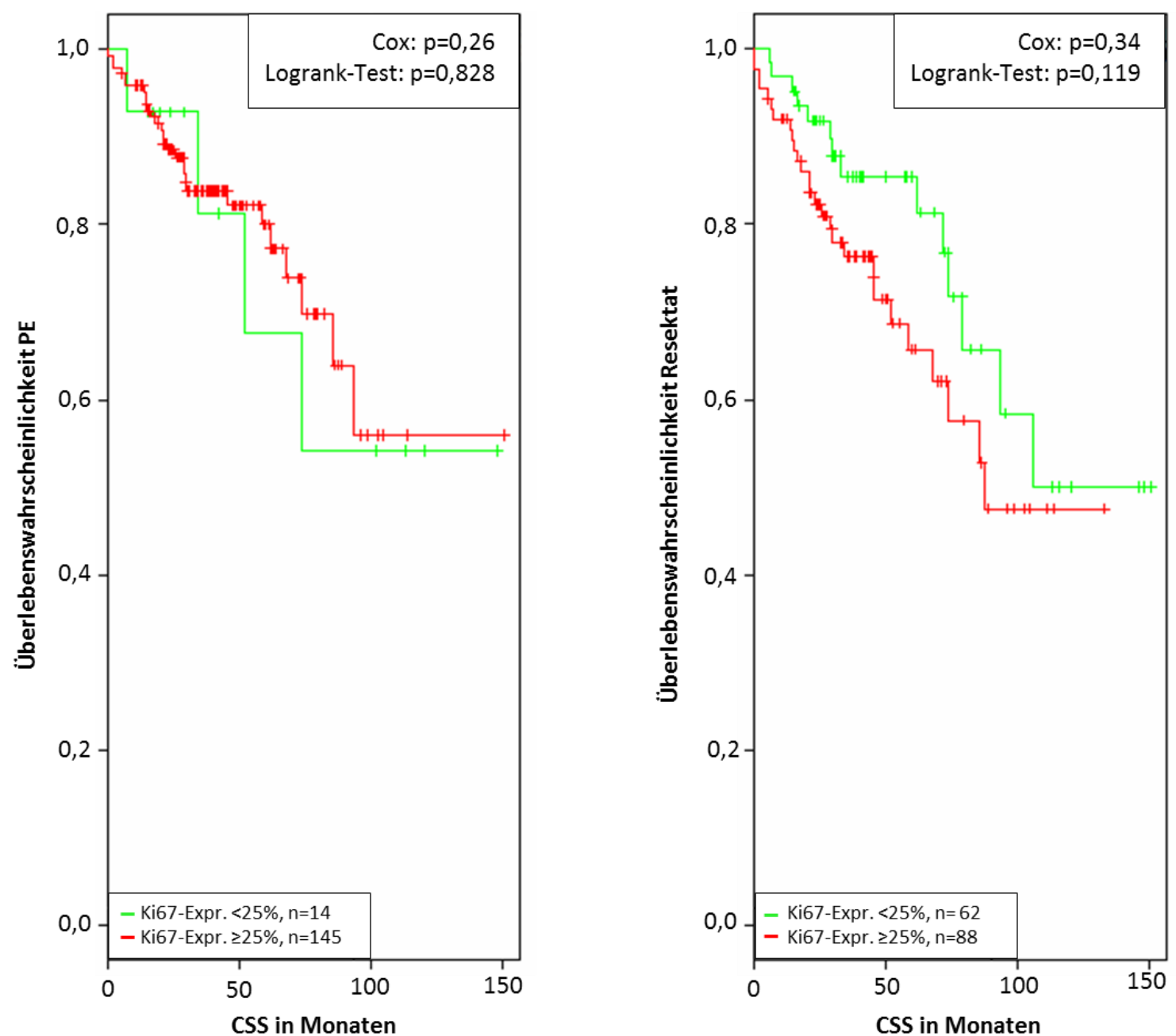

Abbildung 19: Kaplan-Meier-Kurven für das Karzinom-spezifische Überleben (CSS) in Abhängigkeit der prä- und posttherapeutischen Ki67-Expression

Es wird die Wahrscheinlichkeit gezeigt, welches Langzeitüberleben neoadjuvant therapierte Rektumkarzinompatienten mit einer normalen (grün) oder erhöhten (rot) Ki67-Expression haben. Die Erfassung des Expressionslevels erfolgte zum einen prätherapeutisch (Überlebenswahrscheinlichkeit PE) und zum anderen nach erfolgter RO-Resektion des Rektums (Überlebenswahrscheinlichkeit Resektat).

Die Endpunkte beider Graphen unterscheiden sich nicht ( $p>0,05)$. 


\section{Diskussion}

Die vorliegende Untersuchung verfolgt das Ziel die prädiktive und prognostische Relevanz von p53 und Ki67 beim lokal fortgeschrittenen Rektumkarzinom (cUICC-II/III) zu untersuchen. Diese Studie umfasst das bislang größte und standardisierteste Patientenkollektiv zu dieser Fragestellung. Die Studienlage, die zum Anfertigungszeitpunkt dieser Arbeit vorliegt, stellt sich in ihren Ergebnissen sehr heterogen dar, basiert auf limitierten Fallzahlen mit uneinheitlicher Methodik und bezieht sich zumeist auf Biomarkeranalysen bei Kolonkarzinomen. Laut aktuellem Wissensstand ist davon auszugehen, dass es sich bei Kolon- und Rektumkarzinomen um unterschiedliche Tumorentitäten handelt, welche vor allem auch unterschiedliche multimodale Therapieregime erfordern (Li und Lai 2009, Li et al. 2012, Hong et al. 2012). Aus diesem Grund werden nachfolgend nur Studien erwähnt und in die Auswertung einbezogen, die ausschließlich Patienten mit einer Tumorlokalisation im Rektum untersucht haben. Eine Übersicht über die aktuelle Studienlage, welche zum Zeitpunkt dieser Arbeit vorlag, geben die Tabellen 11 und 12 (siehe Seite 70 und 78).

Alle Patienten, deren Biomaterial in der vorliegenden Arbeit immunhistochemisch analysiert wurde, wurden innerhalb großer multizentrischer Phase-III-Studien der GRCSG oder analog zu diesen therapiert. Dies erlaubt eine erstmalige Prüfung der untersuchten Biomarker unter unterschiedlichen Therapieregimen.

\subsection{Klinikopathologische Parameter des Patientenkollektives}

Das Therapieregime gliedert das Patientenkollektiv in drei Behandlungsgruppen. Die Kontrollgruppe wurde primär operiert und erhielt eine adjuvante RCT im Rahmen der CAO/ARO/AIO-94-Studie oder eine adjuvante CTx im Rahmen der GAST-05-Studie. Die anderen beiden Behandlungsgruppen wurden einer neoadjuvanten RCT zugeführt (RCT mit 5-FU oder RCT mit 5-FU und Oxaliplatin).

Um die Vergleichbarkeit innerhalb der Gruppen gewährleisten zu können, wurden die klinikopathologischen Parameter des Patientenkollektivs einander gegenübergestellt. Es zeigt sich ein signifikanter Unterschied in der Verteilung der Tumorhöhe auf die Behandlungsgruppen. So befinden sich in den beiden Kohorten, die eine neoadjuvante 
Therapie erhalten haben, zum größten Teil Tumorlokalisationen in den unteren beiden Rektumdritteln (siehe Tabelle 3, Seite 21). Begründet wird dies durch die verabreichten Therapieregime. Alle Patienten wurden im Rahmen großer multizentrischer Phase-III-Studie oder analog zu diesen therapiert. Eine dieser Studie ist die CAO/ARO/AIO-04-Studie, welche den Einfluss einer intensivierten RCT, bestehend aus einer systemischen Gabe von 5-FU und Oxaliplatin mit begleitender RT, auf das CSS untersucht (Rödel C et al. 2012). In dieser Studie sind keine Patienten mit einer Tumorlokalisation im oberen Rektumdrittel eingeschlossen. Grund hierfür sind Ergebnisse vorrangegangener Untersuchungen. Eine TME-Studie aus Holland zeigt, dass eine präoperative RCT wenig Einfluss auf die lokale Tumorkontrolle von Adenokarzinomen im oberen Rektumdrittel nimmt (van Kapiteijn et al. 2001). Die MRCCR07-Studie erfasst eine unterschiedliche Sensitivität von Tumoren der verschiedenen Rektumdrittel gegenüber einer RCT (Sebag-Montefiore 2006). Es finden sich somit in der Literatur Hinweise, dass bei Tumorlokalisation im oberen Rektumdrittel eine primäre Operation erfolgen sollte. Durch die Ergebnisse dieser vorrangegangenen Untersuchungen sind in die CAO/ARO/AIO-04-Studie nur sehr wenige Patienten mit einer Tumorlokalisation $>10 \mathrm{~cm}$ von der Anokutanlinie eingeschlossen (Rödel C et al. 2012). Daraus ergibt sich der signifikante Unterschied in der Verteilung der Tumorlokalisationen in dem hier vorliegendem Patientenkollektiv $(p=0.04)$.

Bei der Gegenüberstellung der klinikopathologischen Parameter stellt sich weiterhin ein signifikanter Unterschied in der Rate des negativen Nodalstatus heraus $(p=0,02$; siehe Tabelle 7, Seite 46). In der primär operierten Kohorte zeigt die histopathologische Aufarbeitung bei $27,9 \%$ einen pN2-Status. Dem gegenüber zeigen nur 11,1\% der 5-FU-MonoGruppe einen ypN2-Status. Die niedrigste Rate $(8,1 \%)$ an einem Befall von vier oder mehr LK, entsprechend ypN2, findet sich in der Kohorte, die zusätzlich mit Oxaliplatin behandelt wurde (siehe Tabelle 7, Seite 46). Dieser Unterschied zeigte sich in den StagingUntersuchungen nicht ( $p=0,14$; siehe Tabelle 3, Seite 21). Dies stellt einen starken Hinweis auf eine Einflussnahme einer neoadjuvanten RCT auf das Vorhandensein von Tumorabsiedlungen in regionären LK dar. Die Verabreichung einer intensivierten RCT mit einer Kombination von 5-FU und Oxaliplatin (entsprechend dem FOLFOX-Schema) scheint, nach Analyse des untersuchten Patientenkollektivs, am stärksten das Auftreten von Lymphknotenmetastasen zu verhindern. Zum jetzigen Zeitpunkt stellt der Nodalstatus den stärksten prognostischen Faktor auf das Langzeitüberleben bei Patienten mit einem 
Adenokarzinom des Rektums dar. Ob sich durch die Oxaliplatin-induzierte Senkung der Rate an LK-Metastasen ein Vorteil für das CSS dieses Patientenkollektives ergibt, muss aus der Beobachtung des Langzeitverlaufs geschlossen werden (Rödel C et al. 2012). In der MOSAICStudie konnte ein positiver Einfluss von Oxaliplatin auf die Prognose von Kolonkarzinompatienten belegt werden. So erhöht sich bei Verabreichung einer adjuvanten Oxaliplatin-haltigen CT das 5-Jahres DFS und das 6-Jahres OS signifikant (Andre et al. 2009).

\subsection{Quantitative Immunhistochemie mittels zweier Auswerteverfahren}

Bei der Analyse der immunhistochemischen Präparate wurden zwei Parameter quantitativ ausgewertet: der prozentual positive Tumoranteil, sowie die Intensität der Kernanfärbung. Diese Parameter wurden zweifach erhoben - zuerst konventionell-manuell und anschließend mit Anwendung des DIA VIAS. Insgesamt konnten die immunhistochemischen Daten von 772 Präparaten zur Evaluierung des DIA herangezogen werden. Die Korrelation der erhobenen Datensätze ergab eine sehr starke Korrelation der erfassten Daten beider Auswerteverfahren (siehe Kapitel 3.3, Seite 48). Lediglich bei der Erfassung der Färbeintensitäten kann sich ein Unterschied zeigen. Dies begründet sich darin, dass es dem Betrachter bei dem konventionell-manuellen Auswerteverfahren nur möglich ist, die Intensität der Anfärbung in 4 Grade abzugrenzen. DIA sind in der Lage mit einer viel höheren Sensitivität die Intensität der Färbung zu unterscheiden. So wird eine genauere Abgrenzung zwischen den verschiedenen Intensitäten ermöglicht. Für die vorliegenden nukleären Färbungen ist dies jedoch von geringerer Relevanz, da die statistischen Auswertungen keinen Unterschied zwischen den statistischen Berechnungen mit den erfassten positiven Tumoranteilen oder mit der detektierten Färbeintensität ergaben. Bei der immunhistochemischen Analyse zytoplasmatischer Zellproteine ist es dagegen von höherer Bedeutung, eine möglichst genau differenzierte Beurteilung der Färbeintensität zu erfassen. Auch bei diesen Fragestellungen könnte dieses Observer-unabhängige Verfahren zukünftig Vorteile liefern.

Laut Seidal et al. (2001) resultieren Diskrepanzen zwischen pathologischen Befunderhebungen immunhistochemischer Färbungen aus methodischen Unterschieden und vor allem aus einer unterschiedlichen Interpretation der Färbeergebnisse. Bislang steht eine Festsetzung von verbindlichen Analysekriterien für immunhistochemische Färbungen 
aus (Seidal et al. 2001). Daraus resultiert eine hohe Varianz der Auswerteverfahren von Biomarkerexpressionen (siehe Tabelle 11 und 12, Seite 70 und 78). Zudem gestaltet sich die konventionell-manuelle Quantifizierung immunhistochemischer Daten häufig als umständlich, zeitaufwendig und fordert ein hohes Maß an Erfahrung vom Observer ein (Taylor und Levenson 2006). Es ergibt sich daraus eine sehr hohe Intra- und Interobservervariabilität immunhistochemischer Analysen (Slodkowska und Rojo 2011). Da die IHC eine immense Wichtigkeit in der klinischen Routinediagnostik besitzt, einen besonderen Stellenwert in der Tumorhistologie einnimmt und flächendeckend Anwendung findet, muss diese Problematik gelöst werden. Schlussfolgernd aus den Ergebnissen der vorliegenden Untersuchung ist festzustellen, dass dieses DIA vergleichbare Daten, wie eine konventionell-manuelle Präparatanalyse liefert. Entscheidend sind jedoch die festdefinierten Analysekriterien, die eine konstant-hohe Präzision sicherstellen und somit eine weitgehend Observer-unabhängige Analyse gewährleisten. Eine schnellere Befunderhebung mit gleichzeitiger Archivierung der Befundlokalisation eignet sich besonders bei hohen Fallzahlen. Weiterhin zeigt sich eine gute Reproduzierbarkeit der Ergebnisse. Die Problematik der Intra- und Interobservervariabilität könnte durch die Etablierung solcher oder ähnlicher Analysesysteme gelöst werden. So kann der Einsatz von DIA bei immunhistochemischen Analysen zu einer besseren Vergleichbarkeit verschiedener IHCAuswertungen beitragen.

Digitale Bildanalysesysteme ermöglichen eine schnellere, sensitivere und hoch-objektive Messung von Proteinexpressionen (Slodkowska und Rojo 2011). Besonders bei Untersuchungen, die eine hohe Fallzahl aufweisen ist dies von immenser Wichtigkeit. Der Einsatz DIA kann gerade bei translationalen Forschungsvorhaben zur Detektion neuer molekularer Biomarker beitragen.

\subsection{Das prädiktive und prognostische Potential von p53 im lokal fortgeschrittenen Rektumkarzinom}

\subsubsection{Prädiktion des Therapierespons gemessen am (y)pTNM-Status und dem TRG} In der vorliegenden Untersuchung konnte keine Einflussnahme einer neoadjuvanten RCT auf das Expressionslevel von p53 gezeigt werden. In jeder Behandlungsgruppe zeigt sich ein 
gleich hohes und konstantes prä- beziehungsweise posttherapeutisches Expressionslevel des Tumorsuppressors (siehe Abbildung 13, Seite 53).

Es konnte keine Korrelation der Tumorregression nach Verabreichung einer lokalen Therapie mit dem Expressionslevel des Tumorsuppressorproteins p53 ermittelt werden. Eine Übersicht über die aktuelle Studienlage zu dieser Fragestellung zeigt die untenstehende Tabelle (siehe Tabelle 11, Seite 70). Die Autoren dieser Studien vertreten mehrheitlich die Meinung, dass es zu keiner Beeinflussung des Therapieansprechens durch den Grad der prätherapeutischen Expression von p53 kommt. Die Ergebnisse der vorliegenden Arbeit unterstreichen somit die aktuelle Studienlage. Dem widersprechend, vertreten einzelne Autoren die Meinung, dass eine Einflussnahme auf das lokale Therapieansprechen durch eine p53-Überexpression existiert. Luna-Perez et al. (1998) untersuchten ebenfalls das prädiktive Potential der p53-Expression im Gewebe von Rektumresektaten und konnten aus ihren Ergebnissen schlussfolgern, dass Tumore, welche ein hohes Level an p53 exprimieren, einen geringeren TRG und einen höheren pT-Status zeigen. Spitz et al. (1997) belegen ebenfalls den Zusammenhang eines hohen prätherapeutischen p53-Expressionslevels mit einer geringeren Tumorregression nach neoadjuvanter Therapie. Unterstützend zu diesen Ergebnissen zeigen Suzuki et al. (2004) einen statistischen Zusammenhang, zwischen dem Vorliegen von p53-negativen Tumoren, mit einem guten Ansprechen auf die verabreichte zytostatische Therapie. Dem entgegengesetzt postulieren Esposito et al. (2001) mit ihren Untersuchung ein besseres Therapieansprechen, gemessen am Grad der Tumorregression, bei Vorliegen einer posttherapeutischen p53-Überexpression. Die dargelegte Heterogenität der Studienlage lässt sich möglicherweise mit methodischen Unterschieden (unterschiedliche Cut-Off-Levels, uneinheitliche Analysekriterien) und den stets kleinen Fallzahlen begründen (siehe Tabelle 11, Seite 70). Dieser Umstand lässt an der Reproduzierbarkeit und somit an der Repräsentierbarkeit der Daten zweifeln. Weiterhin ist festzuhalten, dass immunhistochemische Analysen keine Aussage über den Funktionsstatus des p53-Proteins liefern. Ein Wildtyp-p53-Protein weist eine sehr niedrige Halbwertszeit von rund 15 Minuten auf und wird im gesunden Gewebe sehr schnell abgebaut (NasierowskaGuttmejer et al. 2000). Daraus resultiert ein konstant niedriger p53-Zellspiegel, was mit einer unzureichenden Anfärbbarkeit von p53 in gesundem Gewebe einhergeht. Bei bis zu 50\% aller KRK liegen inaktivierende Mutationen des p53-Gens vor (Peinado et al. 1993, Jemal et al. 2011). Der Großteil dieser Punktmutationen befinden sich im Bereich der 
Proteinbindungsdomäne (Nasierowska-Guttmejer et al. 2000). Dies bewirkt eine Konformationsänderung des Moleküls, woraus eine gesteigerte Stabilität und eine Verlängerung der Halbwertszeit auf bis zu 20 Stunden resultiert (Kerns et al. 1992, Nasierowska-Guttmejer et al. 2000). Die sich anschließende Akkumulation von p53 im Zellkern ermöglicht eine immunhistochemische Darstellung (Kerns et al. 1992). Dessen ungeachtet können aber auch andere, bislang unbekannte Mechanismen zu einer p53Akkumulation im Zellkern führen. Bosari et al. (1995) fanden in rund 30\% der Fälle, trotz bestehender Akkumulation im Zellkern, keine Mutation des p53-Gens. Ebenfalls konnten Nasierowska-Guttmejer et al. (2000) in ihren Untersuchungen die Diskrepanz einer existierenden Überexpression von p53 und dem Vorliegen einer inaktivierenden Mutation bei $29 \%$ ihres untersuchten Kollektives belegen.

In dieser Untersuchung konnte für das Auffinden von Lymphknoten- oder Fernmetastasen kein prädiktives Potential des Expressionsstatus von p53 ermittelt werden. Bislang konnte auch in keiner anderen Untersuchung eine Einflussnahme bestätigt werden.

Die von mir erhobenen Daten deuten darauf hin, dass das p53-Expressionlevel keinen Einfluss auf den Therapierespons einer neoadjuvanten RCT nimmt und unterstreichen damit die mehrheitlich postulierten Meinungen in der Literatur. Jedoch gibt es auch Untersuchungen mit abweichenden Ergebnissen. Um das prädiktive Potential des Tumorsuppressors endgültig zu klären, bedarf es weiterer Studien, die Rücksicht auf den Vorliegenden Funktionsstatus des p53-Proteins nehmen. Ein prädiktiver Nutzen für den klinischen Alltag lässt sich zum jetzigen Zeitpunkt aus den von mir erhobenen Daten nicht ableiten.

\subsubsection{Das prognostisches Potential von p53 gemessen an den Follow-up-Daten}

Um das prognostische Potential der p53-Expression beurteilen zu können, wurden Korrelationsanalysen mit den erfassten Follow-up-Daten der Patienten durchgeführt. Anhand der erhobenen Kaplan-Meier-Kurven konnte kein Zusammenhang zwischen dem Expressionslevel von p53 und dem CSS oder dem DFS der Patienten gezeigt werden. Weder das prä-, noch das posttherapeutische p53-Expressionslevel der Karzinomzellen ließ einen Zusammenhang mit einem besonders aggressiven Tumorwachstum oder einer schlechten Prognose eines Patienten zu. Saw et al. (2003) schlossen aus ihren Untersuchungen, dass es auch zukünftig problematisch sei, eine Vorhersage über die individuelle Prognose eines 
Patienten zu treffen. Auch sie konnten kein prognostisches Potential für das Expressionslevel von p53 beziehungsweise für den Nachweis inaktivierender Mutationen belegen. Ähnliche Ergebnisse ergaben die Untersuchungen von Rödel F et al. (2002), Lebe et al. (2005), oder Fucini et al. (2012; siehe Tabelle 11Tabelle 11, Seite 70). Somit unterstreichen die von mir erhobenen Ergebnisse die derzeitige Datenlage. Aktuell konnten nur Seicean et al. (2011) ein prognostisches Potential des Tumorsuppressors p53 zeigen. Aus dieser Studie geht hervor, dass p53-überexprimierte Tumore mit einem verkürzten DFS und CSS einhergehen (siehe Tabelle 11, Seite 70). Diese Untersuchung umfasst 87 Patienten, welche einer primären Resektion des Rektums und keiner neoadjuvanten RCT zugeführt wurden. Der negative prognostische Effekt einer p53-Überexpression im primär operierten Patientenkollektiv findet sich auch in den vorliegenden Berechnungen wieder (siehe Kapitel 3.4.4, Seite 55). Die unterschiedlichen Endpunkte der zwei Beobachtungsgruppen sind jedoch aufgrund der geringen Fallzahl nicht signifikant $(p=0,117)$. Eine Erklärung für dieses negativ-prognostische Potential könnte ein Vorliegen einer inaktivierenden Mutation, die mit einer Akkumulation von p53 im Zellkern einhergeht, sein. Ein Funktionsverlust von p53 trägt schon laut der ,Adenom-Karzinom-Sequenz' nach Vogelstein (Fearon und Vogelstein 1990) zu einer Entwicklung eines neoplastischen Potentials einer Zelle bei.

Es gilt als unbestritten, dass der Verlust von p53 eine entscheidende Rolle bei der Entwicklung maligner Zelleigenschaften spielt. Trotzdem scheint zum aktuellen Zeitpunkt der Tumorsuppressor p53 nicht als Biomarker zur Einschätzung des individuellen Erkrankungsprofils bei Patienten mit einem lokal fortgeschrittenen Rektumkarzinom in der klinischen Routinediagnostik geeignet zu sein. 


\begin{tabular}{|c|c|c|c|c|c|}
\hline \multicolumn{6}{|c|}{ Analysen der Expression von p53 in Adenokarzinomen des Rektums } \\
\hline Autor & Fallzahl & Methode & Therapie & $\begin{array}{l}\text { Untersuchte } \\
\text { Endpunkte }\end{array}$ & Ergebnisse \\
\hline $\begin{array}{l}\text { Kudrimoti et al. } \\
2007\end{array}$ & $\mathrm{n}=17$ & IHC; Einteilung der Expression in 4 Grade & neoadj. RCT (5-FU) & CR o. PR & n. s. \\
\hline $\begin{array}{l}\text { Jakob et al. } \\
2008\end{array}$ & $\mathrm{n}=22$ & $\begin{array}{l}\text { IHC; p53-Expression positiv wenn } \geq 10 \% \\
\text { der Zellkerne angefärbt }\end{array}$ & neoadj. RCT (5-FU) & TRG & n. s. \\
\hline $\begin{array}{l}\text { Scott et al. } \\
1998\end{array}$ & $n=22$ & $\begin{array}{l}\text { IHC; positiv, wenn } 1 / 3 \text { aller Zellkerne } \\
\text { angefärbt }\end{array}$ & $\begin{array}{l}\text { neoadj. RCT ( } 5-\mathrm{FU} / \\
\text { Leukovorin) }\end{array}$ & TRG & n.s. \\
\hline Kim et al. 2001 & $n=23$ & $\begin{array}{l}\text { IHC; p53-Expression positiv wenn } \geq 10 \% \\
\text { der Zellkerne angefärbt, Einteilung der } \\
\text { Expression in } 4 \text { Grade }\end{array}$ & $\begin{array}{l}\text { neoadj. RCT ( } 5 \text {-FU/ } \\
\text { Leukovorin) }\end{array}$ & CR o. PR o. NR & n. s. \\
\hline $\begin{array}{l}\text { Okonkwo et al. } \\
2001\end{array}$ & $n=25$ & $\begin{array}{l}\text { IHC; p53-Expression positiv wenn } \geq 10 \% \\
\text { der Zellkerne angefärbt }\end{array}$ & neoadj. RCT (5-FU) & $\begin{array}{l}\text { pos./neg. } \\
\text { Ansprechrate }\end{array}$ & n. s. \\
\hline $\begin{array}{l}\text { Luna-Perez et } \\
\text { al. } 1998\end{array}$ & $n=26$ & $\begin{array}{l}\text { IHC; p53-Expression positiv wenn } \geq 10 \% \\
\text { der Zellkerne angefärbt, Einteilung der } \\
\text { Färbeintensität in } 5 \text { Grade }\end{array}$ & neoadj. RCT (5-FU) & TRG & $\begin{array}{l}\text { p53-positive } \\
\text { Rektumresektate zeigen } \\
\text { eine geringere } \\
\text { Regression und einen } \\
\text { höheren ypT-Status }\end{array}$ \\
\hline $\begin{array}{l}\text { Tannapfel et al. } \\
1998 \text { (a) }\end{array}$ & $n=26$ & $\begin{array}{l}\text { IHC;p-53-Expression positiv wenn } \\
\text { Zellkerne angefärbt }\end{array}$ & neoadj. RCT (5-FU) & $\begin{array}{l}\text { LR; } \\
\text { Downstaging } \\
\text { des T-Status }\end{array}$ & n. s. \\
\hline $\begin{array}{l}\text { Reerink et al. } \\
2004\end{array}$ & $\mathrm{n}=34$ & $\begin{array}{l}\text { IHC; p53-Expression positiv wenn } \geq 5 \% \text { der } \\
\text { Zellkerne angefärbt, Einteilung der } \\
\text { Färbeintensität in } 4 \text { Grade }\end{array}$ & $\begin{array}{l}\text { neoadj. RCT ( } 5 \text {-FU/ } \\
\text { Leukovorin) }\end{array}$ & pT-Status & n. s. \\
\hline $\begin{array}{l}\text { Terzi et al. } \\
2008\end{array}$ & $n=37$ & $\begin{array}{l}\text { IHC; p53-Expression positiv wenn } \geq 10 \% \\
\text { der Zellkerne angefärbt }\end{array}$ & neoadj. RCT (5-FU) & $\begin{array}{l}\text { TRG; } \\
\text { Downstaging } \\
\text { des T- und N- } \\
\text { Status }\end{array}$ & n. s. \\
\hline
\end{tabular}




\begin{tabular}{|c|c|c|}
\hline $\begin{array}{l}\text { Esposito et al. } \\
2001\end{array}$ & $n=38$ & $\begin{array}{l}\text { IHC; p53-Expression positiv wenn }>10 \% \\
\text { der Zellkerne angefärbt, Einteilung der } \\
\text { Expression in } 4 \text { Grade }\end{array}$ \\
\hline $\begin{array}{l}\text { Moral et al. } \\
2009\end{array}$ & $n=39$ & $\begin{array}{l}\text { IHC; p53-Expression positiv wenn } \geq 10 \% \\
\text { der Zellkerne angefärbt, Einteilung des } \\
\text { Expressionslevels in } 3 \text { Grade }\end{array}$ \\
\hline $\begin{array}{l}\text { Spitz et al. } \\
1997\end{array}$ & $n=42$ & $\begin{array}{l}\text { IHC; p53-Expression fokal-positiv wenn } 10 \text { - } \\
50 \% \text { der Zellkerne angefärbt, p53- } \\
\text { Expression positiv wenn }>50 \% \text { der } \\
\text { Zellkerne angefärbt }\end{array}$ \\
\hline $\begin{array}{l}\text { Lebe et al. } \\
2005\end{array}$ & $n=45$ & $\begin{array}{l}\text { IHC; p53-Expression positiv wenn }>5 \% \text { der } \\
\text { Zellkerne angefärbt }\end{array}$ \\
\hline $\begin{array}{l}\text { Charara et al. } \\
2004\end{array}$ & $n=47$ & $\begin{array}{l}\text { IHC; p53-Expression positiv wenn >50\% } \\
\text { der Zellkerne angefärbt }\end{array}$ \\
\hline $\begin{array}{l}\text { Elsaleh et al. } \\
2000\end{array}$ & $n=48$ & $\begin{array}{l}\text { IHC; p53-Expression positiv wenn } \geq 5 \% \text { der } \\
\text { Zellkerne angefärbt } \\
\text { PCR/DNA; Detektion von p53-Mutationen }\end{array}$ \\
\hline $\begin{array}{l}\text { Rödel F et al. } \\
2002\end{array}$ & $n=54$ & $\begin{array}{l}\text { IHC; p53-Expression positiv wenn } \geq 10 \% \\
\text { der Zellkerne angefärbt }\end{array}$ \\
\hline $\begin{array}{l}\text { Negri et al. } \\
2008\end{array}$ & $n=57$ & $\begin{array}{l}\text { IHC; p53-Expression positiv wenn } \geq 10 \% \\
\text { der Zellkerne angefärbt }\end{array}$ \\
\hline Saw et al. 2003 & $n=58$ & $\begin{array}{l}\text { IHC; positiv sobald eine Zellkernanfärbung } \\
\text { detektiert wurde, prozentual positiver } \\
\text { Tumoranteil } \\
\text { PCR/DNA; Detektion von p53-Mutationen }\end{array}$ \\
\hline
\end{tabular}

\begin{tabular}{|c|c|c|}
\hline $\begin{array}{l}\text { neoadj. RCT (5-FU/ } \\
\text { Leukovorin) oder neoadj. RT }\end{array}$ & $\begin{array}{l}\text { TRG; } \\
\text { Downstaging } \\
\text { des T-Status }\end{array}$ & $\begin{array}{l}\text { p53-positive } \\
\text { Rektumresektate sind } \\
\text { mit höherer Regression } \\
\text { assoziiert }\end{array}$ \\
\hline neoadj. RCT (5-FU/Leukovorin) & OS/DFS & n. s. \\
\hline neoadj. RCT (5-FU) & TRG & $\begin{array}{l}\text { prätherap. } \\
\text { Überexpression von p53 } \\
\text { geht mit geringeren } \\
\text { Regression einher }\end{array}$ \\
\hline $\begin{array}{l}\text { primäre Rektumresektion; ggf. } \\
\text { adjuvante RCT }\end{array}$ & $\begin{array}{l}\text { DFS; LR; TNM- } \\
\text { Status }\end{array}$ & n. s. \\
\hline neoadj. RCT (5-FU/ Irinotecan) & CR o. PR & n. s. \\
\hline neoadj. RCT (5-FU) & CR o. PR o. NR & n. s. \\
\hline neoadj. RCT (5-FU) & $\begin{array}{l}\text { DFS;LR; Rate an } \\
\text { Fernmetastase } \\
n\end{array}$ & n. s. \\
\hline $\begin{array}{l}\text { neoadj. RCT (5-FU/ Oxaliplatin) } \\
\text { oder neoadj. RT }\end{array}$ & $\begin{array}{l}\text { positive/nega- } \\
\text { tive } \\
\text { Ansprechrate }\end{array}$ & n. s. \\
\hline $\begin{array}{l}\text { neoadj. RCT (5-FU/ } \\
\text { Leukovorin) oder neoadj. RT }\end{array}$ & $\begin{array}{l}\text { TRG; CSS; LR; } \\
\text { Downstaging } \\
\text { des T-Status }\end{array}$ & n. s. \\
\hline
\end{tabular}




\begin{tabular}{|c|c|c|}
\hline Rau et al. 2003 & $n=65$ & $\begin{array}{l}\text { IHC; Erfassung des prozentual positiven } \\
\text { Tumoranteils von } 0-100 \% \text {, Einteilung der } \\
\text { Färbeintensität in } 4 \text { Grade } \\
\text { PCR/DNA; Detektion von p53-Mutationen }\end{array}$ \\
\hline $\begin{array}{l}\text { Andrade et al. } \\
2011\end{array}$ & $n=61$ & $\begin{array}{l}\text { IHC; p53-Expression positiv wenn } \geq 10 \% \\
\text { der Zellkerne angefärbt }\end{array}$ \\
\hline $\begin{array}{l}\text { Fucini et al. } \\
2012\end{array}$ & $n=67$ & IHC; Expressionslevel in 3 Grade eingeteilt \\
\hline $\begin{array}{l}\text { Brophy et al. } \\
2009\end{array}$ & $n=69$ & $\begin{array}{l}\text { IHC; p53-Expression positiv wenn } \geq 10 \% \\
\text { der Zellkerne angefärbt }\end{array}$ \\
\hline Lin et al. 2006 & $n=70$ & $\begin{array}{l}\text { IHC; p53-Expression positiv wenn } \geq 5 \% \text { der } \\
\text { Zellkerne angefärbt }\end{array}$ \\
\hline Díez et al. 2003 & $n=73$ & $\begin{array}{l}\text { IHC; p53-Expression positiv wenn } \geq 10 \% \\
\text { der Zellkerne angefärbt, Einteilung des } \\
\text { Expressionslevels in } 4 \text { Grade }\end{array}$ \\
\hline $\begin{array}{l}\text { Seicean et al. } \\
2011\end{array}$ & $n=87$ & $\begin{array}{l}\text { IHC; p53-Expression positiv wenn } \geq 10 \% \\
\text { der Zellkerne angefärbt }\end{array}$ \\
\hline $\begin{array}{l}\text { García et al. } \\
2011\end{array}$ & $n=88$ & $\begin{array}{l}\text { IHC; p53-Expression positiv wenn } \geq 50 \% \\
\text { der Zellkerne angefärbt }\end{array}$ \\
\hline
\end{tabular}

\begin{tabular}{|c|c|c|}
\hline $\begin{array}{l}\text { neoadj. RCT ( } 5-\mathrm{FU} / \\
\text { Leukovorin) }\end{array}$ & CR o. PR; DFS & n. s. \\
\hline $\begin{array}{l}\text { neoadj. RCT (5-FU) } \\
\text { adj. RCT (5-FU) }\end{array}$ & TRG; OS & n. s. \\
\hline $\begin{array}{l}\text { primäre Rektumresektion, ggf. } \\
\text { adj. RCT (5-FU/ Leukovorin); } \\
\text { neoadj. RCT (5-FU/ } \\
\text { Leukovorin) }\end{array}$ & DFS; LR & n. s. \\
\hline neoadj. RCT (5-FU) & TRG & n. s. \\
\hline neoadj. RCT (5-FU) & $\begin{array}{l}\text { DFS; } \\
\text { Downstaging } \\
\text { des T-Status }\end{array}$ & $\begin{array}{l}\text { prätherap. niedrige p53- } \\
\text { Expression ist assoziiert } \\
\text { mit einer höheren Rate } \\
\text { an mittlerem } \\
\text { Ansprechen }\end{array}$ \\
\hline $\begin{array}{l}\text { neoadj. RCT (5-FU/UFT/ } \\
\text { Folinsäure) }\end{array}$ & $\begin{array}{l}\text { TRG; ypN- } \\
\text { Status }\end{array}$ & n. s. \\
\hline primäre Rektumresektion & DFS; CSS & $\begin{array}{l}\text { p53-postive } \\
\text { Rektumresektate sind } \\
\text { assoziiert mit einem } \\
\text { verkürzten CSS/DFS }\end{array}$ \\
\hline $\begin{array}{l}\text { neoadj. RCT (UFT/Oxaliplatin/ } \\
\text { Capecitabine) }\end{array}$ & TRG; DSF & n. s. \\
\hline
\end{tabular}




\begin{tabular}{|c|c|c|c|c|c|}
\hline $\begin{array}{l}\text { Suzuki et al. } \\
2004\end{array}$ & $n=93$ & $\begin{array}{l}\text { IHC; p53-Expression positiv wenn } \geq 35 \% \\
\text { der Zellkerne angefärbt }\end{array}$ & neoadj. RT & TRG & $\begin{array}{l}\text { p53-negative } \\
\text { Rektumresektate } \\
\text { korrelieren mit einem } \\
\text { höheren TRG }\end{array}$ \\
\hline $\begin{array}{l}\text { Shinto et al. } \\
2011\end{array}$ & $n=96$ & $\begin{array}{l}\text { IHC; p53-Expression positiv wenn } \geq 10 \% \\
\text { der Zellkerne angefärbt }\end{array}$ & neoadj. RCT (Tegafur/Uracil) & TRG & n. s. \\
\hline $\begin{array}{l}\text { Chang et al. } \\
2005\end{array}$ & $n=130$ & $\begin{array}{l}\text { IHC; p53-Expression positiv wenn } \geq 10 \% \\
\text { der Zellkerne angefärbt }\end{array}$ & $\begin{array}{l}\text { neoadj. RCT (5- } \\
\text { FU/Capecitabine); ggf. adj. CT } \\
\text { (5-FU/ Leukovorin) }\end{array}$ & TRG & n. s. \\
\hline $\begin{array}{l}\text { Edden et al. } \\
2012\end{array}$ & $n=152$ & $\begin{array}{l}\text { IHC; Einteilung des Expressionslevels in } 4 \\
\text { Grade }\end{array}$ & $\begin{array}{l}\text { neoadj. RCT (5-FU/ } \\
\text { Capecitabine) }\end{array}$ & $\begin{array}{l}\text { TRG; } \\
\text { Downstaging } \\
\text { des T-Status }\end{array}$ & n. s. \\
\hline $\begin{array}{l}\text { vorliegende } \\
\text { Untersuchung } \\
2013\end{array}$ & $n=225$ & $\begin{array}{l}\text { IHC; Erfassung des positiven Tumoranteils } \\
\text { und der Färbeintensität mit Hilfe eines DIA }\end{array}$ & $\begin{array}{l}\text { primäre Rektumresektion; } \\
\text { neoadj. RCT (mit 5-FU oder 5- } \\
\text { FU/Oxaliplatin)* }\end{array}$ & $\begin{array}{l}\text { klinikopatholo- } \\
\text { gische } \\
\text { Paramater; } \\
\text { DFS; CSS; LR- } \\
\text { Rate; Auftreten } \\
\text { von } \\
\text { Metastasen }\end{array}$ & n. s. \\
\hline
\end{tabular}

\section{Tabelle 11: Übersicht über die aktuelle Studienlage zum Thema der p53-Expression in Adenokarzinomen des Rektums}

Diese Tabelle bezieht sich nur auf Untersuchungen, welche ausschließlich Patienten mit einer Tumorlokalisation im Rektum einschließen. Tabelle modifiziert nach Kuremsky et al. 2009, Seite 675.

(adj. - adjuvant, CR - komplette Regression, CSS - Karzinom-spezifisches Überleben, DFS - krankheitsfreies Überleben, 5-FU - 5-Fluorouracil, IHC Immunhistochemie, LR - Lokalrezidiv, neoadj. - neoadjuvant, NR - keine Regression, n.s. - nicht signifikant, OS - Gesamtüberleben, PR - partielle Regression, RCT - Radiochemotherapie, RT - Radiotherapie, TRG - Tumorregressionsgrad)

* - alle Patienten wurden im Rahmen großer multizentrischer Phase-III-Studien der GRCSG oder analog zu den Therapieregimen therapiert 


\subsection{Das prädiktive und prognostische Potential von Ki67 im lokal fortgeschrittenen Rektumkarzinom}

\subsubsection{Prädiktion des Therapierespons gemessen am (y)pTNM-Status und dem TRG}

In der vorliegenden Studie konnte gezeigt werden, dass eine neoadjuvante RCT zu einer Downregulation der intranukleären Ki67-Expression führt. Es zeigt sich ein signifikanter Unterschied in der Höhe des prä- und posttherapeutischen Ki67-Expressionslevels (siehe Abbildung 16, Seite 58). Das Zellprotein Ki67 kann mit Hilfe immunhistochemischer Färbetechniken während jeder Phase des Zellzyklus, mit Ausnahme der G0-Phase, dargestellt werden (Gerdes et al. 1984). Dieser Umstand macht dieses nukleär lokalisierte Protein zu einem hervorragenden Marker für die Wachstumsfraktion eines Gewebes (Scholzen und Gerdes 2000). Dabei entspricht der Anteil an Zellen des Tumorgewebes, der eine sichtbare Anfärbung des Zellkerns aufweist, der innerhalb eines Zellverbandes vorherrschenden Proliferationsrate (definiert als Anzahl von Zellkernen mit Ki67-positiver Anfärbung pro 100 Tumorzellen, Tannapfel et al. 1998 b). Beide neoadjuvant behandelten Patientenkollektive weisen in jedem prätherapeutischem Präparat eine Anfärbungen auf und enthalten somit proliferierende Zellen (siehe Tabelle 10, Seite 58). Im Gegensatz dazu, finden sich in den posttherapeutischen Präparaten dieser Behandlungsgruppen Präparate ohne messbare Ki67Expression. In der Kontrollgruppe, die keine präoperative RCT erhalten hat, zeigt sich auch in jedem posttherapeutischem Präparat eine Anfärbung von Zellkernen (siehe Tabelle 10, Seite 58). Eine neoadjuvante RCT erniedrigt demnach die Proliferationsrate eines Gewebes. Diese Daten legen nahe, dass es durch lokoregionäre Therapiemaßnahmen (RT des kleinen Beckens, CT mit 5-FU, teilweise in Kombination mit Oxaliplatin) zu einer Abnahme der Zellproliferation und zu einer Stagnation des Tumorwachstums kommt. Auch Tannapfel et al. (1998 b) zeigen in Ihrer Untersuchung eine Downregulation der Ki67-Expression (entsprechend einer reduzierte Proliferationsrate) in Adenokarzinomen des Rektums durch eine neoadjuvanten RCT (Radiatio des Beckens mit begleitender 5-FU-Gabe). Suzuki et al. (2004) erfassten ebenfalls eine signifikant abgeschwächte Proteinexpression durch eine neoadjuvante Therapie, auch bei alleiniger RT. Schlussfolgernd aus dieser Studie scheint sich dieser Effekt auf die zytostatische Wirkung der Radiatio zu stützen (Suzuki et al. 2004). Die Ergebnisse meiner Untersuchungen bestätigen demnach die Aussage von Tannapfel et al. (1998 b), dass die Applikation einer RCT zu einer Reduzierung der proliferativen Aktivität des 
Tumors führt. Der in dieser Arbeit ermittelte signifikante Zusammenhang zwischen dem TRG und der Ki67-Expression im residuellen Tumor unterstreicht abermals diesen Umstand. So scheint ein gutes Ansprechen einer lokoregionären Tumortherapie (gemessen an einem TRG von >3a nach Dworak) mit einem niedrigem posttherapeutischem Ki67-Expressionslevel einherzugehen (siehe Abbildung 17, Seite 59). Eine andere Untersuchungen von Jakob et al. (2008) konnte eine signifikante Korrelation zwischen einer prätherapeutisch niedrigen Expression von Ki67 mit einem hohen TRG zeigen. Dem widersprechend postulieren Kikuchi et al. (2009), dass eine prätherapeutisch hohe Proteinexpression von Ki67 zu einer höheren Tumorsensitivität gegenüber einer zytostatischen Therapie und so zu einem höheren TRG führt. Ähnliche Überlegungen stellten auch Carlomagno et al. (2010) an. In ihrer Studie wird beschrieben, dass ein hohes prätherapeutisches Ki67-Level in Rektumkarzinomen (in Kombination mit anderen Biomarkern) mit einer kompletten Tumorregression nach neoadjuvanter RCT assoziiert ist. Als mögliche Begründung für ihre Ergebnisse vermuten die Autoren dieser Studie, dass hochproliferierende Tumore empfänglicher für DNAschädigende Agenzien sind. Ähnliche Beobachtungen, gibt es auch in Malignomen anderer Gewebe. So stellten Urruticoechea et al. (2005) in ihrer Metaanalyse über den prädiktiven Nutzen der Ki67-Expression in frühen und lokal fortgeschrittenen Mammakarzinomen fest, dass ein hohe Ki67-Expression mit einem besseren Ansprechen auf eine nicht-operative Therapie einhergeht. Jedoch, so hielten die Autoren fest, ginge eine hohe Proliferationsrate im Tumorgewebe im Langzeitverlauf mit einer schlechteren Prognose einher. Es lässt sich schlussfolgernd vermuten, dass hochproliferierendes Gewebe zwar vergleichsweise gut auf eine neoadjuvante zytostatische Therapie anspricht, jedoch andere Mechanismen, die eine schlechtere Prognose bedingen, wie zum Beispiel eine frühe Absiedlung von Karzinomzellen in regionäre LK, überwiegen. Demgemäß, könnte eine niedrige Proliferationsrate innerhalb des Karzinomgewebes Ausdruck einer geringeren Tumorexpansion und verminderten Aggressivität des Tumors sein. Diese These scheint sich in den Ergebnissen meiner Untersuchungen wiederzufinden. So ergab sich bei der statistischen Auswertung der Trend $(p<0,1)$, dass eine niedrige posttherapeutische Ki67-Proteinexpression mit einem geringeren Auftreten von Fernmetastasen einhergeht (siehe Abbildung 18, Seite 60). Aktuell liegen keine Ergebnisse anderer Studien vor, die eine Aussage über den Zusammenhang der Proteinexpression von Ki67 und dem Auftreten von Fernmetastasen treffen. 
Hinblickend auf die aktuelle Datenlage scheint die Ki67-Expression im lokal fortgeschrittenen Rektumkarzinom ein prädiktives Potential aufzuweisen. Die teilweise widersprüchlichen Ergebnisse der einzelnen Studien gründen sich möglicherweise auf die Heterogenität dieser. Dies zeigt sich bereits bei den festgesetzten Cut-Off-Leveln zum Vorliegen einer Ki67Überexpression (siehe Tabelle 12, Seite 78). Der umfassende Teil der vorliegenden Studien weist zudem ein geringes Patientenkollektiv auf $(n \leq 50)$. Die Verlässlichkeit und Reproduzierbarkeit dieser Daten sind somit strittig.

\subsubsection{Das prognostische Potential von Ki67 gemessen an den Follow-up-Daten}

Um ein mögliches prognostisches Potential des Proliferationsmarkers Ki67 aufzudecken, wurden die immunhistochemischen Daten mit den erhobenen Follow-up-Daten der Patienten korreliert. Die aktuellen Untersuchungen und Ergebnisse zu dieser Fragestellung sind kontrovers (siehe Tabelle 12, Seite 78). Ein Grund hierfür könnte in den heterogen festgesetzten Cut-off-Leveln für das Vorliegen einer Ki67-Überepression liegen. Daneben wird in der aktuellen Untersuchung von García et al. (2011) als kritisch angesehen, dass das Cut-off-Level vieler Studien erst nach der Erfassung der immunhistochemischen Daten festgelegt wird. García et al. (2011) untersuchten das DFS an einem 88 Patienten umfassenden Kollektiv und konnten kein prognostisches Potential von Ki67 erfassen. García et al. legten am Anfang ihrer Untersuchungen einen Cut-Off von einem positiven Tumoranteil $\geq 30 \%$ fest. Auch in der vorliegenden Studie wurde der verwendete Cut-off vor Beginn der Auswertungen festgelegt. Nur diese Vorgehensweise erlaubt eine verlässliche Analyse der immunhistochemischen Daten mit fundierten Ergebnissen. Weiterhin wird eine objektive Interpretation und unabhängige Validierung der statistischen Berechnungen ermöglicht.

Wie im Kapitel 3.5.4 (siehe Seite 61) dargestellt, scheint eine niedrige Ki67-Expression im residuellen Tumor mit einem besseren CSS zwischen dem 20 . Und 80. Nachbeobachtungsmonat einherzugehen. Jedoch unterscheiden sich die Endpunkte beider Patientengruppen nicht (siehe Abbildung 19, Seite 62). Andrade et al. (2011) konnten durch eine Auswertung von Follow-up-Daten ein prognostisches Potential von Ki67 belegen. So geht aus den Ergebnissen ihrer Untersuchungen hervor, dass ein niedriges posttherapeutisches Ki67-Expressionslevel mit einer besseren 5-JÜR korreliert ( $p<0,05$; siehe Tabelle 12, Seite 78). Ein prätherapeutisch erfasstes Ki67-Expressionslevel liegt in dieser 
Untersuchung nicht vor. Alle anderen Studien, die einen Zusammenhang mit dem OS oder dem CSS untersucht haben, konnten keine Korrelation mit der Ki67-Expression erfassen.

Weiterhin ist das prognostische Potential des Proliferationsmarkers Ki67 nicht sicher zu beurteilen. Auffällig ist, dass jeder Zusammenhang, der zwischen dem Ki67-Expressionslevel und dem Überleben der Patienten belegt wurde, auf immunhistochemischen Daten beruht, die aus posttherapeutischem Gewebe gewonnen wurden. Ein gutes Therapieansprechen auf eine neoadjuvante RCT spiegelt sich in einer erniedrigten Proliferationsrate des residuellen Tumors im Rektumresektat wider. Dieses gute Ansprechen auf lokale Therapiemaßnahmen lässt sich im kausalen Zusammenhang sehr gut mit einem besseren Überleben vereinbaren. Es gibt keinen signifikanten oder scheinbaren Zusammenhang zwischen dem prätherapeutischen Ki67-Expressionslevel und dem Outcome der Patienten. Vor Einleitung der Therapiemaßnahmen eine Vorhersage über den Krankheitsverlauf zu treffen, ist demnach anhand des Biomarkers Ki67, nicht möglich. 


\begin{tabular}{|c|c|c|c|c|c|}
\hline \multicolumn{6}{|c|}{ Analysen der Expression von Ki67 in Adenokarzinomen des Rektums } \\
\hline Autor & Fallzahl & Methode & Therapie & $\begin{array}{l}\text { Untersuchte } \\
\text { Endpunkte }\end{array}$ & Ergebnisse \\
\hline $\begin{array}{l}\text { Kudrimoti et } \\
\text { al. } 2007\end{array}$ & $\mathrm{n}=17$ & $\begin{array}{l}\text { IHC; Einteilung des Expressionslevels in } \\
4 \text { Grade }\end{array}$ & neoadj. RCT (5-FU) & CR o. PR & n. s. \\
\hline $\begin{array}{l}\text { Jakob et al. } \\
2008\end{array}$ & $n=22$ & $\begin{array}{l}\text { IHC; Ki67-Expression positiv wenn } \geq 40 \% \\
\text { der Zellkerne angefärbt }\end{array}$ & neoadj. RCT (5-FU) & TRG & $\begin{array}{l}\text { niedrige Ki67-Expression im } \\
\text { residuellen Tumor } \\
\text { korreliert mit höherem TRG }\end{array}$ \\
\hline $\begin{array}{l}\text { Kim et al. } \\
2001\end{array}$ & $n=23$ & $\begin{array}{l}\text { IHC; Anzahl der positiven Zellen pro } \\
1000 \text { Tumorzellen }\end{array}$ & $\begin{array}{l}\text { neoadj. RCT (5-FU/ } \\
\text { Leukovorin) }\end{array}$ & CR o. PR o. NR & $\begin{array}{l}\text { es fand sich ein höherer } \\
\text { Ki67-Index (gemessen im } \\
\text { residuellen Tumor) bei } \\
\text { kompletter/partieller } \\
\text { Tumorregression, als bei } \\
\text { keinem Tumoransprechen }\end{array}$ \\
\hline $\begin{array}{l}\text { Debucquoy et } \\
\text { al. } 2006\end{array}$ & $n=30$ & $\begin{array}{l}\text { IHC; Erfassung des prozentual positiven } \\
\text { Tumoranteils von } 0-100 \%\end{array}$ & $\begin{array}{l}\text { neoadj. RCT (5-FU/ ev. } \\
\text { Celecoxib) }\end{array}$ & $\begin{array}{l}\text { Downstaging } \\
\text { des T-Status }\end{array}$ & n. s. \\
\hline $\begin{array}{l}\text { Tannapfel et } \\
\text { al. } 1998 \text { (a) }\end{array}$ & $n=32$ & IHC; positiv, wenn Zellkerne angefärbt & neoadj. RCT (5-FU) & $\begin{array}{l}\text { Downstaging } \\
\text { des T-Status; LR }\end{array}$ & n. s. \\
\hline $\begin{array}{l}\text { Reerink et al. } \\
2004\end{array}$ & $n=34$ & $\begin{array}{l}\text { IHC; Ki67-Expression positiv wenn } \geq 25 \% \\
\text { der Zellkerne angefärbt, Einteilung des } \\
\text { Expressionslevels in } 4 \text { Grade }\end{array}$ & $\begin{array}{l}\text { neoadj. RCT (5- } \\
\text { FU/Leucovorin) }\end{array}$ & T-Status; OS & n. s. \\
\hline $\begin{array}{l}\text { Terzi et al. } \\
2008\end{array}$ & $n=37$ & $\begin{array}{l}\text { IHC; Anzahl der positiven Zellen pro } 100 \\
\text { Tumorzellen }\end{array}$ & neoadj. RCT (5-FU) & $\begin{array}{l}\text { TRG; } \\
\text { Downstaging } \\
\text { des T- und N- } \\
\text { Status }\end{array}$ & n. s. \\
\hline $\begin{array}{l}\text { Moral et al. } \\
2009\end{array}$ & $n=39$ & $\begin{array}{l}\text { IHC; Ki67-Expression positiv wenn } \geq 50 \% \\
\text { der Zellkerne angefärbt }\end{array}$ & $\begin{array}{l}\text { neoadj. RCT (5- } \\
\text { FU/Leukovorin) }\end{array}$ & OS/DFS & n. s. \\
\hline $\begin{array}{l}\text { Charara et al. } \\
2004\end{array}$ & $\mathrm{n}=45$ & $\begin{array}{l}\text { IHC; Ki67-Expression positiv wenn } \geq 70 \% \\
\text { der Zellkerne angefärbt }\end{array}$ & $\begin{array}{l}\text { neoadj. RCT (5- } \\
\text { FU/Irinotecan) }\end{array}$ & CR o. PR & n.s. \\
\hline
\end{tabular}




\begin{tabular}{|c|c|c|c|c|c|}
\hline $\begin{array}{l}\text { Carlomagno } \\
\text { et al. } 2010\end{array}$ & $n=46$ & $\begin{array}{l}\text { IHC; Erfassung des prozentual positiven } \\
\text { Tumoranteils von } 0-100 \%\end{array}$ & $\begin{array}{l}\text { neoadj. RCT (5-FU/ } \\
\text { Capecitabine) }\end{array}$ & PR o. CR; DFS & $\begin{array}{l}\text { CR ist signifikant assoziiert } \\
\text { mit einem hohen } \\
\text { prätherap. Ki67- } \\
\text { Expressionslevel in } \\
\text { Kombination mit anderen } \\
\text { Biomarkern (TS, EGFR) }\end{array}$ \\
\hline $\begin{array}{l}\text { Smith et al. } \\
2006\end{array}$ & $n=49$ & $\begin{array}{l}\text { IHC; Erfassung des prozentual positiven } \\
\text { Tumoranteils von } 0-100 \%\end{array}$ & neoadj. RCT (5-FU) & TRG & n. s. \\
\hline $\begin{array}{l}\text { Kikuchi et al. } \\
2009\end{array}$ & $n=60$ & $\begin{array}{l}\text { IHC; Erfassung des prozentual positiven } \\
\text { Tumoranteils von } 0-100 \%\end{array}$ & neoadj. RCT (Irinotecan) & TRG & $\begin{array}{l}\text { eine prätherapeutisch hohe } \\
\text { Ki67-Expression geht mit } \\
\text { einer höheren Sensitivität } \\
\text { auf eine RCT einher }\end{array}$ \\
\hline $\begin{array}{l}\text { Andrade et al. } \\
2011\end{array}$ & $n=61$ & $\begin{array}{l}\text { IHC; Erfassung des prozentual positiven } \\
\text { Tumoranteils von } 0-100 \%(<50 \% \\
\text { niedriger Proliferationsindex, } \geq 50 \% \\
\text { hoher Proliferationsindex) }\end{array}$ & $\begin{array}{l}\text { neoadj. RCT (5-FU) } \\
\text { adj. RCT (5-FU) }\end{array}$ & TRG; OS & $\begin{array}{l}\text { ein niedriges Ki67- } \\
\text { Expressionslevel im } \\
\text { residuellen Tumor geht mit } \\
\text { einem besseren OS einher } \\
(p<0,05)\end{array}$ \\
\hline $\begin{array}{l}\text { Rau et al. } \\
2003\end{array}$ & $n=63$ & $\begin{array}{l}\text { IHC; Erfassung des prozentual positiven } \\
\text { Tumoranteils von 0-100\%, Einteilung } \\
\text { der Färbeintensität in } 4 \text { Grade }\end{array}$ & $\begin{array}{l}\text { neoadj. RCT (5- } \\
\text { FU/Leucovorin) }\end{array}$ & CR o. PR & n. s. \\
\hline $\begin{array}{l}\text { García et al. } \\
2011\end{array}$ & $n=88$ & $\begin{array}{l}\text { IHC; Ki67-Expression positiv wenn } \geq 30 \% \\
\text { der Zellkerne angefärbt }\end{array}$ & $\begin{array}{l}\text { neoadj. RCT } \\
\text { (UFT/Oxaliplatin/ } \\
\text { Capecitabine) }\end{array}$ & TRG; OS; DSF & n. s. \\
\hline $\begin{array}{l}\text { Suzuki et al. } \\
2004\end{array}$ & $n=93$ & $\begin{array}{l}\text { IHC; Ki67-Expression positiv wenn } \geq 60 \% \\
\text { der Zellkerne angefärbt }\end{array}$ & neoadj. RT & TRG & n. s. \\
\hline $\begin{array}{l}\text { Debucquoy et } \\
\text { al. } 2008\end{array}$ & $n=95$ & $\begin{array}{l}\text { IHC; Erfassung des prozentual positiven } \\
\text { Tumoranteils }\end{array}$ & $\begin{array}{l}\text { neoadj. RT o. neoadj. RCT (5- } \\
\text { FU/Leucovorin) }\end{array}$ & $\begin{array}{l}\text { OS; DFS; } \\
\text { Downstaging } \\
\text { des T-Status }\end{array}$ & n. s. \\
\hline $\begin{array}{l}\text { Chang et al. } \\
2005\end{array}$ & $n=130$ & $\begin{array}{l}\text { IHC; positiv, wenn } \geq 50 \% \text { des Zellkerne } \\
\text { angefärbt }\end{array}$ & $\begin{array}{l}\text { neoadj. RCT (5- } \\
\text { FU/Leucovorin) }\end{array}$ & TRG & n. s. \\
\hline
\end{tabular}




\begin{tabular}{|c|c|c|c|c|c|}
\hline $\begin{array}{l}\text { vorliegende } \\
\text { Untersuchung } \\
2013\end{array}$ & $n=225$ & $\begin{array}{l}\text { IHC; Erfassung des positiven } \\
\text { Tumoranteils und der Färbeintensität } \\
\text { mit Hilfe eines DIA }\end{array}$ & $\begin{array}{l}\text { primäre Rektumresektion; } \\
\text { neoadj. RCT (mit 5-FU oder } \\
\text { 5-FU/Oxaliplatin)* }\end{array}$ & $\begin{array}{l}\text { klinikopatholo- } \\
\text { gische } \\
\text { Paramater; } \\
\text { DFS; CSS; LR- } \\
\text { Rate; Auftreten } \\
\text { von } \\
\text { Metastasen }\end{array}$ & $\begin{array}{l}\text { ein posttherapeutisch } \\
\text { niedrige Ki67-Expression } \\
\text { korreliert mit einem } \\
\text { höheren TRG }\end{array}$ \\
\hline
\end{tabular}

\section{Tabelle 12: Übersicht über die aktuelle Studienlage zum Thema der Ki67-Expression in Adenokarzinomen des Rektums}

Diese Tabelle zeigt nur Studien, die ausschließlich Patienten mit Rektumkarzinomen einbezogen haben. Tabelle modifiziert nach Kuremsky et al. 2009, Seite 681.

(adj. - adjuvant, CR - komplette Regression, CSS - Karzinom-spezifisches Überleben, DFS - krankheitsfreies Überleben, EGFR - epidermal growth factor receptor, 5-FU - 5-Fluorouracil, IHC - Immunhistochemie, LR - Lokalrezidiv, neoadj. - neoadjuvant, NR - keine Regression, n.s. - nicht signifikant, OS Gesamtüberleben, PR - partielle Regression, RCT - Radiochemotherapie, TRG - Tumorregressionsgrad, TS - Thymidylatsynthase)

* - alle Patienten wurden im Rahmen großer multizentrischer Phase-III-Studien der GRCSG oder analog zu den Therapieregimen therapiert 


\subsection{Bedeutung der Ergebnisse für die klinische Praxis}

Die Evaluation, der mit VIAS erhobenen immunhistochemischen Daten, belegt, dass dieses DIA äquivalente Daten, wie die konventionell-manuelle Auswertung immunhistochemischer Färbungen liefert. Die DIA-gestützte Befundung immunhistochemischer Präparate wird mit einer konstant hohen Präzision nach fest definierten Kriterien durchgeführt. Dadurch wird eine standardisierte Messung der immunhistochemischen Parameter (positiver Tumoranteil, Färbeintensität) sichergestellt. Durch den Einsatz von VIAS in der immunhistochemischen Analyse wird eine weitgehend Observer-unabhängige Analyse ermöglicht und somit eine hohe Objektivität der Befunde sichergestellt. Des Weiteren gewährleistet der Einsatz eines computergestützten Analysesystems eine bessere Reproduzierbarkeit der Ergebnisse und eine höhere Präzision der erhobenen Daten. Die Resultate der vorliegenden Arbeit, in Kombination mit den immensen Vorteilen eines DIA, autorisiert dieses für eine verlässliche Erfassung immunhistochemischer Parameter - sowohl im Einsatz in der klinischen Routinediagnostik, aber auch für Datenerhebungen zur Klärung wissenschaftlicher Fragestellungen.

Die Einflussnahme des Expressionslevels des Tumorsuppressors p53 auf den Therapierespons und die Prognose von Rektumkarzinompatienten stellt sich in der aktuellen Studienlage kontrovers dar. Die abschließenden Resultate der vorliegenden Arbeit offenbaren kein gesichertes prädiktives und prognostisches Potential der Proteinexpression von p53 im lokal fortgeschrittenen Rektumkarzinom. Ein bedeutender Umstand, der Einfluss auf die widersprüchliche Studienlage nimmt, ist, dass kein Rückschluss von den immunhistochemischen Färbeergebnissen auf den vorliegenden Funktionsstatus von p53 möglich ist. Das Protein p53 stellt den meist mutierten Tumorsuppressor in humanen Karzinomen dar und weist durch eine sehr kurze Halbwertszeit nur bei Akkumulation eine immunhistochemische Anfärbbarkeit auf (Kerns et al. 1992, Berns 2010). Jedoch sind die ursächlichen Gründe für eine Akkumulation vielfältig und gehen nicht zwangsläufig mit einem Funktionsverlust des Proteins einher (Bosari et al. 1995, Nasierowska-Guttmejer et al. 2000). Dadurch wird die Bedeutsamkeit der immunhistochemischen Daten für den klinischen Routineeinsatz gemindert. Daher offenbart sich die Notwendigkeit, bei der Interpretation immunhistochemischer Färbeergebnisse, weitere Methoden hinzuzuziehen, um zukünftig 
verlässliche Aussagen über den individuell vorliegenden Funktionsstatus des p53-Proteins treffen zu können. Ein sicheres Wissen über den vorliegenden Gen-Status könnte bei der Einschätzung des individuellen Risikoprofils eines Rektumkarzinompatienten dienlich sein. So liegt die Vermutung nahe, dass ein Funktionsverlust des p53-Proteins in den Tumorzellen zu einem mangelnden Ansprechen auf eine zytostatische Therapie führt, da ein wesentlicher Kontrollpunkt im Zellzyklus entfällt. Eine erneute Untersuchung des prädiktiven und prognostischen Nutzens des p53-Expressionlevels im lokal fortgeschrittenen Rektumkarzinom unter Kenntnis des p53-Funktionsstatus könnte neue Erkenntnisse liefern.

Das prognostische und prädiktive Potential der Ki67-Expression im lokal fortgeschrittenen Rektumkarzinom stellt sich in der aktuellen Studienlage zu uneindeutig dar, um einen gesicherten Nutzen für die klinische Routinediagnostik abzuleiten. Es gilt als unumstritten, dass das intranukleäre Protein Ki67 hervorragend geeignet ist, um die Proliferationsrate eines Gewebes einfach und zuverlässig zu bestimmen. Es hat sich in der vorliegenden Untersuchung gezeigt, dass der Ki67-Nachweiß mittels immunhistochemischer Aufarbeitung und Analyse ein geeignetes Verfahren für die Beurteilung der Proliferationsrate eines Gewebes darstellt. Ein möglicher Benefit, der sich aus diesem Umstand ergibt, stellt die Möglichkeit des Therapiemonitorings einer zytostatischen Behandlung dar. Ein gutes Therapieansprechen spiegelt sich in einer Abnahme der Proliferationsrate des Tumorgewebes unter Verabreichung einer lokoregionären Tumortherapie dar. Diese Reduktion der Zellproliferation innerhalb des Tumorgewebes könnte durch mehrmalige Tumorbiopsien mit anschließender immunhistochemischer Aufarbeitung überwacht werden. Gerade bei einem Einsatz neuer Therapeutika oder Therapieregime ergibt sich hieraus möglicherweise ein prädiktiver Nutzen. Auch die Möglichkeit einer Wirksamkeitsvorhersage zwischen verschiedenen Therapeutika könnte gegeben sein. Eine Notwendigkeit hierfür, stellt eine mehrmalige Tumorbiospie unter der neoadjuvanten RCT dar. Nicht nur für maligne Tumore des Rektums, sondern auch für andere gut zugängliche solide Tumore, wie zum Beispiel beim Vorliegen eines Mammakarzinoms, könnte zukünftig das Expressionslevel von Ki67 im Tumorgewebe von Nutzen sein (Urruticoechea et al. 2005). 


\section{Zusammenfassung}

Aktuell umfasst die Behandlung des lokal fortgeschrittenen Rektumkarzinoms (Stadium UICC-II/III) ein multimodales Therapiekonzept. Unter anderem beinhaltet dieses eine neoadjuvante Radiatio des Beckens mit begleitender Chemotherapie vor der operativen Rektumresektion. Dieses Therapieregime beruht auf Ergebnissen der multizentrischen CAO/AIO-/ARO-94-Studie, die eine langfristige Senkung der Lokalrezidivrate durch eine neoadjuvante Therapie, bestehend aus einer Bestrahlung des Beckens mit begleitender 5FU-Chemotherapie, zeigt. Die Nachfolgestudie (CAO-/AIO-/ARO-04-Studie) untersucht, ob eine intensivierte Radiochemotherapie, basierend auf einer konkomitanten Gabe von 5-FU und Oxaliplatin begleitend zur Radiotherapie, das Prognose-limitierende Auftreten von Fernmetastasen verringern und damit das Langzeitüberleben verbessern kann. Ziel ist eine weitere langfristige Prognoseverbesserung zu erwirken. Trotz dieser intensiven Bemühungen zeigen aktuell bis zu $40 \%$ aller Patienten, die an einem lokal fortgeschrittenen Rektumkarzinom erkrankt sind, ein schlechtes bis fehlendes Therapieansprechen. Diese Poor-Responder beziehungsweise Non-Responder müssen einer Risiko-adaptierten Therapie zugeführt werden. Zur Entwicklung solch individualisierter Therapiekonzepte bedarf es der Identifikation eines personalisierten Risikoprofils, anhand prädiktiver und prognostischer Biomarker und neuer Therapie-Targets. Zwei vielversprechende Marker stellen die intranukleären Proteine p53 und Ki67 dar. Das Protein p53 nimmt eine Schlüsselrolle in der Zellzykluskontrolle ein und gilt als der meistmutierte Tumorsuppressor in humanen Karzinomen. Bei Ki67 handelt es sich um einen etablierten Proliferationsmarker. Diese beiden Zellproteine können mittels immunhistochemischer Färbetechniken dargestellt werden. Die Immunhistochemie stellt ein relativ kostengünstiges und flächendeckend verfügbares Verfahren dar, um die Proteinexpression in Biomaterialien zu untersuchen. Jedoch weist diese Methode erhebliche Schwächen auf. So zeigt sich aufgrund der fehlenden Festsetzung von Analysekriterien und einer ausstehenden Standardisierung der Färbemethoden eine hohe Inter- und Intraobservervariabilität.

Ziel dieser Arbeit ist es, die prädiktive und prognostische Relevanz der Biomarker p53 und Ki67 im lokal fortgeschrittenen Rektumkarzinom zu überprüfen, sowie die Evaluation eines 
digitalen Bildanalysesystems zur Sicherung einer Observer-unabhängigen Erfassung immunhistochemischer Daten.

Die durchgeführten Untersuchungen zeigen, dass sich zum aktuellen Zeitpunkt kein prädiktiver oder prognostischer Nutzen aus der p53-Expression im lokal fortgeschrittenen Rektumkarzinom ableiten lässt. Weitere Analysen der p53-Expression in Rektumkarzinomgewebe, unter Berücksichtigung des vorliegenden Funktionsstatus des Proteins, könnten einen klinischen Nutzen aufdecken.

Das Protein Ki67 stellt einen sehr guten Marker für den Proliferationsindex eines Gewebes, auch in der klinischen Routinediagnostik, dar. Es zeigt sich, dass eine lokoregionäre Tumortherapie zu einer Downregulation des Ki67-Expressionslevels führt und mit einem signifikant höheren Tumorregressionsgrad einhergeht. Somit spiegelt diese Downregulation das Ansprechen der neoadjuvanten Therapie wider. Eine Einflussnahme auf die Prognose zeigt sich in den vorliegenden Daten nicht.

Die Evaluation des digitalen Bildanalysesystems VIAS belegt, dass durch den Einsatz von VIAS eine verlässliche Erfassung immunhistochemischer Daten ermöglicht wird. Die Analyse erfolgt anhand festdefinierter Kriterien und stellt so eine konstant hohe Präzision bei der Erfassung immunhistochemischer Daten sicher. Infolgedessen wird eine weitgehend Betrachter-unabhängige Auswertung ermöglicht und die Intra- und Interobservervarianz minimiert. Digitale Bildanalysesysteme sollten bei der Erfassung immunhistochemischer Daten häufiger Anwendung finden. 


\section{Anhang}

a) Aktuell gültige TNM-Klassifikation rektaler Karzinome nach Wittekind und Mever, 2010

\begin{tabular}{|c|c|}
\hline \multicolumn{2}{|r|}{ TNM-Klassifikation (Wittekind und Meyer 2010) } \\
\hline Tis & $\begin{array}{l}\text { Carcinoma in situ; Infiltrationstiefe geht nicht über die Muscularis mucosae } \\
\text { hinaus }\end{array}$ \\
\hline T1 & Tumor infiltriert Submucosa, ohne Eindringen in die Muscularis propria \\
\hline T2 & Tumor infiltriert die Muscularis propria \\
\hline T3 & $\begin{array}{l}\text { Tumor durchbricht Muscularis propria und infiltriert die Subserosa / } \\
\text { perirektales Gewebe }\end{array}$ \\
\hline T4 & $\begin{array}{l}\text { Tumor infiltriert angrenzende Organe und / oder durchbricht das Peritoneum } \\
\text { T4 a - Perforation des viszeralen Peritoneums } \\
\text { T4 b - Direkte Infiltration benachbarter Organe/Strukturen }\end{array}$ \\
\hline No & keine Metastasen in regionären LK nachweisbar \\
\hline N1 & $\begin{array}{l}\text { Metastasen in 1-3 regionären LK } \\
\text { N1 a - eine regionärer LK befallen } \\
\text { N1 b-2-3 regionäre LK befallen } \\
\text { N1 c - Befall von Fettgewebe der Subserosa / nicht-peritonealisiertem } \\
\text { perikolischen oder perirektalem Fettgewebe ohne regionäre LK-Metastasen } \\
\text { mit Satelliten }\end{array}$ \\
\hline N2 & $\begin{array}{l}\text { Metastasen in } 4 \text { oder mehr regionären LK } \\
N 2 a-4-6 \text { regionäre LK befallen } \\
\text { N2 } b-\text { mehr als } 6 \text { regionäre LK befallen }\end{array}$ \\
\hline Mo & keine Fernmetastasen \\
\hline M1 & $\begin{array}{l}\text { Fernmetastasen vorhanden } \\
\text { M1 a - Fernmetastasen auf ein Organ beschränkt (Ovar, Lunge, Leber, } \\
\text { nichtregionäre Lymphknoten) } \\
\text { M1 b - Fernmetastase in versch. Organen oder im Peritoneum }\end{array}$ \\
\hline
\end{tabular}


b) Aktuell gültige UICC-Stadiengruppierung rektaler Karzinome nach Wittekind und Meyer, 2010

\begin{tabular}{|llll|}
\hline \multicolumn{3}{|c|}{ Stadiengruppierung } & nach UICC (Wittekind und \\
\hline Stadium 0 & Tis & N0 & M0 2010) \\
\hline Stadium I & T1, T2 & N0 & M0 \\
\hline Stadium II A & T3 & N0 & M0 \\
Stadium II B & T4a & N0 & M0 \\
Stadium II C & T4b & N0 & M0 \\
\hline Stadium III A & T1, T2 & N1a & M0 \\
& T1 & N2a & M0 \\
Stadium III B & T3, T4a & N1 & M0 \\
& T2, T3 & N2a & M0 \\
& T4a & N2a & M0 \\
Stadium III C & T3, T4b & N2b & M0 \\
& T4b & N1, N2 & M0 \\
\hline Stadium IV A & Jedes T & Jedes N & M1a \\
Stadium IV B & Jedes T & Jedes N & M1b \\
\hline
\end{tabular}

\section{c) Studienprotokoll der CAO/ARO/AIO-94-Studie}

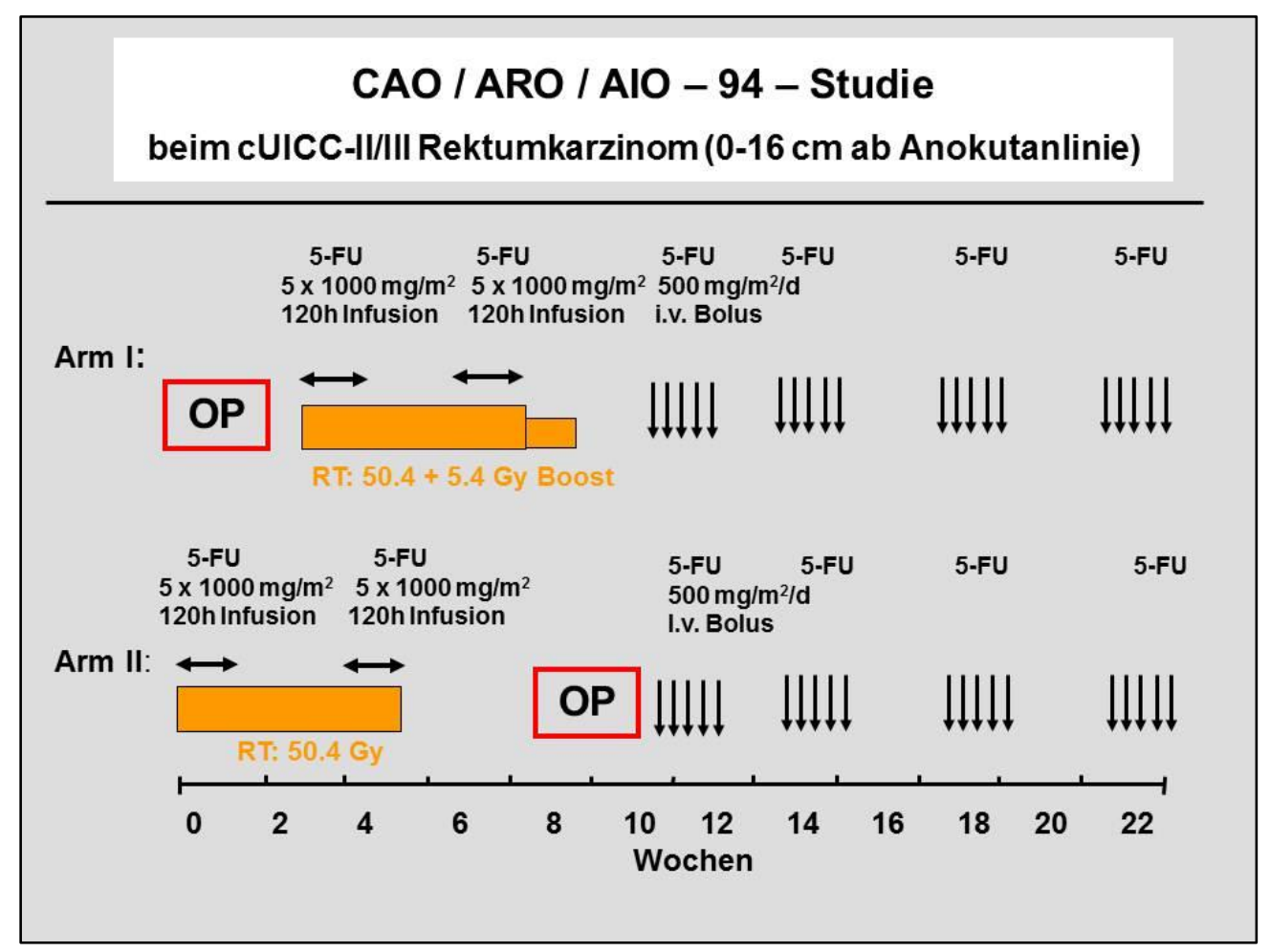




\section{d) Studienprotokoll der CAO/ARO/AIO-04-Studie}

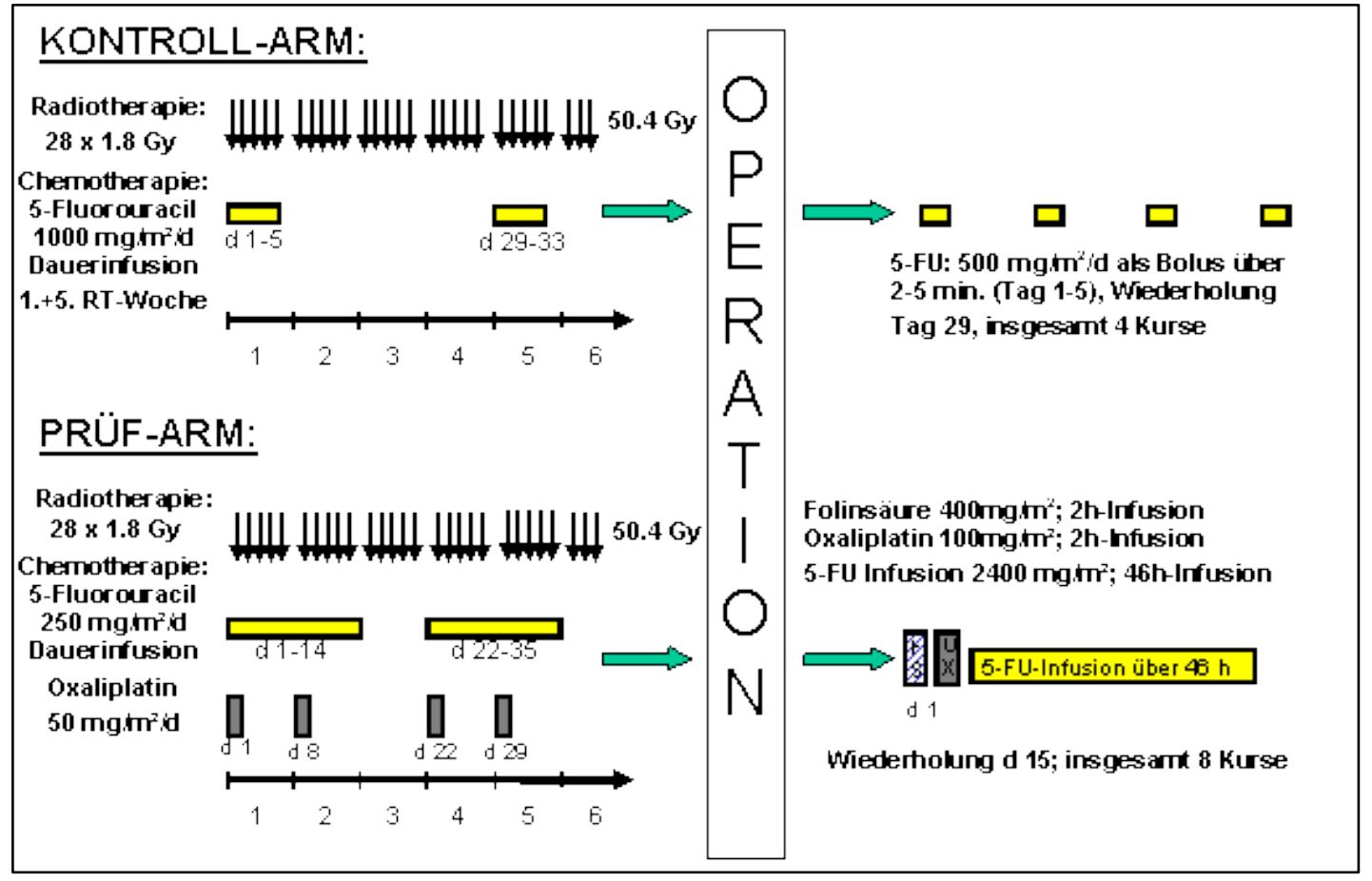

e) Studienprotokoll der GAST-05-Studie

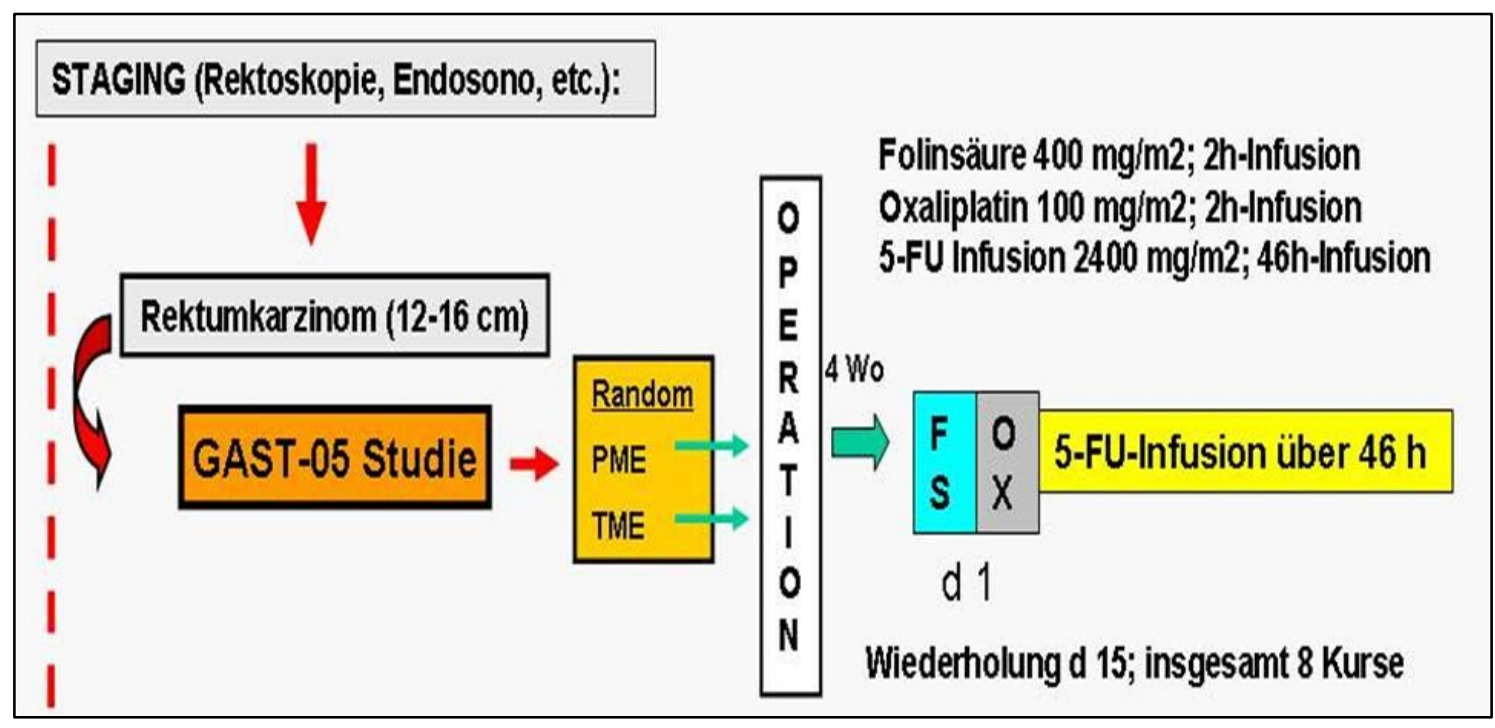




\section{Literaturverzeichnis}

Alison, MR (1995): Assessing cellular proliferation: what's worth measuring? Hum Exp Toxicol 14, 935-944.

Andrade NR, Oshima CTF, Gomes TS, Neto RA, Forones NM (2011): Imunoexpression of Ki-67 and p53 in Rectal Cancer Tissue After Treatment with Neoadjuvant Chemoradiation. J Gastrointest Cancer $\underline{42}$, 34-39.

Andre T, Boni C, Navarro M, Tabernero J, Hickish T, Topham C, Bonetti A, Clingan P, Bridgewater J, Rivera F (2009): Improved Overall Survival With Oxaliplatin, Fluorouracil, and Leucovorin As Adjuvant Treatment in Stage II or III Colon Cancer in the MOSAIC Trial. J Clin Oncol 19 , 3109-3116.

Barbareschi M, Caffo O, Veronese S, Leek RD, Fina P, Fox S, Bonzanini M, Girlando S, Morelle L, Eccher C (1996): Bcl-2 and p53 Expression in Node-Negative Breast Carcinoma: A Study With Long-Term Follow-Up. Hum Pathol 11, 1149-1155.

Becker H, Encke A, Röher HD: Viszeralchirurgie, 2. Auflage; Elsevier, Urban und Fischer, München 2006.

Becker RL (1993): Standardization and quality control of quantitative microscopy in pathology. J Cell Biochem 17G, 199-204.

Berns A (2010): Cancer: The blind spot of p53. Nature $\underline{468}$, 519-520.

Borre M, Bentzen SM, Nerstrøm B, Overgaard J (1998): Tumor cell proliferation and survival in patients with prostate cancer followed expectantly. J Urol 159, 1609-1614. 
Bosari S, Viale G, Roncalli M, Graziani D, Borsani G, Lee AK, Coggi G (1995): p53 Gene Mutations, p53 Protein Accumulation and Compartmentalization in Colorectal Adenocarcinoma. Am J Pathol $\underline{147}, 790-798$.

Brophy S, Sheehan KM, McNamara DA, Deasy J, Bouchier-Hayes DJ, Kay EW (2009): GLUT-1 expression and response to chemoradiotherapy in rectal cancer. Int J Cancer Suppl $\underline{125}$, 2778-2782.

Brown CJ, Lain S, Verma CS, Fersht AR, Lane DP (2009): Awakening guardian angels: drugging the p53 pathway. Nat Rev Cancer $\underline{9}, 862-873$.

Bruns CJ, Kreis ME, Typmner C, Geinitz H, Adam M, Gross M, Michl GM, Walther J, WieseJunginger D, Göring $\mathrm{H}$, et al.: Gastrointestinale Tumore - Empfehlungen zur Diagnostik, Therapie und Nachsorge., 8. Auflage; Zuckschwerdt Verlag, München 2010.

Carlomagno C, Pepe S, D’Armiento FP, D’Armiento M, Cannella L, Stefano de A, Crispo A, Giordano M, Placido de S (2010): Predictive Factors of Complete Response to Neoadjuvant Chemoradiotherapy in Patients with Rectal Cancer. Oncology $\underline{78}$, 369-375.

Chang HJ, Jung KH, Kim DY, Jeong S, Choi HS, Kim YH, Sohn DK, Yoo BC, Lim S, Kim D et al. (2005): Bax, a predictive marker for therapeutic response to preoperative chemoradiotherapy in patients with rectal carcinoma. Hum Pathol $\underline{36}$, 364-371.

Chapman MAS, Buckley D, Henson DB, Armitage NC (1998): Preoperative carcinoembryonic antigen is related to tumour stage and long-term survival in colorectal cancer. $\mathrm{Br} \mathrm{J}$ Cancer $\underline{78}$, 1346-1349.

Charara M, Edmonston TB, Burkholder S, Walters R, Anne P, Mitchell E, Fry R, Boman B, Rose D, Fishel R et al. (2004): Microsatellite status and cell cycle associated markers in rectal cancer patients undergoing a combined regimen of 5-FU and CPT-11 chemotherapy and radiotherapy. Anticancer Res $\underline{24}$, 3161-3167. 
Charnley RM, Morris DL, Dennison AR, Amar SS, Hardcastle JD (1991): Detection of colorectal liver metastases using intraoperative ultrasonography. Br J Surg $\underline{78}$, 45-48.

Chen H, Sheen-Chen S (2000): Synchronous and "early" metachronous colorectal adenocarcinoma. Dis Colon Rectum 43, 1093-1099.

Clarke AR, Purdie CA, Harrison DJ, Morris RG, Bird CC, Hooper ML, Wyllie AH (1993): Thymocyte apoptosis induced by p53-dependent and independent pathways. Nature $\underline{362}$ 849-852.

Debucquoy A, Goethals L, Geboes K, Roels S, Mc Bride WH, Haustermans K (2006): Molecular responses of rectal cancer to preoperative chemoradiation. Radiother Oncol 80, 172-177.

Debucquoy A, Libbrecht L, Roobrouck V, Goethals L, McBride W, Haustermans K (2008): Morphological features and molecular markers in rectal cancer from 95 patients included in the European Organisation for Research and Treatment of Cancer 22921 trial: prognostic value and effects of preoperative radio (chemo) therapy. Eur J Cancer $\underline{44}$, 791-797.

Díez M, Ramos P, Medrano MJ, Mugüerza JM, Villeta R, Lozano O, Escribano J, Noguerales F, Ruíz A, Granell J (2003): Preoperatively irradiated rectal carcinoma: analysis of the histopathologic response and predictive value of proliferating cell nuclear antigen immunostaining. Oncology $\underline{64}$, 213-219.

Dworak O, Keilholz L, Hoffmann A (1997): Pathological features of rectal cancer after preoperative radiochemotherapy. Int J Colorectal Dis 12, 19-23.

Edden Y, Wexner SD, Berho M (2012): The use of molecular markers as a method to predict the response to neoadjuvant therapy for advanced stage rectal adenocarcinoma. Int J Colorectal Dis $\underline{14}, 555-561$.

Edge SB: AJCC Cancer Staging Manual., 7. Auflage; Springer Verlag, New York 2010. 
Elsaleh H, Robbins P, Joseph D, Powell B, Grieu F, Menso L, lacopetta B (2000): Can p53 alterations be used to predict tumour response to pre-operative chemo-radiotherapy in locally advanced rectal cancer? Radiother Oncol 56, 239-244.

Esposito G, Pucciarelli S, Alaggio R, Giacomelli L, Marchiori E, laderosa GA, Friso ML, Toppan P, Chieco-Bianchi L, Lise M (2001): P27kip1 expression is associated with tumor response to preoperative chemoradiotherapy in rectal cancer. Ann Surg Oncol $\underline{8}$, 311-318.

Fearon ER, Vogelstein B (1990): A genetic model for colorectal tumorigenesis. Cell $\underline{61}$, 759767.

Fuchs R, Guggenberger D, Trautwein C: Diagnostik und Therapie gastrointestinaler Tumore 2011/2012., 20. Auflage; Nora-Verlag, Stolberg 2011.

Fucini C, Messerini L, Saieva C, Orzalesi L, Carroni V, Bartolini N (2012): Apoptotic proteins as prognostic markers and indicators of radiochemosensitivity in stage II/III rectal cancers. Int J Colorectal Dis $\underline{14}, 64-71$.

Gaedcke J, Liersch T, Hess C, Becker H, Rödel C, Ghadimi B (2011): Rektumkarzinom: Aktueller Stand der multimodalen Therapie - wann und wie? Zentralbl Chir $\underline{136}$, 334-342.

García VM, Batlle JF, Casado E, Burgos E, Castro J de, Belda C, Barriuso J, Sánchez JJ, GarcíaCabezas MÁ, González-Barón M et al. (2011): Immunohistochemical analysis of tumour regression grade for rectal cancer after neoadjuvant chemoradiotherapy. Int J Colorectal Dis $\underline{13}, 989-998$.

Gavioli M, Bagni A, Piccagli I, Fundaro' S, Natalini G (2000): Usefulness of endorectal ultrasound after preoperative radiotherapy in rectal cancer. Dis Colon Rectum $\underline{43}, 1075-$ 1083. 
Gerdes J, Schwab U, Lemke H, Stein H (1983): Production of a mouse monoclonal antibody reactive with a human nuclear antigen associated with cell proliferation. Int J Cancer Suppl 31, 13-20.

Gerdes J, Lemke H, Baisch H, Wacker HH, Schwab U, Stein H (1984): Cell cycle analysis of a cell proliferation-associated human nuclear antigen defined by the monoclonal antibody Ki67. J Immunol 133, 1710-1715.

Glynne-Jones R (2012): Rectal cancer--the times they are a-changing. Lancet Oncol $\underline{7}, 651-$ 653.

Grube D (2004): Constants and variables in immunohistochemistry. Arch Histol Cytol $\underline{67}$, 115134.

Hermanek P (1995): pTNM and residual tumor classifications: Problems of assessment and prognostic significance. World J Surg $\underline{19}, 184-190$.

Hermanek P, Hohenberger W, Klimpfinger M, Kockerling F, Papadopoulos T (2003): The pathological assessment of mesorectal excision: implications for further treatment and quality management. Int J Colorectal Dis $\underline{18}, 335-341$.

Hilgers R, Bauer P, Scheiber V: Einführung in die medizinische Statistik., 2. Auflage; Springer Verlag, Berlin 2007.

Hollstein M, Sidransky D, Vogelstein B, Harris C (1991): p53 mutations in human cancers. Science $\underline{253}$, 49-53.

Hong TS, Clark JW, Haigis KM (2012): Cancers of the Colon and Rectum: Identical or Fraternal Twins? Cancer Discov 2, $117-121$. 
Horio Y, Takahashi T, Kuroishi T, Hibi K, Suyama M, Numi T, Shimokata K, Yamakawa K, Nakamura Y, Ueda R et al. (1993): Prognostic Significance of p53 Mutations and 3p Deletions in Primary Resected Non-Small Cell Lung Cancer. Cancer Res 53, 1-4.

Husmann G: Krebs in Deutschland., 7. Auflage; Robert Koch-Institut, Berlin 2010.

Jakob C, Liersch T, Meyer W, Becker H, Baretton Gusavo B, Aus DE (2008): Predictive value of Ki67 and p53 in locally advanced rectal cancer: Correlation with thymidylate synthase and histopathological tumor regression after neoadjuvant 5-FU-based chemoradiotherapy. World J Gastroenterol 또, 1060-1066.

Jemal A, Bray F, Center MM, Ferlay J, Ward E, Forman D (2011): Global cancer statistics. CA Cancer J Clin $\underline{61}, 69-90$.

Jung S, Jeong J, Shin SH, Kwon Y, Kim E, Ko KL, Shin KH, Ro J, Lee KS, Park IH et al. (2011): Accumulation of p53 determined by immunohistochemistry as a prognostic marker in node negative breast cancer; analysis according to st gallen consensus and intrinsic subtypes. J Surg Oncol $\underline{103}, 207-211$.

Kapiteijn E van, Marijnen CA, Nagtegaal ID, Putter H, Steup WH, Wiggers T, Rutten HJ, Pahlman L, Glimelius B, Krieken JJ van (2001): Preoperative Radiotherapy combined with Total Mesorectal Excision for Resectable Rectal Cancer. N Engl J Med 345, 638-646.

Kerns BJ, Jordan PA, Moore MB, Humphrey PA, Berchuck A, Kohler MF, Bast RC, Iglehart JD, Marks JR (1992): p53 overexpression in formalin-fixed, paraffin-embedded tissue detected by immunohistochemistry. J Histochem Cytochem $\underline{40}$, 1047-1051.

Kikuchi M, Mikami T, Sato T, Tokuyama W, Araki K, Watanabe M, Saigenji K, Okayasu I (2009): High Ki67, Bax, and thymidylate synthase expression well correlates with response to chemoradiation therapy in locally advanced rectal cancers: proposal of a logistic model for prediction. Br J Cancer 101, 116-123. 
Kim NK, Park JK, Lee KY, Yang WI, Yun SH, Sung J, Min JS (2001): p53, BCL-2, and Ki-67 expression according to tumor response after concurrent chemoradiotherapy for advanced rectal cancer. Ann Surg Oncol $\underline{8}$, 418-424.

Kudrimoti M, Lee EY, Kang Y, Ahmed M, Mohiuddin M (2007): Genetic markers predictive of response to induction chemoradiotherapy for locally advanced rectal cancers. J Ky Med Assoc 105, 18-22.

Kuremsky JG, Tepper JE, McLeod HL (2009): Biomarkers for Response to Neoadjuvant Chemoradiation for Rectal Cancer. Int J Radiat Oncol Biol Phys $\underline{74}$, 673-688.

Kwok H, Bissett IP, Hill GL (2000): Preoperative staging of rectal cancer. Int J Colorectal Dis $\underline{15}, 9-20$.

Lane DP (1992): p53, guardian of the genome. Nature $\underline{358}, 15-16$.

Lebe B, Sarioğlu S, Sökmen S, Ellidokuz H, Füzün M, Küpelioğlu A (2005): The clinical significance of p53, p21, and p27 expressions in rectal carcinoma. Appl Immunohistochem Mol Morphol $\underline{13}, 38-44$.

Levine AJ, Momand J, Finlay CA (1991): The p53 tumour suppressor gene. Nature $\underline{351}$, 453456.

Li JN, Zhao L, Wu J, Wu B, Yang H, Zhang HH, Qian JJ (2012): Differences in gene expression profiles and carcinogenesis pathways between colon and rectal cancer. J Dig Dis $\underline{13}$, 24-32.

Li F, Lai M (2009): Colorectal cancer, one entity or three. J Zhejiang Univ Sci B $\underline{10}$, 219-229.

Liersch T, Langer C, Ghadimi BM, Becker H (2005): Aktuelle Behandlungsstrategien beim Rektumkarzinom. Chirurg $\underline{76}$, 309-334. 
Liersch T, Becker H, Langer C (2007): Rektumkarzinom. Allgemeine und Viszeralchirurgie up2date $\underline{1}, 41-69$.

Liersch T, Rothe H, Ghadimi B, Becker H (2009): Therapie beim lokal fortgeschrittenen Rektumkarzinom. Chirurg $\underline{80}$, 281-293.

Lin L, Lee H, Hwang W, Li C, Huang C, Que J, Lin K, Lin F, Lu C (2006): p53 and p27 as predictors of clinical outcome for rectal-cancer patients receiving neoadjuvant therapy. Surg Oncol $\underline{15}, 211-216$.

Lowe SW, Ruley HE, Jacks T, Housman DE (1993 a): p53- Dependent Apotosis Modulates the Cytotoxicity of Anticancer Agents. Cell 74, 957-967.

Lowe SW, Schmitt EM, Smith SW, Osborne BA, Jacks T (1993 b): p53 is required for radiationinduced apoptosis in mouse thymocytes. Nature $\underline{362}, 847-849$.

Luna-Perez P, Arriola EL, Cuadra Y, Alvarado I, Quintero A (1998): p53 protein overexpression and response to induction chemoradiation therapy in patients with locally advanced rectal adenocarcinoma. Ann Surg Oncol $\underline{5}, 203-208$.

Mason AY (1976): President's Address. Rectal Cancer: The Spectrum of Selective Surgery. Proc R Soc Med 69, 237-244.

Mcllwrath AJ, Vasey PA, Ross GM, Brown R (1994): Cell Cycle Arrests and Radiosensitivity of Human Tumor Cell Lines: Dependence on Wild-Type p53 for Radiosensitivity'. Cancer Res $\underline{54}$, 3718-3722.

M.E.R.C.U.R.Y.: M.E.R.C.U.R.Y. Project (Magnetic Resonance Imaging and Rectal Cancer European Equivalence Study) Study Protocol (Study Coordinator I. Daniels, FRCS, Pelican Centre, North Hampshire Hospital, Basingstoke, Hampshire, UK, 2002. 
Moral M, Fdez-Aceñero MAJ, Cuberes R, Suárez A (2009): Factors influencing histological response after neoadjuvant chemoradiation therapy for rectal carcinoma. Pathol Res Pract $\underline{205}, 695-699$.

Muto T, Bussey HJR, Morson BC (1975): The evolution of cancer of the colon and rectum. Cancer 36, 2251-2270.

Nasierowska-Guttmejer A, Trzeciak L, Nowacki MP, Ostrowski J (2000): p53 protein accumulation and p53 gene mutation in colorectal cancer. Pathol Oncol Res $\underline{6}, 275-279$.

Negri FV, Campanini N, Camisa R, Pucci F, Bui S, Ceccon G, Martinelli R, Fumagalli M, Losardo PL, Crafa P et al. (2008): Biological predictive factors in rectal cancer treated with preoperative radiotherapy or radiochemotherapy. $\mathrm{Br} J$ Cancer $\underline{98}$, 143-147.

Okonkwo A, Musunuri S, Talamonti M, Benson A, Small W, Stryker SJ, Rao MS (2001): Molecular markers and prediction of response to chemoradiation in rectal cancer. Oncol Rep $\underline{8}, 497-500$.

Peinado MA, Fernandezrenat M, Capella G, Wilson L, Perucho M (1993): Mutations in th p53 suppressor gene do not correlate with c-k-ras oncogne mutations in colorectal-cancer. Int J Oncol $2,123-134$.

Petrelli N, Douglass HO, Herrera L, Russell D, Stablein DM, Bruckner HW, Mayer RJ, Schinella R, Green MD, Muggia FM et al. (1989): The Modulation of Fluorouracil With Leucovorin in Metastatic Colorectal Carcinoma: A Prospective Randomized Phase III Trial. J Clin Oncol 그, 1419-1426.

Poon MA, O'Connell MJ, Moertel CG, Wieand HS, Cullinan SA, Everson LK, Krook JE, Mailliard JA, Laurie JA, Tschetter LK et al. (1989): Biochemical Modulation of Fluorouracil: Evidence of Significant Improvement of Survival and Quality of Life in Patients With Carcinoma Advanced Colorectal Carcinoma. J Clin Oncol ㄱ, 1407-1418. 
Rau B, Sturm I, Lage H, Berger S, Schneider U, Hauptmann S, Wust P, Riess H, Schlag PM, Dörken B et al. (2003): Dynamic expression profile of p21WAF1/CIP1 and Ki-67 predicts survival in rectal carcinoma treated with preoperative radiochemotherapy. J Clin Oncol $\underline{18}$, 3391-3401.

Reerink O, Karrenbeld A, Plukker JTM, Verschueren RCJ, Szabó BG, Sluiter WJ, Hospers GAP, Mulder NH (2004): Molecular prognostic factors in locally irresectable rectal cancer treated preoperatively by chemo-radiotherapy. Anticancer Res 24, 1217-1221.

Remmele W, Stegner HE (1987): Recommendation for uniform definition of an immunoreactive score (IRS) for immunohistochemical estrogen receptor detection (ER-ICA) in breast cancer tissue. Pathologe $\underline{8}, 138-140$.

Rödel C, Liersch T, Becker H, Fietkau R, Hohenberger W, Hothorn T, Graeven U, Arnold D, Lang-Welzenbach M, Raab H et al. (2012): Preoperative chemoradiotherapy and postoperative chemotherapy with fluorouracil and oxaliplatin versus fluorouracil alone in locally advanced rectal cancer: initial results of the German CAO/ARO/AIO-04 randomised phase 3 trial. Lancet Oncol $\underline{13}$, 679-687.

Rödel F, Hoffmann J, Grabenbauer GG, Papadopoulos T, Weiss C, Günther K, Schick C, Sauer R, Rödel C (2002): High survivin expression is associated with reduced apoptosis in rectal cancer and may predict disease-free survival after preoperative radiochemotherapy and surgical resection. Strahlenther Onkol $\underline{8}$ 426-435.

Rudolph P, Olsson H, Bonatz G, Ratjen V, Bolte H, Baldetorp B, Fernö M, Parwaresch R, Alm P (1999): Correlation between p53, c-erbB-2, and topoisomerase II alpha expression, DNA ploidy, hormonal receptor status and proliferation in 356 node-negative breast carcinomas: prognostic implications. J Pathol $\underline{187}$, 207-216.

Sauer R, Becker H, Hohenberger W, Rodel C, Wittekind C, Fietkau R, Martus P, Tschmelitsch J, Hager E, Hess C et al. (2004): Preoperative versus postoperative chemoradiotherapy for rectal cancer. N Engl J Med $\underline{351}$ 1731-1740. 
Sauer R, Liersch T, Merkel S, Fietkau R, Hohenberger W, Hess C, Becker H, Raab H, Villanueva M, Witzigmann H et al. (2012): Preoperative Versus Postoperative Chemoradiotherapy for Locally Advanced Rectal Cancer: Results of the German CAO/ARO/AIO-94 Randomized Phase III Trial After a Median Follow-Up of 11 Years. J Clin Oncol 16, 1926-1933.

Saw RPM, Morgan M, Koorey D, Painter D, Findlay M, Stevens G, Clarke S, Chapuis P, Solomon MJ (2003): p53, deleted in colorectal cancer gene, and thymidylate synthase as predictors of histopathologic response and survival in low, locally advanced rectal cancer treated with preoperative adjuvant therapy. Dis Colon Rectum $\underline{46}, 192-202$.

Schmiegel W, Pox C, Reinacher-Schick A, Adler G, Arnold D, Fleig W, Fölsch U, Frühmorgen P, Graeven U, Heinemann V et al. (2010): S3 guidelines for colorectal carcinoma: results of an evidence-based consensus conference on February 6/7, 2004 and June 8/9, 2007 (for the topics IV, VI and VII). Z Gastroenterol 46, 65-136.

Scholzen T, Gerdes J (2000): The Ki-67 protein: from the known and the unknown. J Cell Physiol 182, 311-322.

Scott N, Hale A, Deakin M, Hand P, Adab FA, Hall C, Williams GT, Elder JB (1998): A histopathological assessment of the response of rectal adenocarcinoma to combination chemo-radiotherapy: relationship to apoptotic activity, p53 and bcl-2 expression. Eur J Surg Oncol 24, 169-173.

Sebag-Montefiore D (2006): Developments in the use of chemoradiotherapy in rectal cancer. Int J Colorectal Dis $\underline{8}, 14-17$.

Seicean R, Crisan D, Boers JE, Mocan T, Seicean A, Funariu G, Ciuce C (2011): The Prognostic Role of Apoptosis Mediators in Rectal Adenocarcinoma. Hepatogastroenterology $\underline{58}$, 14901494.

Seidal T, Balaton AJ, Battifora H (2001): Interpretation and Quantification of Immunostains. Am J Surg Pathol 25, 1204-1207. 
Seshadri R, Leong AS, McCaul K, Firgaira FA, Setlur V, Horsfall DJ (1996): Relationship between p53 gene abnormalities and other tumour characteristics in breast-cancer prognosis. Int J Cancer $\underline{69}, 135-141$.

Shinto E, Hashiguchi Y, Ueno H, Kobayashi H, Ishiguro M, Mochizuki H, Yamamoto J, Hase K (2011): Pretreatment CD133 and cyclooxygenase-2 expression as the predictive markers of the pathological effect of chemoradiotherapy in rectal cancer patients. Dis Colon Rectum $\underline{54}$, 1098-1106.

Słodkowska J, Rojo MG (2011): Digital pathology in personalized cancer therapy. Folia Histochem Cytobiol 49 , 570-578.

Smith FM, Reynolds JV, Kay EW, Crotty P, Murphy JO, Hollywood D, Gaffney EF, Stephens RB, Kennedy MJ (2006): COX-2 overexpression in pretreatment biopsies predicts response of rectal cancers to neoadjuvant radiochemotherapy. Int J Radiat Oncol Biol Phys $\underline{64}$, 466-472.

Spitz FR, Giacco GG, Hess K, Larry L, Rich TA, Janjan N, Cleary KR, Skibber JM (1997): p53 immunohistochemical staining predicts residual disease after chemoradiation in patients with high-risk rectal cancer. Clin Cancer Res $\underline{3}$, 1685-1690.

Sprenger T, Rothe H, Langer C, Becker H, Liersch T (2009): Comment on "Lymph Nodes After Preoperative Chemoradiotherapy for Rectal Carcinoma: Number, Status, and Impact on Survival". Am J Surg Pathol $\underline{33}, 1107$.

Stattin P, Damber JE, Karlberg L, Bergh A (1997): Cell proliferation assessed by Ki-67 immunoreactivity on formalin fixed tissues is a predictive factor for survival in prostate cancer. J Urol 157, 219-222.

Sterk P, Nagel T, Günter S, Schubert F, Klein P (2000): Verfahren zur postoperativen Kontrolle der vollständigen Exzision des Mesorektums. Zentralbl Chir $\underline{125}$, 370-374. 
Suzuki T, Sadahiro S, Fukasawa M, Ishikawa K, Kamijo A, Yasuda S, Makuuchi H, Ohizumi Y, Murayama C (2004): Predictive factors of tumor shrinkage and histological regression in patients who received preoperative radiotherapy for rectal cancer. Jpn J Clin Oncol $\underline{34}$, 740746.

Tannapfel A, Nüsslein S, Fietkau R, Katalinic A, Köckerling F, Wittekind C (1998 a): Apoptosis, proliferation, bax, bcl-2 and p53 status prior to and after preoperative radiochemotherapy for locally advanced rectal cancer. Int J Radiat Oncol Biol Phys 411, 585-591.

Tannapfel A, Nüsslein S, Katalinic A, Köckerling F, Wittekind C, Fietkau R (1998 b): Proliferation und Apoptose vor und nach präoperativer simultaner Radiochemotherapie von Rektumkarzinomen. Strahlenther Onkol 174, 295-299.

Taylor CR, Levenson RM (2006): Quantification of immunohistochemistry issues concerning methods, utility and semiquantitative assessment II. Histopathology 49, 411-424.

Terzi C, Canda AE, Sagol O, Atila K, Sonmez D, Fuzun M, Gorken IB, Oztop I, Obuz F (2008): Survivin, p53, and Ki-67 as predictors of histopathologic response in locally advanced rectal cancer treated with preoperative chemoradiotherapy. Int J Colorectal Dis 23 , 37-45.

Trampisch HJ, Windeler J, Ehle B, Lange S: Medizinische Statistik., 1. Auflage; Springer Verlag, Berlin 1997.

Urruticoechea A, Smith IE, Dowsett M (2005): Proliferation Marker Ki-67 in Early Breast Cancer. J Clin Oncol 23, 7212-7220.

Vogelstein B, Kinzler KW. (1992): p53 function and dysfunction. Cell 70, 523-526.

Vohmann C, Urbschat I, Kieschke J, Rohde M, Böckmann S: Krebs in Niedersachsen 2008; Prull-Druck, Oldenburg 2011. 
Vorwerk H, Liersch T, Rothe H, Ghadimi M, Christiansen H, Hess CF, Hermann RM (2009): Gold markers for tumor localization and target volume delineation in radiotherapy for rectal cancer. Strahlenther Onkol $\underline{2}, 127-133$.

Wittekind C, Sobin LH: TNM. Classification of malignant tumours, 6. Auflage; Wiley-LissVerlag, New York 2002.

Wittekind C, Tannapfel A (2003): Regressionsgrading des präoperativradiochemotherapierten Rektumkarzinoms. Pathologe 24, 61-65.

Wittekind C, Meyer HJ: TNM. Klassifikation maligner Tumore, 7. Auflage; Wiley-VCH-Verlag Gmbh, 2010. 


\section{Veröffentlichung zum Thema}

Teile dieser Dissertation wurden im Rahmen eines Kongressbeitrages veröffentlicht.

\section{Abstract zu einem Vortrag auf den ,16. Chirurgischen Forschungstagen' in Regensburg:}

Lena-Christin Conradi*, Susanna Posern*, Annalen Bleckmann, Thilo Sprenger, Peter Middel,

Hendrik A. Wolff, B. Michael Ghadimi, Tim Beissbarth, Torsten Liersch

*gleichberechtigte Co-Autoren

Evaluation der Auswertesoftware Ventana Image Analysis System (VIAS) zur Quantifizierung immunhistochemischer Färbungen am Beispiel der p53- und Ki67-Expression in

Rektumkarzinomgewebe

\section{Hintergründe}

Die Immunhistochemie ist eine gut etablierte und in der klinischen Routinediagnostik wie auch in der Forschung vielfach eingesetzte Methode. Eine allgemeingültige Standardisierung der Färbemethoden und Vereinheitlichung der Analysekriterien steht jedoch noch aus. Inzwischen stehen verschieden Computer-basierte Auswerteprogramme zur Verfügung. Innerhalb der Klinischen Forschergruppe 179 wurden die Antigene p53 und Ki67 in Rektumkarzinomzellen immunhistochemisch gefärbt und konventionell (nicht Software-gestützt) sowie mit Hilfe des Ventana Image Analysis System (VIAS; Ventana Medical Systems, Tucson, Arizona, USA) ausgewertet. Dabei handelt es sich um ein neuartiges digitales Bildanalysesystem (digital image analysis, DIA), welches die zu untersuchenden Objektträger digital verarbeitet und innerhalb manuell definierter Gewebebezirke verschiedene Parameter standardisiert erfasst.

\section{Material und Methoden}

Für die vergleichende Analyse einer konventionellen Auswertung sowie der VIAS-basierten Auswertung der nukleären Expression von p53 und Ki67 wurde Tumorgewebe von insgesamt 225 konsekutiven Patienten mit einem lokal fortgeschrittenen Rektumkarzinom untersucht. Es wurde jeweils die im Rahmen der Diagnosesicherung entnommene Tumorbiopsie sowie bei der Rektumresektion entnommenes Gewebe untersucht und mittels eines DAB-gekoppelten Sekundärantikörpers gefärbt und ausgewertet. Alle Schnitte wurden verblindet mit beiden Verfahren analysiert unter Berücksichtigung des Anteils positiv gefärbter Tumorzellen sowie der Färbeintensität.

\section{Ergebnisse}

Bei der Analyse der immunhistochemischen Präparate wurden zwei Parameter quantitativ ausgewertet: der prozentual positive Tumoranteil, sowie die Intensität der Kernanfärbung. Diese Parameter wurden mit und ohne Hilfe der digitalen Bildanalysesoftware VIAS erhoben. Die Korrelation der erhobenen Datensätze ergab einen starken Zusammenhang beider Auswerteverfahren. Der prozentuale Tumoranteil, welcher mittels beider Auswerteverfahren erfasst 
wurde ergab eine fast lineare Korrelation (Korrelationskoeffizient $>0,9 ; p<0.00001$ ) für Biopsien wie auch im Tumorgewebe der Resektate.

\section{Schlussfolgerungen}

Die Computer-gestützte Befundung immunhistochemischer Präparate wird mit einer konstant hohen Präzision nach fest definierten Kriterien durchgeführt und führt so zu einer standardisierten Messung von Färbeintensität und Färbeverteilung. DIA ermöglichen eine objektive, schnelle und sensitive Messung von Proteinexpressionen mit einer Reduktion von Intra- und Interobservervariabilität. 


\section{Danksagung}

Ich richte meinen besonderen Dank an Frau Dr. med. Lena Conradi. Sie hat durch ihr außerordentliches Engagement und ihre großartige Betreuung den Entwicklungsprozess der vorliegenden Dissertation maßgeblich beeinflusst und stets angetrieben. Besonders unsere zweimaligen Promotionsworkshop's stellen einen Meilenstein bei der Anfertigung dieser Arbeit dar.

Herrn PD Dr. med. Thorsten Liersch bin ich ebenfalls zu großem Dank verpflichtet. Er lieferte die Idee zu dem Thema meiner Dissertation und hat stets konstruktiv bei der Entstehung dieser Arbeit mitgewirkt.

Ohne Frau Birgit Jünemann wäre mir diese immunhistochemische Analyse nicht möglich gewesen. Für die zahlreichen hervorragenden Paraffinschnitte und Färbungen möchte ich mich vielmals von ganzem Herzen bedanken.

Herrn Prof. Dr. Tim Beissbarth danke ich für seine professionelle Unterstützung bei der Erstellung der statistischen Analysen, die grundlegend zu den Ergebnissen dieser Untersuchung beigetragen haben.

Für die großzügige finanzielle Unterstützung, die entscheidend die Umsetzung der Promotionsworkshop's ermöglicht hat, danke ich mehrfach Herrn Prof. Gisbert Vogt.

Ich möchte mich auch vielfach bei meinen Eltern bedanken. Sie verhelfen mir durch ihre grenzenlose Unterstützung zu einem sorgenfreien Studium und ermöglichten mir dadurch die Anfertigung meiner Dissertation. 